\title{
ENERGY
}

\section{Conversion of Hydrogen Sulfide in Coal Gases to Liquid Elemental Sulfur with Monolithic Catalysts}

Annual Technical Progress Report for the Period

October 1, 2006 to September 30, 2007

K. C. Kwon

Tel: (334) 727-8976, Fax: (334) 724-4188

December 2007

Work Performed Under Contract No

DE-FG26-04NT42129

For

U.S. Department of Energy

National Energy Technology Laboratory

Pittsburgh, PA 15236-0940

By

Tuskegee University

Tuskegee, Alabama 36088 
Conversion of Hydrogen Sulfide in Coal Gases to Liquid Elemental Sulfur with Monolithic Catalysts

Annual Technical Progress Report

for the Period October 1, 2006 to September 30, 2007

K. C. Kwon

Tel: (334) 727-8976, Fax: (334) 727-9688

December 2007

Work Performed Under Contract No.: DE-FG26-04NT42129

For

U.S. Department of Energy

Office of Fossil Energy

National Energy Technology Laboratory

P.O. Box 10940

Pittsburgh, PA 15236-0940

By

Tuskegee University

Tuskegee, Alabama 36088 


\section{DISCLAIMER}

This report was prepared as an account of work sponsored by an agency of the United States Government. Neither the United States Government nor any agency thereof, nor any of their employees, makes any warranty, express or implied, or assume any legal liability or responsibility for the accuracy, completeness, or usefulness of any information, apparatus, product, or process disclosed, or represents that its use would not infringe privately owned rights. Reference herein to any specific commercial product, process, or service by trade name, trademark, manufacturer, or otherwise does not necessarily constitute or imply its endorsement, recommendation, or favoring by the United States Government or any agency thereof. The views and opinions of authors expressed herein do not necessarily state or reflect those of the United States Government or any agency thereof. 


\section{CONTENTS}

Page

DISCLAIMER

iii

LIST OF TABLES

$\mathrm{V}$

LIST OF FIGURES - vii

SUMMARY

$\begin{array}{ll}\text { INTRODUCTION } & 2\end{array}$

EXPERIMENTAL SETUPS

$\begin{array}{lr}\text { CALCULATIONS } & 23\end{array}$

RESULTS AND DISCUSSION 23

Effects of Temperature on Conversion of $\mathrm{H}_{2} \mathrm{~S}$ and formation of COS 24

Effects of Catlayst Aging on Conversion of $\mathrm{H}_{2} \mathrm{~S}$ and formation of COS 25

Temperature Effects of Removing Elemental Sulfur from a Catalyst on Conversion 25

of $\mathrm{H}_{2} \mathrm{~S}$ and formation of COS

Effects of Sulfur Removal from a Zn-Treated Monolithic Catalyst on Conversion of $\quad 26$

$\mathrm{H}_{2} \mathrm{~S}$ and Formation of COS

Effects of Soaking a Zn-Treated Catalyst in $\mathrm{NaOH}$ Aqueous Solution on Conversion 27

of $\mathrm{H}_{2} \mathrm{~S}$ and Formation of COS

Effects of Removing Elemental Sulfur from a Zn-Treated and $\mathrm{NaOH}$-Regenerated 28

Catalyst on Conversion of $\mathrm{H}_{2} \mathrm{~S}$ and Formation of COS

Effects of Washing a Catalyst in $\mathrm{NaOH}$ Aqueous Solution on Conversion of $\mathrm{H}_{2} \mathrm{~S}$ and 29

Formation of COS

Effects of Soaking a Catalyst in Zn Aqueous Solution and then $\mathrm{KOH}$ Aqueous

Solution on Conversion of $\mathrm{H}_{2} \mathrm{~S}$ and Formation of COS

Effects of Soaking a Catalyst in $\mathrm{Fe}^{3+}$ Aqueous Solution on Conversion of $\mathrm{H}_{2} \mathrm{~S}$ and 31

Formation of COS

Effects of Soaking a Catalyst in $\mathrm{NaOH}, \mathrm{KOH}$, and $\mathrm{MgCl}_{2}$ Aqueous Solutions on

Conversion of $\mathrm{H}_{2} \mathrm{~S}$ and Formation of $\mathrm{COS}$

CONCLUSIONS

33

$\begin{array}{ll}\text { REFERENCES } & 34\end{array}$

PUBLICATIONS AND PRESENTATIONS

STUDENTS ASSIGNED FOR THIS PROJECT 34 


\section{LIST OF TABLES}

Table

Page

1 Experimental conditions for the reaction of hydrogen sulfide with sulfur dioxide as an oxidant using a monolithic catalyst reactor.

2 Dimensions and properties of the monolithic catalyst support.

3 Conversion of $\mathrm{H}_{2} \mathrm{~S}$ to elemental sulfur and formation of COS with $114-132$

SCCM feed streams containing 3,300 - 3,800 ppmv $\mathrm{H}_{2} \mathrm{~S}, 1,600-1,900 \mathrm{ppmv}$

$\mathrm{SO}_{2}$ as an oxidant, $29-34 \mathrm{v} \% \mathrm{CO}, 18-21 \mathrm{v} \% \mathrm{H}_{2}, 8-10 \mathrm{v} \% \mathrm{CO}_{2}$ and $5-18$ -

$\mathrm{v} \%$ moisture at $120-140^{\circ} \mathrm{C}, 116-129 \mathrm{psia}$, and $130-156$ s space time, regenerating the monolithic catalyst with $\mathrm{N}_{2}$ at $140-270^{\circ} \mathrm{C}$ overnight.

4 Effects of temperature on conversion of $\mathrm{H}_{2} \mathrm{~S}$ to elemental sulfur and formation of COS with a 120-SCCM feed stream containing 3,600-ppmv $\mathrm{H}_{2} \mathrm{~S}, 1,800$-ppmv $\mathrm{SO}_{2}, 32-\mathrm{v} \% \mathrm{CO}, 20-\mathrm{v} \% \mathrm{H}_{2}, 9-\mathrm{v} \% \mathrm{CO}_{2}$ and $10-\mathrm{v} \%$ moisture at $120-140^{\circ} \mathrm{C}, 117-$ 124 psia and 135 - 149 s space time, removing elemental sulfur from a $\gamma$-alumina wash-coated monolithic catalyst support with $\mathrm{N}_{2}$ overnight.

5 Effects of catalyst aging on conversion of $\mathrm{H}_{2} \mathrm{~S}$ and formation of COS with a $\gamma$ alumina wash-coated monolithic catalyst support soaked in 1-w\% Zn aqueous solution and heated for 4 hours at $450^{\circ} \mathrm{C}$, removing elemental sulfur from the catalyst with $\mathrm{N}_{2}$ overnight at $140^{\circ} \mathrm{C}$.

6 Effects of removal temperature of elemental sulfur attached to a catalyst on conversion of $\mathrm{H}_{2} \mathrm{~S}$ and formation of COS with the $\gamma$-alumina wash-coated monolithic catalyst support soaked in $1-\mathrm{w} \% \mathrm{Zn}$ aqueous solution followed by heating it for 4 hours at $450^{\circ} \mathrm{C}$, removing elemental sulfur from the catalyst with $\mathrm{N}_{2}$ overnight.

7 Effects of elemental sulfur removed from a monolithic catalyst on conversion of $\mathrm{H}_{2} \mathrm{~S}$ and formation of COS with the $\gamma$-alumina wash-coated catalyst support soaked in $1-\mathrm{w} \% \mathrm{Zn}$ aqueous solution followed by heating it for 4 hours at $450^{\circ} \mathrm{C}$, removing elemental sulfur from the catalyst with $\mathrm{N}_{2}$ at $200^{\circ} \mathrm{C}$ overnight.

8 Effects of washing a $\gamma$-alumina wash-coated monolithic catalyst in $\mathrm{NaOH}$ aqueous solution on conversion of $\mathrm{H}_{2} \mathrm{~S}$ and formation of COS with the catalyst support soaked in 1-w\% $\mathrm{Zn}$ aqueous solution followed by heating it for $4 \mathrm{hrs}$ at $450^{\circ} \mathrm{C}$

9 Effects of elemental sulfur removed from a $\gamma$-alumina wash-coated catalyst on conversion of $\mathrm{H}_{2} \mathrm{~S}$ and formation of $\mathrm{COS}$ with the catalyst support soaked in 1$\mathrm{w} \% \mathrm{Zn}$ aqueous solution followed by heating it for 4 hours at $450^{\circ} \mathrm{C}$, and then washed in $0.3 \mathrm{M} \mathrm{NaOH}$ aqueous solution followed by heating it for $4 \mathrm{hrs}$ at $900^{\circ} \mathrm{C}$, removing elemental sulfur from the catalyst with $\mathrm{N}_{2}$ at $200^{\circ} \mathrm{C}$. 
LIST OF TABLES Continued - 1

Table

Page

10 Effects of washing a $\gamma$-alumina wash-coated monolithic catalyst support in $\mathrm{NaOH}$ aqueous solution on conversion of $\mathrm{H}_{2} \mathrm{~S}$ and formation of COS.

11 Conversion of $\mathrm{H}_{2} \mathrm{~S}$ and formation of $\mathrm{COS}$ with a $\gamma$-alumina wash-coated monolithic catalyst support, soaked in $4-\mathrm{w} \% \mathrm{Zn}$ aqueous solution followed by heating it for $4 \mathrm{hrs}$ at $600^{\circ} \mathrm{C}$, and soaked in $4-\mathrm{w} \% \mathrm{KOH}$ aqueous solution followed by heating it for $4 \mathrm{hrs}$ at $550^{\circ} \mathrm{C}$.

12 Conversion of $\mathrm{H}_{2} \mathrm{~S}$ and formation of $\mathrm{COS}$ with a $\gamma$-alumina wash-coated monolithic catalyst support soaked in $4-\mathrm{w} \% \mathrm{KOH}$ aqueous solution followed by heating it for $4 \mathrm{hrs}$ at $550^{\circ} \mathrm{C}$.

13 Conversion of $\mathrm{H}_{2} \mathrm{~S}$ and formation of $\mathrm{COS}$ with a $\gamma$-alumina wash-coated monolithic catalyst support soaked in $2-\mathrm{w} \% \mathrm{Fe}^{3+}$ aqueous solution followed by heating it for 4 hrs at $450^{\circ} \mathrm{C}$, removing sulfur from the catalyst with $\mathrm{N}_{2}$ overnight.

14 Conversion of $\mathrm{H}_{2} \mathrm{~S}$ and formation of $\mathrm{COS}$ with a $\gamma$-alumina wash-coated monolithic catalyst support, soaked in $0.6-\mathrm{M} \mathrm{NaOH}$ aqueous solution followed by heating it for $4 \mathrm{hrs}$ at $950^{\circ} \mathrm{C}$, soaked in $4-\mathrm{w} \% \mathrm{KOH}$ aqueous solution followed by heating it for $2 \mathrm{~h}$ at $550^{\circ} \mathrm{C}$, and soaked in $0.5-\mathrm{w} \% \mathrm{MgCl}_{2}$ aqueous solution followed by heating it for $2 \mathrm{hrs}$ at $550^{\circ} \mathrm{C}$, removing no sulfur. 


\section{LIST OF FIGURES}

Figure

1 Schematic Diagram on the monolithic catalyst reactor assembly

2 Effects of temperature on conversion of $\mathrm{H}_{2} \mathrm{~S}$ to elemental sulfur and formation of COS with a 120-SCCM feed stream containing 3,600-ppmv $\mathrm{H}_{2} \mathrm{~S}, 1,800$ ppmv $\mathrm{SO}_{2}, 32-\mathrm{v} \% \mathrm{CO}, 20-\mathrm{v} \% \mathrm{H}_{2}, 9-\mathrm{v} \% \mathrm{CO}_{2}$ and $10-\mathrm{v} \%$ moisture at $120-$ $140^{\circ} \mathrm{C}$, 117- 124 psia and 135 - 149 s space time, removing elemental sulfur from a $\gamma$-alumina wash-coated monolithic catalyst with $\mathrm{N}_{2}$ overnight.

3 Effects of catalyst aging on conversion of $\mathrm{H}_{2} \mathrm{~S}$ and formation of $\mathrm{COS}$ with a $\gamma$ alumina wash-coated catalyst support soaked in 1-w\% Zn aqueous solution followed by heating it for 4 hours at $450^{\circ} \mathrm{C}$, removing elemental sulfur from the catalyst with $\mathrm{N}_{2}$ overnight at $140^{\circ} \mathrm{C}$.

4 Effects of removal temperature of elemental sulfur attached to a $\gamma$-alumina wash-coated catalyst on conversion of $\mathrm{H}_{2} \mathrm{~S}$ and formation of COS with the monolithic catalyst support soaked in 1-w\% Zn aqueous solution followed by heating it for 4 hours at $450^{\circ} \mathrm{C}$, removing elemental sulfur from the catalyst with $\mathrm{N}_{2}$ overnight.

5 Effects of sulfur removal from a $\gamma$-alumina wash-coated monolithic catalyst on conversion of $\mathrm{H}_{2} \mathrm{~S}$ and formation of COS with the catalyst support soaked with $1-\mathrm{w} \% \mathrm{Zn}$ aqueous solution followed by heating it for 4 hours at $450^{\circ} \mathrm{C}$, removing elemental sulfur from the catalyst with $\mathrm{N}_{2}$ at $200^{\circ} \mathrm{C}$ overnight.

6 Effects of soaking a catalyst in $\mathrm{NaOH}$ aqueous solution on conversion of $\mathrm{H}_{2} \mathrm{~S}$ and formation of COS with the $\gamma$-alumina wash-coated monolithic catalyst support soaked in 1-w\% $\mathrm{Zn}$ aqueous solution followed by heating it for $4 \mathrm{hrs}$ at $450^{\circ} \mathrm{C}$

7 Effects of removing elemental sulfur from a catalyst on conversion of $\mathrm{H}_{2} \mathrm{~S}$ and formation of COS with the $\gamma$-alumina wash-coated catalyst support soaked in 1$\mathrm{w} \% \mathrm{Zn}$ aqueous solution followed by heating it for 4 hours at $450^{\circ} \mathrm{C}$, and washed in $0.3 \mathrm{M} \mathrm{NaOH}$ aqueous solution followed by heating it for $4 \mathrm{hrs}$ at $900^{\circ} \mathrm{C}$, removing sulfur from the catalyst with $\mathrm{N}_{2}$ at $200^{\circ} \mathrm{C}$ overnight.

$8 \quad$ Effects of washing a $\gamma$-alumina wash-coated monolithic catalyst support in $\mathrm{NaOH}$ aqueous solution on conversion of $\mathrm{H}_{2} \mathrm{~S}$ and formation of COS.

9 Conversion of $\mathrm{H}_{2} \mathrm{~S}$ and formation of $\mathrm{COS}$ with a $\gamma$-alumina wash-coated monolithic catalyst support, soaked in 4-w\% Zn aqueous solution followed by heating it for $4 \mathrm{hrs}$ at $600^{\circ} \mathrm{C}$, and then soaked in $4-\mathrm{w} \% \mathrm{KOH}$ aqueous solution followed by heating it for $4 \mathrm{hrs}$ at $550^{\circ} \mathrm{C}$. 


\section{LIST OF FIGURES Continued - 1}

Figure $\quad$ Page

10 Conversion of $\mathrm{H}_{2} \mathrm{~S}$ and formation of $\mathrm{COS}$ with a $\gamma$-alumina wash-coated 30 monolithic catalyst support soaked with $4-\mathrm{w} \% \mathrm{KOH}$ aqueous solution followed by heating it for $4 \mathrm{hrs}$ at $550^{\circ} \mathrm{C}$.

11 Conversion of $\mathrm{H}_{2} \mathrm{~S}$ and formation of $\mathrm{COS}$ with a $\gamma$-alumina wash-coated monolithic catalyst support soaked in $2-\mathrm{w} \% \mathrm{Fe}^{3+}$ aqueous solution followed by heating it for $4 \mathrm{hrs}$ at $450^{\circ} \mathrm{C}$, removing elemental sulfur from the catalyst with $\mathrm{N}_{2}$ at $270^{\circ} \mathrm{C}$.

12 Conversion of $\mathrm{H}_{2} \mathrm{~S}$ and formation of $\mathrm{COS}$ with a $\gamma$-alumina wash-coated monolithic catalyst support soaked in $2-\mathrm{w} \% \mathrm{Fe}^{3+}$ aqueous solution followed by heating it for $4 \mathrm{hrs}$ at $450^{\circ} \mathrm{C}$, removing sulfur from the catalyst with $\mathrm{N}_{2}$ at $200^{\circ} \mathrm{C}$ overnight.

13 Conversion of $\mathrm{H}_{2} \mathrm{~S}$ and formation of $\mathrm{COS}$ with a $\gamma$-alumina wash-coated monolithic catalyst support, soaked in $0.6-\mathrm{M} \mathrm{NaOH}$ aqueous solution followed by heating it for $4 \mathrm{hrs}$ at $950^{\circ} \mathrm{C}$, soaked in $4-\mathrm{w} \% \mathrm{KOH}$ followed by heating it for $2 \mathrm{~h}$ at $550^{\circ} \mathrm{C}$, and soaked in $0.5-\mathrm{w} \% \mathrm{MgCl}_{2}$ aqueous solution by heating it for $2 \mathrm{hrs}$ at $550^{\circ} \mathrm{C}$, removing no sulfur. 


\section{SUMMARY}

Removal of hydrogen sulfide $\left(\mathrm{H}_{2} \mathrm{~S}\right)$ from coal gasifier gas and sulfur recovery are key steps in the development of Department of Energy's (DOE's) advanced power plants that produce electric power and clean transportation fuels with coal and natural gas. These plants will require highly clean coal gas with $\mathrm{H}_{2} \mathrm{~S}$ below 1 ppmv and negligible amounts of trace contaminants such as hydrogen chloride, ammonia, alkali, heavy metals, and particulate. The conventional method of sulfur removal and recovery employing amine, Claus, and tail-gas treatment is very expensive. A second generation approach developed under DOE's sponsorship employs hot-gas desulfurization (HGD) using regenerable metal oxide sorbents followed by Direct Sulfur Recovery Process (DSRP). However, this process sequence does not remove trace contaminants and is targeted primarily towards the development of advanced integrated gasification combined cycle (IGCC) plants that produce electricity (not both electricity and transportation fuels).

There is an immediate as well as long-term need for the development of cleanup processes that produce highly clean coal gas for next generation power plants. To this end, a novel process is now under development at several research organizations in which the $\mathrm{H}_{2} \mathrm{~S}$ in coal gas is directly oxidized to elemental sulfur over a selective catalyst. Such a process is ideally suited for coal gas from commercial gasifiers with a quench system to remove essentially all the trace contaminants except $\mathrm{H}_{2} \mathrm{~S}$

In the Single-Step Sulfur Recovery Process (SSRP), the direct oxidation of $\mathrm{H}_{2} \mathrm{~S}$ to elemental sulfur in the presence of $\mathrm{SO}_{2}$ is ideally suited for coal gas from commercial gasifiers with a quench system to remove essentially all the trace contaminants except $\mathrm{H}_{2} \mathrm{~S}$. This direct oxidation process has the potential to produce a super clean coal gas more economically than both conventional amine-based processes and HGD/DSRP. The $\mathrm{H}_{2}$ and $\mathrm{CO}$ components of syngas appear to behave as inert with respect to sulfur formed at the SSRP conditions. One problem in the SSRP process that needs to be eliminated or minimized is COS formation that may occur due to reaction of $\mathrm{CO}$ with sulfur formed from the Claus reaction.

The objectives of this research are to formulate monolithic catalysts for removal of $\mathrm{H}_{2} \mathrm{~S}$ from coal gases and minimum formation of COS with monolithic catalyst supports, $\gamma$-alumina wash or carbon coats, and catalytic metals, to develop a catalytic regeneration method for a deactivated monolithic catalyst, to measure kinetics of both direct oxidation of $\mathrm{H}_{2} \mathrm{~S}$ to elemental sulfur with $\mathrm{SO}_{2}$ as an oxidizer and formation of $\mathrm{COS}$ in the presence of a simulated coal gas mixture containing $\mathrm{H}_{2}, \mathrm{CO}, \mathrm{CO}_{2}$, and moisture, using a monolithic catalyst reactor, and to develop kinetic rate equations and model the direct oxidation process to assist in the design of large-scale plants. This heterogeneous catalytic reaction has gaseous reactants such as $\mathrm{H}_{2} \mathrm{~S}$ and $\mathrm{SO}_{2}$. However, this heterogeneous catalytic reaction has heterogeneous products such as liquid elemental sulfur and steam.

Experiments on conversion of hydrogen sulfide into elemental sulfur and formation of $\mathrm{COS}$ were carried out for the space time range of $130-156$ seconds at $120-140^{\circ} \mathrm{C}$ to formulate catalysts suitable for the removal of $\mathrm{H}_{2} \mathrm{~S}$ and $\mathrm{COS}$ from coal gases, evaluate removal capabilities of hydrogen sulfide and COS from coal gases with formulated catalysts, and develop an 
economic regeneration method of deactivated catalysts. Simulated coal gas mixtures consist of 3,300 - 3,800-ppmv hydrogen sulfide, 1,600 - 1,900 ppmv sulfur dioxide, $18-21 \mathrm{v} \%$ hydrogen, $29-34 \mathrm{v} \% \mathrm{CO}, 8-10 \mathrm{v} \% \mathrm{CO}_{2}, 5-18 \mathrm{vol} \%$ moisture, and nitrogen as remainder. Volumetric feed rates of a simulated coal gas mixture to the reactor are 114-132 SCCM. The temperature of the reactor is controlled in an oven at $120-140^{\circ} \mathrm{C}$. The pressure of the reactor is maintained at $116-129$ psia. The molar ratio of $\mathrm{H}_{2} \mathrm{~S}$ to $\mathrm{SO}_{2}$ in the monolithic catalyst reactor is maintained approximately at 2 for all the reaction experiment runs

\section{INTRODUCTION}

Coal is our most abundant energy resource. It is strategically important to our nation to increase coal use as an energy source in an environmentally acceptable manner. Coal gasification, a primary step in advanced coal utilization processes, produces a coal gas containing hydrogen $\left(\mathrm{H}_{2}\right)$ and carbon monoxide $(\mathrm{CO})$ as the fuel components. Raw coal gas, however, also contains a number of major and trace contaminants including hydrogen sulfide $\left(\mathrm{H}_{2} \mathrm{~S}\right)$, carbonyl sulfide $(\mathrm{COS})$, ammonia $\left(\mathrm{NH}_{3}\right)$, hydrogen chloride $(\mathrm{HCl})$, alkali, heavy metals, and particulate. Thus, this gas must be cleaned before further use. $\mathrm{H}_{2} \mathrm{~S}$ is a major coal gas contaminant that can range from 1000 to $10,000 \mathrm{ppmv}$, depending on the sulfur content of the coal. Removal of $\mathrm{H}_{2} \mathrm{~S}$ from coal gas and sulfur recovery are key steps in the development of Department of Energy's (DOE's) advanced Vision 21 plants combining a power plant and a refinery based on coal and natural gas to co-produce electricity and clean transportation-grade liquid fuels. These Vision 21 plants will require highly clean coal gas with $\mathrm{H}_{2} \mathrm{~S}$ below 1 ppmv and negligible amounts of other contaminants such as $\mathrm{COS}, \mathrm{HCl}, \mathrm{NH}_{3}$, alkali, heavy metals, and particulate.

The conventional method of removing $\mathrm{H}_{2} \mathrm{~S}$ and sulfur recovery involves a number of steps including amine scrubbing at low temperature followed by amine regeneration using steam to produce a concentrated $\mathrm{H}_{2} \mathrm{~S}$-containing gas. This concentrated $\mathrm{H}_{2} \mathrm{~S}$-containing gas is then combusted to produce a gas with a $\mathrm{H}_{2} \mathrm{~S}$ to sulfur dioxide $\left(\mathrm{SO}_{2}\right)$ ratio of 2 to 1 in a Claus furnace. This is followed by up to three (3) stages of Claus reaction at temperatures of around $250-280^{\circ} \mathrm{C}$ over an alumina catalyst to recover elemental sulfur:

$$
2 \mathrm{H}_{2} \mathrm{~S}(g)+\mathrm{SO}_{2}(g) \leftrightarrow 3 \mathrm{~S}(\ell)+2 \mathrm{H}_{2} \mathrm{O}(g)
$$

The Claus reaction is exothermic and equilibrium limited. To circumvent equilibrium limitations, the reaction is conducted in up to three (3) reaction stages with interstage cooling/ sulfur condensation followed by interstage re-heating. However, even with three (3) stages, the reaction is not complete due to thermodynamic limitations at $250^{\circ} \mathrm{C}$. The Claus tail gas contains sulfur that must be further treated in an expensive tail gas treatment plant (e.g., SCOT) before discharge. Thus, overall $\mathrm{H}_{2} \mathrm{~S}$ removal and sulfur recovery using this conventional sequence is extremely cumbersome, equipment intensive, and expensive.

A second generation approach for sulfur removal/recovery developed under DOE's sponsorship involves three steps:

(i) hot-gas desulfurization (HGD) using regenerable zinc oxide-based sorbents 


$$
\mathrm{ZnO}+\mathrm{H}_{2} \mathrm{~S} \leftrightarrow \mathrm{ZnS}+\mathrm{H}_{2} \mathrm{O} \quad \text { (HGD) }
$$

(ii) sorbent regeneration using air to produce $\mathrm{SO}_{2}$

$$
\mathrm{ZnS}+3 / 2 \mathrm{O}_{2} \leftrightarrow \mathrm{SO}_{2}+\mathrm{ZnO} \quad \text { (regeneration) }
$$

(iii) catalytic reduction of $\mathrm{SO}_{2}$ to elemental sulfur with a small portion of the coal gas in the Direct Sulfur Recovery Process (DSRP):

$$
\mathrm{SO}_{2}+2 \mathrm{H}_{2}(\text { or } 2 \mathrm{CO}) \leftrightarrow \mathrm{S}+2 \mathrm{H}_{2} \mathrm{O}\left(\text { or } 2 \mathrm{CO}_{2}\right) \quad(\mathrm{DSRP})
$$

This approach integrates well with a coal gasifier in an integrated gasification (IGCC) system because the raw coal gas does not have to be cooled all the way down to near room temperature as is the case with the conventional amine/Claus/tail-gas treatment method. However, the overall process scheme requires solid sorbent handling/circulation, and three separate reactors. Also, there is a small energy penalty associated with the use of coal gas to reduce $\mathrm{SO}_{2}$ by DSRP. Furthermore, since trace contaminants e.g. $\mathrm{NH}_{3}$ and $\mathrm{HCl}$ are not removed by the zinc-based sorbents. This approach is primarily targeted towards the development of advanced IGCC plants that produce electricity only (but do not co-produce both electricity and clean transportation grade fuels).

There is an immediate as well as long-term need for the development of clean processes that produce highly clean coal gas for next generation Vision 21 plants producing both electricity and transportation-grade liquid fuels. To this end, several research organizations are developing a novel process in which the $\mathrm{H}_{2} \mathrm{~S}$ in coal gas is directly oxidized to elemental sulfur over a selective catalyst using sulfur dioxide $\left(\mathrm{SO}_{2}\right)$ produced by burning a portion of the sulfur produced.

The direct oxidation process is ideally suited for coal gas from a commercial gasifier with a quench system. During quench, the trace contaminants (except sulfur) are essentially completely removed and $\mathrm{H}_{2} \mathrm{~S}$ (with some COS) remains as the only contaminant. The gas contains all of the major coal gas components including $\mathrm{H}_{2}, \mathrm{CO}, \mathrm{CO}_{2}$ and $\mathrm{H}_{2} \mathrm{O}$. Its typical pressure and temperature conditions are 40 to $220 \mathrm{psia}$ and 125 to $155^{\circ} \mathrm{C}$. In the direct oxidation process, the Claus reaction is carried out over a selective monolithic catalyst in the presence of the major gas components at around 125 to $155^{\circ} \mathrm{C}$ to yield liquid sulfur. The low-temperature phase change allows the $\mathrm{H}_{2} \mathrm{~S}-\mathrm{SO}_{2}$ reaction to proceed selectively over a catalyst and removes equilibrium limitation. Due to low reactant concentrations, the reaction proceeds nearly isothermally and has the potential to proceed to completion in a single reactor. Burning a required portion of the liquid sulfur in a sulfur burner produces the $\mathrm{SO}_{2}$ for the process. The process has the potential to produce a super clean coal gas much more economically than both conventional amine-based processes and HGD/DSRP.

The Single-Step Sulfur Recovery Process (SSRP) consists of injecting sulfur dioxide $\left(\mathrm{SO}_{2}\right)$ directly into the quenched syngas in the presence of a monolithic catalyst at 125 to $160^{\circ} \mathrm{C}$ ( 257 to $320^{\circ} \mathrm{F}$ ) to oxidize $\mathrm{H}_{2} \mathrm{~S}$ and recover elemental sulfur in a single step via the Claus reaction 
$\left(2 \mathrm{H}_{2} \mathrm{~S}+\mathrm{SO}_{2} \rightarrow 3 / \mathrm{n} \mathrm{S}_{\mathrm{n}}+2 \mathrm{H}_{2} \mathrm{O}\right)$. The $\mathrm{SO}_{2}$ needed is obtained by burning a portion of the produced sulfur in an external sulfur burner. The key differences between the above-mentioned SSRP process and the traditional Claus process are: (a) in the proposed SSRP process, the Claus reaction occurs in a highly reducing syngas atmosphere containing hydrogen $\left(\mathrm{H}_{2}\right)$ and carbon monoxide (CO) and (b) the reaction is carried out at the pressure of the syngas (40-1200 psia). Furthermore, in conventional low-temperature fixed-bed Claus processes e.g. SuperClaus, the catalyst is poisoned by sulfur plugging and must be regenerated by heating externally. In the proposed SSRP process, the liquid elemental sulfur formed from the $\mathrm{H}_{2} \mathrm{~S}$ removal reaction (Claus reaction) can be detached from the monolithic catalyst surface with the aid of the slip velocity (special flow pattern) of the gaseous reaction mixture at the interface between the thin liquid sulfur layer and the gaseous reaction mixture. The slip velocity, developed from a special flow pattern in monolithic catalyst support channels, induces the pressure difference between the solid catalyst surface and the liquid-sulfur interface by the venturi effect, thereby facilitating catalyst regeneration, sulfur recovery, and favorable shift in thermodynamic limitation on sulfur formation.

Work to date at DOE/NETL, Tuskegee University and RTI has shown the potential of SSRP to convert $99+\%$ of the $\mathrm{H}_{2} \mathrm{~S}$ at $40-220$ psia to elemental sulfur with less than 40 ppmv COS slip. Differential kinetic experiments at Tuskegee University have shown significant increases in rate with pressure increase from 40 to 170 psia. Considering that the commercial SSRP plant will operate at up to 1200 psia, there is potential for complete sulfur removal and recovery. One problem in SSRP that needs to be eliminated or minimized is COS formation that may occur due to reaction of $\mathrm{CO}$ with sulfur formed from the Claus reaction.

The objectives of this research are to formulate monolithic catalysts for removal of $\mathrm{H}_{2} \mathrm{~S}$ from coal gases and minimum formation of COS with monolithic catalyst supports, $\gamma$-alumina wash coats, and catalytic metals, to develop a catalytic regeneration method for a deactivated monolithic catalyst, to measure kinetics of both direct oxidation of $\mathrm{H}_{2} \mathrm{~S}$ to elemental sulfur with $\mathrm{SO}_{2}$ as an oxidizer and formation of $\mathrm{COS}$ in the presence of a simulated coal gas mixture containing, $\mathrm{H}_{2}, \mathrm{CO}, \mathrm{CO}_{2}$, and moisture, using a monolithic catalyst reactor, and to develop kinetic rate equations and model the direct oxidation process to assist in the design of large-scale plants. This heterogeneous catalytic reaction has gaseous reactants such as $\mathrm{H}_{2} \mathrm{~S}$ and $\mathrm{SO}_{2}$. However, this heterogeneous catalytic reaction has heterogeneous products such as liquid elemental sulfur and steam.

Experiments on conversion of hydrogen sulfide to elemental sulfur and formation of COS using a monolithic catalyst reactor were carried out for the space time range of $130-156$ seconds at $120-140^{\circ} \mathrm{C}$ and $116-129$ psia to formulate catalysts suitable for the removal of $\mathrm{H}_{2} \mathrm{~S}$ and COS from coal gases, evaluate removal capabilities of hydrogen sulfide and COS from coal gases with formulated catalysts, and develop an economic regeneration method of deactivated catalysts. Simulated coal gas mixtures consist of 3,300-3,800-ppmv hydrogen sulfide, 1,6001,900 ppmv sulfur dioxide, $18-21 \mathrm{v} \%$ hydrogen, $29-34 \mathrm{v} \% \mathrm{CO}, 8-10 \mathrm{v} \% \mathrm{CO}_{2}, 5-18$ vol \% moisture, and nitrogen as remainder. Volumetric feed rates of a simulated coal gas mixture to the monolithic catalyst reactor are $114-132 \mathrm{SCCM}$. The molar ratio of $\mathrm{H}_{2} \mathrm{~S}$ to $\mathrm{SO}_{2}$ in the monolithic catalyst reactor is maintained approximately at 2 for all the reaction experiment runs. 


\section{EXPERIMENTAL SETUPS}

A monolithic catalyst reactor was fabricated with a $2.2-\mathrm{cm}$ inside diameter and $15-\mathrm{cm}$ long 316-stainless steel HPLC column. A $\gamma$-alumina wash-coated monolithic catalyst support, 2$\mathrm{cm}$ in the diameter and $15-\mathrm{cm}$ long, has 200 square cells and $1040 \mathrm{~cm}^{2}$ flat surface area. The cell density and the wall thickness of the cordierite monolithic catalyst support are 400 square cells/inch ${ }^{2}$ and $0.02 \mathrm{~cm}$, respectively. A simulated coal gas mixture containing $\mathrm{H}_{2} \mathrm{~S}$ and $\mathrm{SO}_{2}$ was reacted with the aid of the catalyst in the monolithic catalyst reactor at $120-140^{\circ} \mathrm{C}$. Conversion of hydrogen sulfide to elemental sulfur was analyzed with the flame photometric detector (FPD) and the thermal conductivity detector (TCD) of a gas chromatograph. The range of space (residence) time of the reaction gas mixture in the reactor was 130 - 156 seconds under the reaction conditions. Space times are obtained by dividing the bulk volume of the monolithic catalyst in the reactor with the volumetric flow rate of a feed gaseous mixture at reaction conditions.

A reactor assembly mainly consists of four mass flow meters for gases, one reactor, two preheaters, one high pressure liquid pump for water, one four-way switch valve, one oven, five filters for gases, four check valves, and one water collection bottle, as shown in Figure 1. The preheaters are made of 20 -ft-long $1 / 16$-inch Teflon tubing.

Figure 1. Schematic Diagram on a monolithic catalyst reactor assembly

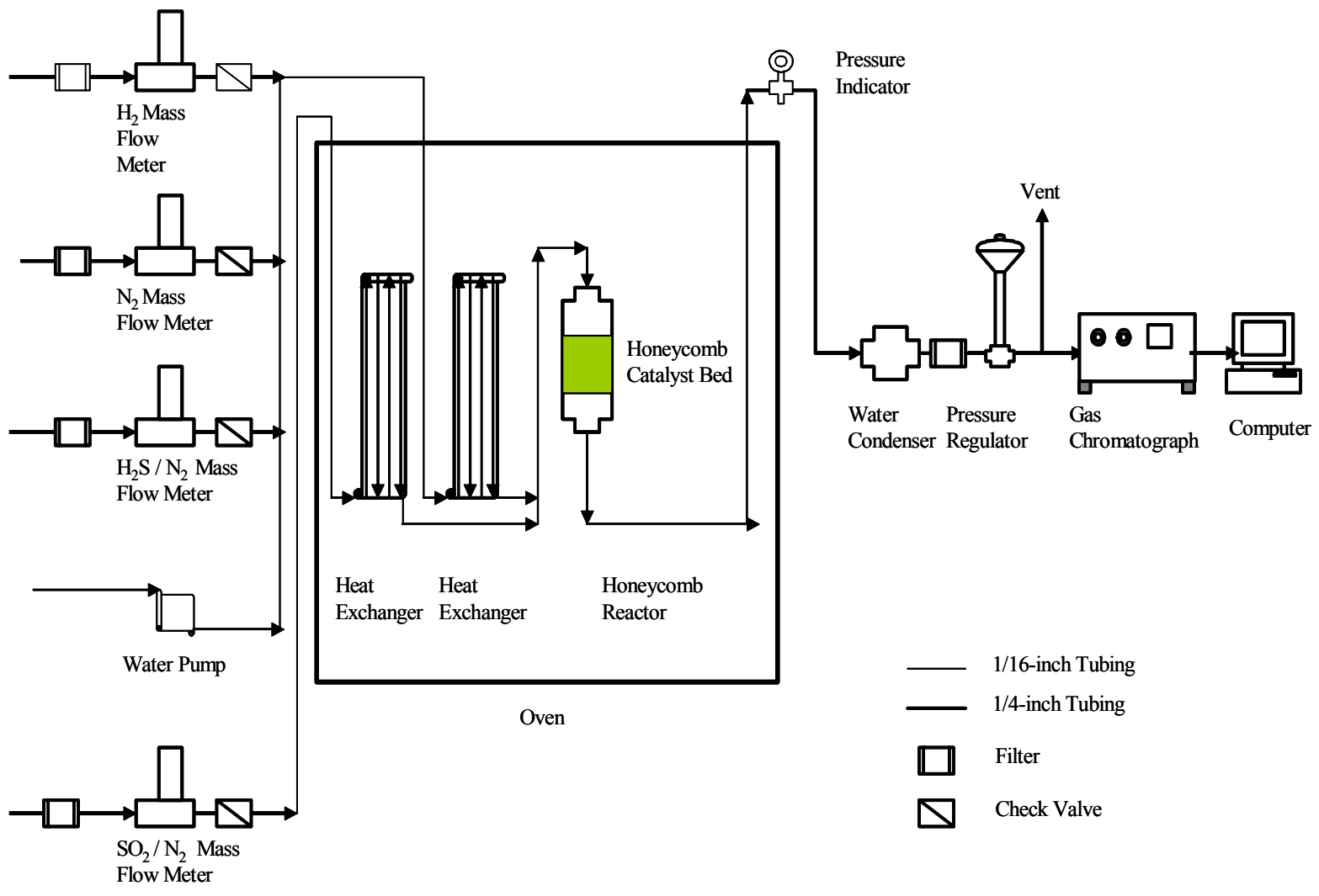


The reaction gas mixtures are fed downward to a vertical monolithic catalyst reactor, as shown in Figure 1. The reactor was loaded with a $\gamma$-alumina-wash-coated monolithic catalyst in the vertical reactor. The vertical reactor, loaded with the monolithic catalyst, was placed inside the oven to be heated at a desired temperature. Nitrogen was introduced into the catalyst-loaded reactor during preheating the reactor. When the temperature of the reactor was raised at the desired temperature, one simulated coal gas mixture stream containing $\mathrm{H}_{2} \mathrm{~S}$ and another feed stream containing $\mathrm{SO}_{2}$ were introduced into the reactor, by switching nitrogen with the simulated coal gas mixture. The reaction conditions are shown in Table 1. The properties of the monolithic catalyst support are shown in Table 2. The experimental data, shown in Tables 3 through 14, were used for drawing the Figures 2 through 13.

Table 1. Experimental conditions for the reaction of hydrogen sulfide with sulfur dioxide as an oxidant using a monolithic catalyst reactor.

$\begin{array}{ll}\text { Bulk Volume of the honeycomb catalyst bed, } \mathrm{cm}^{3}: & 47 \\ \text { Temperature, }{ }^{\circ} \mathrm{C}: & 120-140 \\ \text { Reaction Pressure, psia } & 116-129 \\ \text { New Space Time under the reaction conditions, s: } & 130-156 \\ \text { Total Feed Rate, } \mathrm{SCCM} & 114-132 \\ \text { Concentration of } \mathrm{H}_{2} \mathrm{~S}, \text { ppmv } & 3,300-3,800 \\ \text { Concentration of } \mathrm{SO}_{2}, \text { ppmv } & 1,600-1,900 \\ \text { Carbon Monoxide, } \mathrm{v} \% & 29-34 \\ \text { Hydrogen, vol \% } & 18-21 \\ \text { Carbon Dioxide, vol \% } & 8-10 \\ \text { Moisture, vol \%: } & 5-18 \\ \text { Nitrogen, vol \% } & \text { Remainder }\end{array}$

Table 2. Dimensions and properties of the monolithic catalyst support

Diameter, $\mathrm{cm}$

2

Length, $\mathrm{cm}$

Flat Surface Area, $\mathrm{cm}^{2}$

Wash Coat

Cell Shape

Cells/inch ${ }^{2}$ (CPSI)

Wall Thickness, cm

Flat Area/Length/Cell, $\mathrm{cm}^{2} / \mathrm{cm}$-length/cell

Chemical Composition

Oxide Additives
15

1,040

$\gamma-\mathrm{Al}_{2} \mathrm{O}_{3}$

square

400

0.02

0.345

Cordierite

$\left(2 \mathrm{MgO}-2 \mathrm{AL}_{2} \mathrm{O}_{3}-5 \mathrm{SIO}_{2}\right)$

$\mathrm{Na}, \mathrm{K}, \mathrm{Mg}, \mathrm{Zn}, \mathrm{Fe}$ (III) 
Table 3. Conversion of $\mathrm{H}_{2} \mathrm{~S}$ to elemental sulfur and formation of COS with $114-132 \mathrm{SCCM}$ feed streams containing $3,300-3,800 \mathrm{ppmv}_{2} \mathrm{~S}, 1,600-1,900$ ppmv $\mathrm{SO}_{2}$ as an oxidant, $29-$ $34 \mathrm{v} \% \mathrm{CO}, 18-21 \mathrm{v} \% \mathrm{H}_{2}, 8-10 \mathrm{v} \% \mathrm{CO}_{2}$ and $5-18$-v $\%$ moisture at $120-140^{\circ} \mathrm{C}, 116-129$ psia, and $130-156 \mathrm{~s}$ space time, regenerating the monolithic catalyst with $\mathrm{N}_{2}$ at $140-270^{\circ} \mathrm{C}$ overnight.

\begin{tabular}{|c|c|c|c|c|c|c|c|c|c|c|c|c|c|c|c|}
\hline \multirow[t]{2}{*}{ Run \# } & \multirow{2}{*}{$\begin{array}{c}\text { Temp. } \\
{ }^{\circ} \mathrm{C}\end{array}$} & \multirow{2}{*}{$\begin{array}{l}\text { Press. } \\
\text { psia }\end{array}$} & \multirow{2}{*}{$\begin{array}{l}\text { Total } \\
\text { Flow } \\
\\
\text { Rate, } \\
\text { SCCM } \\
\end{array}$} & \multirow{2}{*}{$\begin{array}{r}\text { Space } \\
\text { Time, s } \\
\end{array}$} & \multicolumn{7}{|c|}{ Feed Composition, v\% } & \multirow{2}{*}{$\begin{array}{c}\text { conversion } \\
\mathrm{H}_{2} \mathrm{~S} \\
\end{array}$} & \multicolumn{3}{|c|}{$\mathrm{COS}, \mathrm{ppm}$} \\
\hline & & & & & $\mathrm{H}_{2} \mathrm{~S}$ & $\mathrm{SO}_{2}$ & $\mathrm{CO}$ & $\mathrm{H}_{2}$ & $\mathrm{H}_{2} \mathrm{O}$ & $\mathrm{CO}_{2}$ & $\mathrm{~N}_{2}$ & & $\begin{array}{c}\text { Cylinder } \\
\text { Feed } \\
\end{array}$ & $\begin{array}{c}\text { Blank } \\
\text { Product } \\
\text { Mixture } \\
\end{array}$ & $\begin{array}{l}\text { Reaction } \\
\text { Product } \\
\text { Mixture } \\
\end{array}$ \\
\hline 283 & 130 & 118.7 & 120 & 141 & 0.36 & 0.18 & 32.02 & 20.26 & 10.01 & 9.07 & 28.11 & -0.0400 & 10 & 75 & 88 \\
\hline 284 & 130 & 118.7 & 120 & 141 & 0.36 & 0.18 & 32.02 & 20.26 & 10.00 & 9.07 & 28.11 & 0.1223 & 22 & 68 & 103 \\
\hline 285 & 130 & 120.7 & 120 & 143 & 0.36 & 0.18 & 32.02 & 20.26 & 10.00 & 9.07 & 28.11 & 0.8095 & 13 & 76 & 47 \\
\hline 286 & 130 & 120.7 & 120 & 143 & 0.36 & 0.18 & 32.02 & 20.26 & 10.00 & 9.07 & 28.11 & 0.8066 & 8 & 69 & 108 \\
\hline 287 & 130 & 117.7 & 120 & 140 & 0.36 & 0.18 & 32.02 & 20.26 & 10.00 & 9.07 & 28.11 & 0.8103 & 11 & 89 & 105 \\
\hline 288 & 130 & 120.7 & 120 & 143 & 0.36 & 0.18 & 32.02 & 20.26 & 10.00 & 9.07 & 28.11 & 0.8599 & 9 & 94 & 105 \\
\hline 289 & 130 & 122.7 & 120 & 145 & 0.36 & 0.18 & 32.02 & 20.26 & 10.00 & 9.07 & 28.11 & 0.7929 & 9 & 112 & 116 \\
\hline 290 & 130 & 121.7 & 120 & 144 & 0.36 & 0.18 & 32.02 & 20.26 & 10.00 & 9.07 & 28.11 & 0.8034 & 10 & 110 & 108 \\
\hline 291 & 130 & 120.7 & 120 & 143 & 0.36 & 0.18 & 32.02 & 20.26 & 10.00 & 9.07 & 28.11 & 0.8168 & 10 & 104 & 130 \\
\hline 292 & 125 & 119.7 & 120 & 144 & 0.36 & 0.18 & 32.02 & 20.26 & 10.00 & 9.07 & 28.11 & 0.7797 & 11 & 98 & 94 \\
\hline 293 & 125 & 120.7 & 120 & 145 & 0.36 & 0.18 & 32.02 & 20.26 & 10.00 & 9.07 & 28.11 & 0.7635 & 10 & 106 & 104 \\
\hline 294 & 125 & 121.7 & 120 & 146 & 0.36 & 0.18 & 32.02 & 20.26 & 10.00 & 9.07 & 28.11 & 0.7152 & 10 & 108 & 112 \\
\hline 295 & 125 & 118.7 & 120 & 142 & 0.36 & 0.18 & 32.02 & 20.26 & 10.00 & 9.07 & 28.11 & 0.7455 & 10 & 108 & 107 \\
\hline 296 & 125 & 120.7 & 120 & 145 & 0.36 & 0.18 & 32.02 & 20.26 & 10.00 & 9.07 & 28.11 & 0.7171 & 10 & 107 & 111 \\
\hline 297 & 125 & 120.7 & 120 & 145 & 0.36 & 0.18 & 32.02 & 20.26 & 10.00 & 9.07 & 28.11 & 0.7171 & 11 & 120 & 117 \\
\hline 298 & 120 & 120.7 & 120 & 147 & 0.36 & 0.18 & 32.02 & 20.26 & 10.00 & 9.07 & 28.11 & 0.6390 & 10 & 115 & 125 \\
\hline 299 & 120 & 118.7 & 120 & 144 & 0.36 & 0.18 & 32.02 & 20.26 & 10.00 & 9.07 & 28.11 & 0.5667 & 11 & 101 & 107 \\
\hline 300 & 120 & 120.7 & 120 & 147 & 0.36 & 0.18 & 32.02 & 20.26 & 10.00 & 9.07 & 28.11 & 0.4911 & 11 & 26 & 63 \\
\hline 301 & 120 & 119.7 & 120 & 146 & 0.36 & 0.18 & 32.02 & 20.26 & 10.00 & 9.07 & 28.11 & 0.4098 & 11 & 29 & 68 \\
\hline 302 & 120 & 118.7 & 120 & 144 & 0.36 & 0.18 & 32.02 & 20.26 & 10.00 & 9.07 & 28.11 & 0.5135 & 11 & 43 & 89 \\
\hline 303 & 120 & 120.7 & 120 & 147 & 0.36 & 0.18 & 32.02 & 20.26 & 10.00 & 9.07 & 28.11 & 0.3223 & 12 & 86 & 93 \\
\hline 304 & 120 & 120.7 & 120 & 147 & 0.36 & 0.18 & 32.02 & 20.26 & 10.00 & 9.07 & 28.11 & 0.1760 & 12 & 93 & 106 \\
\hline 305 & 120 & 122.7 & 120 & 149 & 0.36 & 0.18 & 32.02 & 20.26 & 10.00 & 9.07 & 28.11 & 0.2094 & 11 & 86 & 114 \\
\hline 306 & 125 & 122.7 & 120 & 147 & 0.36 & 0.18 & 32.02 & 20.26 & 10.00 & 9.07 & 28.11 & 0.1639 & 12 & 133 & 121 \\
\hline 307 & 130 & 121.7 & 120 & 144 & 0.36 & 0.18 & 32.02 & 20.26 & 10.00 & 9.07 & 28.11 & 0.1398 & 12 & 124 & 129 \\
\hline 308 & 140 & 120.7 & 120 & 140 & 0.36 & 0.18 & 32.02 & 20.26 & 10.00 & 9.07 & 28.11 & 0.1607 & 13 & 119 & 130 \\
\hline 309 & 140 & 118.7 & 120 & 137 & 0.36 & 0.18 & 32.02 & 20.26 & 10.00 & 9.07 & 28.11 & 0.8925 & 12 & 125 & 119 \\
\hline 310 & 140 & 119.7 & 120 & 138 & 0.36 & 0.18 & 32.02 & 20.26 & 10.00 & 9.07 & 28.11 & 0.8552 & 12 & 122 & 109 \\
\hline 311 & 140 & 118.7 & 120 & 137 & 0.36 & 0.18 & 32.02 & 20.26 & 10.00 & 9.07 & 28.11 & 0.8332 & 12 & 118 & 112 \\
\hline 312 & 140 & 120.7 & 120 & 140 & 0.36 & 0.18 & 32.02 & 20.26 & 10.00 & 9.07 & 28.11 & 0.8075 & 13 & 115 & 111 \\
\hline 313 & 140 & 117.7 & 120 & 136 & 0.36 & 0.18 & 32.02 & 20.26 & 10.00 & 9.07 & 28.11 & 0.4480 & 12 & 115 & 108 \\
\hline 314 & 120 & 117.7 & 120 & 143 & 0.36 & 0.18 & 32.02 & 20.26 & 10.00 & 9.07 & 28.11 & 0.7617 & 12 & 74 & 88 \\
\hline 315 & 120 & 120.7 & 120 & 147 & 0.36 & 0.18 & 32.02 & 20.26 & 10.00 & 9.07 & 28.11 & 0.6981 & 13 & 61 & 99 \\
\hline 316 & 120 & 119.7 & 120 & 146 & 0.36 & 0.18 & 32.02 & 20.26 & 10.00 & 9.07 & 28.11 & 0.5888 & 13 & 77 & 101 \\
\hline 317 & 120 & 118.7 & 120 & 144 & 0.36 & 0.18 & 32.02 & 20.26 & 10.00 & 9.07 & 28.11 & 0.5506 & 13 & 96 & 5 \\
\hline 318 & 120 & 119.7 & 120 & 146 & 0.36 & 0.18 & 32.02 & 20.26 & 10.00 & 9.07 & 28.11 & 0.4650 & 13 & 75 & 113 \\
\hline 319 & 120 & 117.7 & 120 & 143 & 0.36 & 0.18 & 32.02 & 20.26 & 10.00 & 9.07 & 28.11 & 0.6981 & 13 & 65 & 104 \\
\hline 320 & 140 & 116.7 & 120 & 135 & 0.36 & 0.18 & 32.02 & 20.26 & 10.00 & 9.07 & 28.11 & 0.4799 & 14 & 128 & 118 \\
\hline 321 & 140 & 118.7 & 120 & 137 & 0.36 & 0.18 & 32.02 & 20.26 & 10.00 & 9.07 & 28.11 & 0.4297 & 14 & 138 & 130 \\
\hline 322 & 140 & 118.7 & 120 & 137 & 0.36 & 0.18 & 32.02 & 20.26 & 10.00 & 9.07 & 28.11 & 0.3554 & 13 & 120 & 103 \\
\hline
\end{tabular}


Table 3. Continued -1

\begin{tabular}{|c|c|c|c|c|c|c|c|c|c|c|c|c|c|c|c|}
\hline \multirow[t]{2}{*}{ Run \# } & \multirow{2}{*}{$\begin{array}{l}\text { Temp. } \\
{ }^{\circ} \mathrm{C} \\
\end{array}$} & \multirow{2}{*}{$\begin{array}{l}\text { Press. } \\
\text { psia } \\
\end{array}$} & \multirow{2}{*}{$\begin{array}{l}\text { Total } \\
\text { Flow } \\
\text { Rate, } \\
\text { SCCM } \\
\end{array}$} & \multirow{2}{*}{$\begin{array}{c}\text { Space } \\
\text { Time, s } \\
\end{array}$} & \multicolumn{7}{|c|}{ Feed Composition, v\% } & \multirow{2}{*}{$\begin{array}{c}\text { conversion } \\
\\
\mathrm{H}_{2} \mathrm{~S} \\
\end{array}$} & \multicolumn{3}{|c|}{$\mathrm{COS}, \mathrm{ppm}$} \\
\hline & & & & & $\mathrm{H}_{2} \mathrm{~S}$ & $\mathrm{SO}_{2}$ & $\mathrm{CO}$ & $\mathrm{H}_{2}$ & $\mathrm{H}_{2} \mathrm{O}$ & $\mathrm{CO}_{2}$ & $\mathrm{~N}_{2}$ & & $\begin{array}{l}\text { Cylinder } \\
\text { Feed }\end{array}$ & \begin{tabular}{|c|} 
Blank \\
Product \\
Mixture \\
\end{tabular} & $\begin{array}{l}\text { Reaction } \\
\text { Product } \\
\text { Mixture }\end{array}$ \\
\hline 323 & 140 & 118.7 & 120 & 137 & 0.36 & 0.18 & 32.02 & 20.26 & 10.00 & 9.07 & 28.11 & 0.3777 & 13 & 121 & 106 \\
\hline 324 & 140 & 119.7 & 120 & 138 & 0.36 & 0.18 & 32.02 & 20.26 & 10.00 & 9.07 & 28.11 & 0.2955 & 13 & 110 & 110 \\
\hline 325 & 140 & 119.7 & 120 & 138 & 0.36 & 0.18 & 32.02 & 20.26 & 10.00 & 9.07 & 28.11 & 0.3816 & 15 & 109 & 90 \\
\hline 326 & 140 & 121.7 & 120 & 141 & 0.36 & 0.18 & 32.02 & 20.26 & 10.00 & 9.07 & 28.11 & 0.3009 & 14 & 96 & 91 \\
\hline 327 & 140 & 120.7 & 120 & 140 & 0.36 & 0.18 & 32.02 & 20.26 & 10.00 & 9.07 & 28.11 & 0.3179 & 14 & 101 & 103 \\
\hline 328 & 140 & 123.7 & 120 & 143 & 0.36 & 0.18 & 32.02 & 20.26 & 10.00 & 9.07 & 28.11 & 0.2225 & 15 & 97 & 94 \\
\hline 329 & 140 & 118.7 & 120 & 137 & 0.36 & 0.18 & 32.02 & 20.26 & 10.00 & 9.07 & 28.11 & 0.2230 & 15 & 118 & 119 \\
\hline 330 & 140 & 117.7 & 120 & 136 & 0.36 & 0.18 & 32.02 & 20.26 & 10.00 & 9.07 & 28.11 & 0.3355 & 15 & 114 & 103 \\
\hline 331 & 140 & 119.7 & 120 & 138 & 0.36 & 0.18 & 32.02 & 20.26 & 10.00 & 9.07 & 28.11 & 0.2711 & 15 & 99 & 88 \\
\hline 332 & 140 & 118.7 & 120 & 137 & 0.36 & 0.18 & 32.02 & 20.26 & 10.00 & 9.07 & 28.11 & 0.9760 & 15 & 94 & 149 \\
\hline 333 & 140 & 118.7 & 120 & 137 & 0.36 & 0.18 & 32.02 & 20.26 & 10.00 & 9.07 & 28.11 & 0.9331 & 16 & 102 & 286 \\
\hline 334 & 140 & 119.7 & 120 & 138 & 0.36 & 0.18 & 32.02 & 20.26 & 10.00 & 9.07 & 28.11 & 0.4850 & 16 & 102 & 235 \\
\hline 335 & 140 & 118.7 & 120 & 137 & 0.36 & 0.18 & 32.02 & 20.26 & 10.00 & 9.07 & 28.11 & 0.3630 & 18 & 101 & 218 \\
\hline 336 & 125 & 117.7 & 120 & 141 & 0.36 & 0.18 & 32.02 & 20.26 & 10.00 & 9.07 & 28.11 & 0.4461 & 16 & 64 & 200 \\
\hline 337 & 125 & 121.7 & 120 & 146 & 0.36 & 0.18 & 32.02 & 20.26 & 10.00 & 9.07 & 28.11 & 0.9584 & 17 & 81 & 44 \\
\hline 338 & 125 & 119.7 & 120 & 144 & 0.36 & 0.18 & 32.02 & 20.26 & 10.00 & 9.07 & 28.11 & 0.8188 & 18 & 87 & 120 \\
\hline 339 & 125 & 120.7 & 120 & 145 & 0.36 & 0.18 & 32.02 & 20.26 & 10.00 & 9.07 & 28.11 & 0.6118 & 17 & 81 & 99 \\
\hline 340 & 125 & 120.7 & 120 & 145 & 0.36 & 0.18 & 32.02 & 20.26 & 10.00 & 9.07 & 28.11 & 0.4529 & 17 & 76 & 100 \\
\hline 341 & 125 & 118.7 & 120 & 142 & 0.36 & 0.18 & 32.02 & 20.26 & 10.00 & 9.07 & 28.11 & 0.4419 & 19 & 94 & 116 \\
\hline 342 & 125 & 119.7 & 120 & 144 & 0.36 & 0.18 & 32.02 & 20.26 & 10.00 & 9.07 & 28.11 & 0.4014 & 18 & 105 & 96 \\
\hline 343 & 125 & 117.7 & 120 & 141 & 0.36 & 0.18 & 32.02 & 20.26 & 10.00 & 9.07 & 28.11 & 0.3348 & 17 & 100 & 89 \\
\hline 344 & 140 & 121.7 & 120 & 141 & 0.36 & 0.18 & 32.02 & 20.26 & 10.00 & 9.07 & 28.11 & 0.3155 & 18 & 124 & 120 \\
\hline 345 & 125 & 121.7 & 120 & 146 & 0.36 & 0.18 & 32.02 & 20.26 & 10.00 & 9.07 & 28.11 & na & 18 & 100 & 135 \\
\hline 346 & 125 & 120.7 & 120 & 145 & 0.36 & 0.18 & 32.02 & 20.26 & 10.00 & 9.07 & 28.11 & 0.9649 & 18 & 100 & 171 \\
\hline 347 & 125 & 120.7 & 120 & 145 & 0.36 & 0.18 & 32.02 & 20.26 & 10.00 & 9.07 & 28.11 & 0.7282 & 18 & 124 & 196 \\
\hline 348 & 125 & 116.7 & 120 & 140 & 0.36 & 0.18 & 32.02 & 20.26 & 10.00 & 9.07 & 28.11 & -0.0440 & 18 & 126 & 221 \\
\hline 349 & 125 & 121.7 & 120 & 146 & 0.36 & 0.18 & 32.02 & 20.26 & 10.00 & 9.07 & 28.11 & -0.8358 & 19 & 29 & 184 \\
\hline 350 & 125 & 122.7 & 120 & 147 & 0.36 & 0.18 & 32.02 & 20.26 & 10.00 & 9.07 & 28.11 & -0.3571 & 18 & 26 & 161 \\
\hline 351 & 125 & 116.7 & 120 & 140 & 0.36 & 0.18 & 32.02 & 20.26 & 10.00 & 9.07 & 28.11 & 0.1906 & 19 & 34 & 75 \\
\hline 352 & 125 & 121.7 & 120 & 146 & 0.36 & 0.18 & 32.02 & 20.26 & 10.00 & 9.07 & 28.11 & 0.9057 & 18 & 49 & 74 \\
\hline 353 & 125 & 119.7 & 120 & 144 & 0.36 & 0.18 & 32.02 & 20.26 & 10.00 & 9.07 & 28.11 & 0.9479 & 19 & 52 & 134 \\
\hline 354 & 125 & 117.7 & 120 & 141 & 0.36 & 0.18 & 32.02 & 20.26 & 10.00 & 9.07 & 28.11 & 0.8795 & 19 & 48 & 157 \\
\hline 355 & 125 & 117.7 & 120 & 141 & 0.36 & 0.18 & 32.02 & 20.26 & 10.00 & 9.07 & 28.11 & 0.8676 & 19 & 43 & 121 \\
\hline 356 & 125 & 123.7 & 120 & 148 & 0.36 & 0.18 & 32.02 & 20.26 & 10.00 & 9.07 & 28.11 & 0.8974 & 18 & 38 & 107 \\
\hline 357 & 125 & 116.7 & 120 & 140 & 0.36 & 0.18 & 32.02 & 20.26 & 10.00 & 9.07 & 28.11 & 0.9005 & 19 & 58 & 130 \\
\hline 358 & 125 & 118.7 & 120 & 142 & 0.36 & 0.18 & 32.02 & 20.26 & 10.00 & 9.07 & 28.11 & 0.9034 & 19 & 58 & 125 \\
\hline 359 & 125 & 119.7 & 120 & 144 & 0.36 & 0.18 & 32.02 & 20.26 & 10.00 & 9.07 & 28.11 & 0.8823 & 19 & 58 & 123 \\
\hline 360 & 125 & 120.7 & 120 & 145 & 0.36 & 0.18 & 32.02 & 20.26 & 10.00 & 9.07 & 28.11 & 0.8568 & 19 & 47 & 119 \\
\hline 361 & 125 & 118.7 & 120 & 142 & 0.36 & 0.18 & 32.02 & 20.26 & 10.00 & 9.07 & 28.11 & 0.8965 & 19 & 65 & 123 \\
\hline 362 & 125 & 121.7 & 120 & 146 & 0.36 & 0.18 & 32.02 & 20.26 & 10.00 & 9.07 & 28.11 & 0.8760 & 19 & 53 & 25 \\
\hline 363 & 125 & 117.7 & 120 & 141 & 0.36 & 0.18 & 32.02 & 20.26 & 10.00 & 9.07 & 28.11 & 0.9529 & 19 & 67 & 117 \\
\hline 364 & 125 & 120.7 & 120 & 145 & 0.36 & 0.18 & 32.02 & 20.26 & 10.00 & 9.07 & 28.11 & 0.9231 & 20 & 58 & 128 \\
\hline 365 & 125 & 121.7 & 120 & 146 & 0.36 & 0.18 & 32.02 & 20.26 & 10.00 & 9.07 & 28.11 & 0.9331 & 20 & 49 & 128 \\
\hline 366 & 125 & 121.7 & 120 & 146 & 0.36 & 0.18 & 32.02 & 20.26 & 10.00 & 9.07 & 28.11 & 0.9326 & 19 & 56 & 114 \\
\hline 367 & 125 & 115.7 & 120 & 139 & 0.36 & 0.18 & 32.02 & 20.26 & 10.00 & 9.07 & 28.11 & 0.9285 & 20 & 56 & 122 \\
\hline 368 & 125 & 118.7 & 120 & 142 & 0.36 & 0.18 & 32.02 & 20.26 & 10.00 & 9.07 & 28.11 & 0.8644 & 20 & 71 & 133 \\
\hline
\end{tabular}


Table 3. Continued -2

\begin{tabular}{|c|c|c|c|c|c|c|c|c|c|c|c|c|c|c|c|}
\hline \multirow[t]{2}{*}{ Run \# } & \multirow{2}{*}{$\begin{array}{l}\text { Temp. } \\
{ }^{\circ} \mathrm{C} \\
\end{array}$} & \multirow{2}{*}{$\begin{array}{r}\text { Press. } \\
\text { psia } \\
\end{array}$} & \multirow{2}{*}{$\begin{array}{c}\text { Total } \\
\text { Flow } \\
\text { Rate, } \\
\text { SCCM } \\
\end{array}$} & \multirow{2}{*}{$\begin{array}{c}\text { Space } \\
\text { Time, s }\end{array}$} & \multicolumn{7}{|c|}{ Feed Composition, v\% } & \multirow{2}{*}{$\begin{array}{c}\text { conversion } \\
\mathrm{H}_{2} \mathrm{~S} \\
\end{array}$} & \multicolumn{3}{|c|}{$\mathrm{COS}, \mathrm{ppm}$} \\
\hline & & & & & $\mathrm{H}_{2} \mathrm{~S}$ & $\mathrm{SO}_{2}$ & $\mathrm{CO}$ & $\mathrm{H}_{2}$ & $\mathrm{H}_{2} \mathrm{O}$ & $\mathrm{CO}_{2}$ & $\mathrm{~N}_{2}$ & & $\begin{array}{c}\text { Cylinder } \\
\text { Feed }\end{array}$ & $\begin{array}{c}\text { Blank } \\
\text { Product } \\
\text { Mixture } \\
\end{array}$ & $\begin{array}{l}\text { Reaction } \\
\text { Product } \\
\text { Mixture } \\
\end{array}$ \\
\hline 369 & 125 & 118.7 & 120 & 142 & 0.36 & 0.18 & 32.02 & 20.26 & 10.00 & 9.07 & 28.11 & 0.8942 & 20 & 62 & 135 \\
\hline 370 & 125 & 118.7 & 120 & 142 & 0.36 & 0.18 & 32.02 & 20.26 & 10.00 & 9.07 & 28.11 & 0.7891 & 21 & 92 & 135 \\
\hline 371 & 125 & 119.7 & 120 & 144 & 0.36 & 0.18 & 32.02 & 20.26 & 10.00 & 9.07 & 28.11 & 0.7402 & 21 & 89 & 193 \\
\hline 372 & 125 & 117.7 & 120 & 141 & 0.36 & 0.18 & 32.02 & 20.26 & 10.00 & 9.07 & 28.11 & 0.7520 & 21 & 109 & 204 \\
\hline 373 & 125 & 118.7 & 132 & 130 & 0.33 & 0.16 & 29.11 & 18.42 & 18.18 & 8.25 & 25.55 & 0.6703 & 20 & 169 & 336 \\
\hline 374 & 125 & 121.7 & 132 & 133 & 0.33 & 0.16 & 29.11 & 18.42 & 18.18 & 8.25 & 25.55 & 0.6499 & 25 & 152 & 302 \\
\hline 375 & 125 & 118.7 & 132 & 130 & 0.33 & 0.16 & 29.11 & 18.42 & 18.18 & 8.25 & 25.55 & 0.582 & 24 & 154 & 320 \\
\hline 376 & 125 & 118.7 & 114 & 150 & 0.38 & 0.19 & 33.71 & 21.32 & 5.26 & 9.55 & 29.59 & 0.7115 & 24 & 152 & 237 \\
\hline 377 & 125 & 121.7 & 114 & 154 & 0.38 & 0.19 & 33.61 & 21.45 & 5.26 & 9.54 & 29.57 & 0.6578 & 10 & 64 & 183 \\
\hline 378 & 125 & 121.7 & 114 & 154 & 0.38 & 0.19 & 33.61 & 21.45 & 5.26 & 9.54 & 29.57 & 0.6821 & 7 & 61 & 216 \\
\hline 379 & 125 & 118.7 & 114 & 150 & 0.38 & 0.19 & 33.61 & 21.45 & 5.26 & 9.54 & 29.57 & 0.6316 & 7 & 75 & 330 \\
\hline 380 & 125 & 119.7 & 114 & 151 & 0.38 & 0.19 & 33.61 & 21.45 & 5.26 & 9.54 & 29.57 & 0.6298 & 6 & 74 & 193 \\
\hline 381 & 125 & 119.7 & 114 & 151 & 0.38 & 0.19 & 33.61 & 21.45 & 5.26 & 9.54 & 29.57 & 0.3957 & 6 & 89 & 187 \\
\hline 382 & 125 & 120.7 & 114 & 152 & 0.38 & 0.19 & 33.61 & 21.45 & 5.26 & 9.54 & 29.57 & 0.4566 & 6 & 94 & 147 \\
\hline 383 & 125 & 120.7 & 114 & 152 & 0.38 & 0.19 & 33.61 & 21.45 & 5.26 & 9.54 & 29.57 & 0.3991 & 6 & 99 & 124 \\
\hline 384 & 125 & 120.7 & 114 & 152 & 0.38 & 0.19 & 33.61 & 21.45 & 5.26 & 9.54 & 29.57 & 0.5082 & 6 & 62 & 253 \\
\hline 385 & 125 & 123.7 & 114 & 156 & 0.38 & 0.19 & 33.61 & 21.45 & 5.26 & 9.54 & 29.57 & 0.3885 & 5 & 76 & 231 \\
\hline 386 & 125 & 121.7 & 114 & 154 & 0.38 & 0.19 & 33.61 & 21.45 & 5.26 & 9.54 & 29.57 & 0.2779 & 5 & 52 & 221 \\
\hline 387 & 125 & 121.7 & 120 & 146 & 0.36 & 0.18 & 31.93 & 20.38 & 10.00 & 9.07 & 28.09 & 0.9044 & 4 & 62 & 141 \\
\hline 388 & 125 & 122.7 & 114 & 155 & 0.38 & 0.19 & 33.61 & 21.45 & 5.26 & 9.54 & 29.57 & 0.8395 & 3 & 85 & 128 \\
\hline 389 & 125 & 120.7 & 120 & 145 & 0.36 & 0.18 & 31.93 & 20.38 & 10.00 & 9.07 & 28.09 & 0.8731 & 5 & 57 & 220 \\
\hline 390 & 125 & 118.7 & 120 & 142 & 0.36 & 0.18 & 31.93 & 20.38 & 10.00 & 9.07 & 28.09 & 0.9287 & 5 & 71 & 141 \\
\hline 391 & 125 & 118.7 & 120 & 142 & 0.36 & 0.18 & 31.93 & 20.38 & 10.00 & 9.07 & 28.09 & 0.6987 & 4 & 52 & 248 \\
\hline 392 & 125 & 122.7 & 120 & 147 & 0.36 & 0.18 & 31.93 & 20.38 & 10.00 & 9.07 & 28.09 & 0.3410 & 5 & 51 & 184 \\
\hline 393 & 125 & 120.7 & 120 & 145 & 0.36 & 0.18 & 31.93 & 20.38 & 10.00 & 9.07 & 28.09 & 0.7553 & 6 & 63 & 139 \\
\hline 394 & 125 & 121.7 & 120 & 146 & 0.36 & 0.18 & 31.93 & 20.38 & 10.00 & 9.07 & 28.09 & 0.5210 & 5 & 123 & 133 \\
\hline 395 & 125 & 119.7 & 120 & 144 & 0.36 & 0.18 & 31.93 & 20.38 & 10.00 & 9.07 & 28.09 & 0.5254 & 5 & 142 & 179 \\
\hline 396 & 125 & 120.7 & 120 & 145 & 0.36 & 0.18 & 31.93 & 20.38 & 10.00 & 9.07 & 28.09 & 0.3428 & 6 & 53 & 99 \\
\hline 397 & 125 & 120.7 & 120 & 145 & 0.36 & 0.18 & 31.93 & 20.38 & 10.00 & 9.07 & 28.09 & 0.2062 & 6 & 89 & 121 \\
\hline 398 & 125 & 117.7 & 120 & 141 & 0.36 & 0.18 & 31.93 & 20.38 & 10.00 & 9.07 & 28.09 & 0.8108 & 5 & 79 & 207 \\
\hline 399 & 125 & 119.7 & 120 & 144 & 0.36 & 0.18 & 31.93 & 20.38 & 10.00 & 9.07 & 28.09 & 0.7348 & 5 & 59 & 224 \\
\hline 400 & 125 & 120.7 & 120 & 145 & 0.36 & 0.18 & 31.93 & 20.38 & 10.00 & 9.07 & 28.09 & 0.7744 & 5 & 72 & 163 \\
\hline 401 & 125 & 119.7 & 120 & 144 & 0.36 & 0.18 & 31.93 & 20.38 & 10.00 & 9.07 & 28.09 & 0.8154 & 5 & 53 & 161 \\
\hline 402 & 125 & 121.7 & 120 & 146 & 0.36 & 0.18 & 31.93 & 20.38 & 10.00 & 9.07 & 28.09 & 0.1779 & 5 & 62 & 193 \\
\hline 403 & 125 & 119.7 & 120 & 144 & 0.36 & 0.18 & 31.93 & 20.38 & 10.00 & 9.07 & 28.09 & 0.7339 & 5 & 45 & 138 \\
\hline 404 & 125 & 121.7 & 120 & 146 & 0.36 & 0.18 & 31.93 & 20.38 & 10.00 & 9.07 & 28.09 & 0.8201 & 5 & 48 & 119 \\
\hline 405 & 125 & 123.7 & 120 & 148 & 0.36 & 0.18 & 31.93 & 20.38 & 10.00 & 9.07 & 28.09 & 0.6095 & 4 & 68 & 153 \\
\hline 406 & 125 & 119.7 & 120 & 144 & 0.36 & 0.18 & 31.93 & 20.38 & 10.00 & 9.07 & 28.09 & 0.3270 & 5 & 70 & 137 \\
\hline 407 & 125 & 120.7 & 120 & 145 & 0.36 & 0.18 & 31.93 & 20.38 & 10.00 & 9.07 & 28.09 & 0.2864 & 6 & 80 & 121 \\
\hline 408 & 125 & 118.7 & 120 & 142 & 0.36 & 0.18 & 31.93 & 20.38 & 10.00 & 9.07 & 28.09 & 0.8602 & 7 & 69 & 106 \\
\hline 409 & 125 & 118.7 & 120 & 142 & 0.36 & 0.18 & 31.93 & 20.38 & 10.00 & 9.07 & 28.09 & 0.9269 & 5 & 60 & 121 \\
\hline 410 & 125 & 120.7 & 120 & 145 & 0.36 & 0.18 & 31.93 & 20.38 & 10.00 & 9.07 & 28.09 & 0.9309 & 4 & 59 & 145 \\
\hline 411 & 125 & 122.7 & 120 & 147 & 0.36 & 0.18 & 31.93 & 20.38 & 10.00 & 9.07 & 28.09 & 0.9027 & 4 & 148 & 178 \\
\hline 412 & 125 & 122.7 & 120 & 147 & 0.36 & 0.18 & 31.93 & 20.38 & 10.00 & 9.07 & 28.09 & 0.8547 & 5 & 125 & 161 \\
\hline 413 & 125 & 119.7 & 120 & 144 & 0.36 & 0.18 & 31.93 & 20.38 & 10.00 & 9.07 & 28.09 & 0.8410 & 4 & 177 & 188 \\
\hline 414 & 125 & 120.7 & 120 & 145 & 0.36 & 0.18 & 31.93 & 20.38 & 10.00 & 9.07 & 28.09 & 0.7072 & 4 & 116 & 190 \\
\hline
\end{tabular}


Table 3. Continued -3

\begin{tabular}{|c|c|c|c|c|c|c|c|c|c|c|c|c|c|c|c|}
\hline \multirow[t]{2}{*}{ Run \# } & \multirow{2}{*}{$\begin{array}{l}\text { Temp. } \\
{ }^{\circ} \mathrm{C} \\
\end{array}$} & \multirow{2}{*}{$\begin{array}{l}\text { Press. } \\
\text { psia }\end{array}$} & \multirow{2}{*}{$\begin{array}{c}\text { Total } \\
\text { Flow } \\
\\
\text { Rate, } \\
\text { SCCM } \\
\end{array}$} & \multirow{2}{*}{$\begin{array}{l}\text { Space } \\
\text { Time, s } \\
\end{array}$} & \multicolumn{7}{|c|}{ Feed Composition, v\% } & \multirow{2}{*}{$\begin{array}{c}\text { conversion } \\
\mathrm{H}_{2} \mathrm{~S} \\
\end{array}$} & \multicolumn{3}{|c|}{$\mathrm{COS}, \mathrm{ppm}$} \\
\hline & & & & & $\mathrm{H}_{2} \mathrm{~S}$ & $\mathrm{SO}_{2}$ & $\mathrm{CO}$ & $\mathrm{H}_{2}$ & $\mathrm{H}_{2} \mathrm{O}$ & $\mathrm{CO}_{2}$ & $\mathrm{~N}_{2}$ & & $\begin{array}{c}\text { Cylinder } \\
\text { Feed } \\
\end{array}$ & \begin{tabular}{|c|} 
Blank \\
Product \\
Mixture \\
\end{tabular} & $\begin{array}{l}\text { Reaction } \\
\text { Product } \\
\text { Mixture } \\
\end{array}$ \\
\hline 415 & 125 & 119.7 & 120 & 144 & 0.36 & 0.18 & 31.93 & 20.38 & 10.00 & 9.07 & 28.09 & 0.6785 & 4 & 97 & 165 \\
\hline 416 & 125 & 122.7 & 120 & 147 & 0.36 & 0.18 & 31.93 & 20.38 & 10.00 & 9.07 & 28.09 & 0.8935 & 4 & 110 & 191 \\
\hline 417 & 125 & 122.7 & 120 & 147 & 0.36 & 0.18 & 31.93 & 20.38 & 10.00 & 9.07 & 28.09 & 0.7925 & 4 & 121 & 216 \\
\hline 418 & 125 & 121.7 & 120 & 146 & 0.36 & 0.18 & 31.93 & 20.38 & 10.00 & 9.07 & 28.09 & 0.7027 & 4 & 122 & 248 \\
\hline 419 & 125 & 119.7 & 120 & 144 & 0.36 & 0.18 & 31.93 & 20.38 & 10.00 & 9.07 & 28.09 & 0.6082 & 5 & 157 & 231 \\
\hline 420 & 125 & 121.7 & 120 & 146 & 0.36 & 0.18 & 31.93 & 20.38 & 10.00 & 9.07 & 28.09 & 0.5535 & 5 & 116 & 215 \\
\hline 421 & 125 & 119.7 & 120 & 144 & 0.36 & 0.18 & 31.93 & 20.38 & 10.00 & 9.07 & 28.09 & 0.6156 & 4 & 116 & 209 \\
\hline 422 & 125 & 119.7 & 120 & 144 & 0.36 & 0.18 & 31.93 & 20.38 & 10.00 & 9.07 & 28.09 & 0.7023 & 4 & 101 & 187 \\
\hline 423 & 125 & 116.7 & 120 & 140 & 0.36 & 0.18 & 31.93 & 20.38 & 10.00 & 9.07 & 28.09 & 0.7857 & 4 & 110 & 202 \\
\hline 424 & 125 & 119.7 & 120 & 144 & 0.36 & 0.18 & 31.93 & 20.38 & 10.00 & 9.07 & 28.09 & 0.7343 & 4 & 111 & 223 \\
\hline 425 & 125 & 121.7 & 120 & 146 & 0.36 & 0.18 & 31.93 & 20.38 & 10.00 & 9.07 & 28.09 & 0.6678 & 4 & 142 & 243 \\
\hline 426 & 125 & 120.7 & 120 & 145 & 0.36 & 0.18 & 31.93 & 20.38 & 10.00 & 9.07 & 28.09 & 0.6056 & 5 & 129 & 218 \\
\hline 427 & 125 & 115.7 & 120 & 139 & 0.36 & 0.18 & 31.93 & 20.38 & 10.00 & 9.07 & 28.09 & 0.7794 & 4 & 129 & 402 \\
\hline 428 & 125 & 118.7 & 120 & 142 & 0.36 & 0.18 & 31.93 & 20.38 & 10.00 & 9.07 & 28.09 & 0.8661 & 5 & 131 & 148 \\
\hline 429 & 125 & 121.7 & 120 & 146 & 0.36 & 0.18 & 31.93 & 20.38 & 10.00 & 9.07 & 28.09 & 0.9073 & 5 & 98 & 115 \\
\hline 430 & 125 & 117.7 & 120 & 141 & 0.36 & 0.18 & 31.93 & 20.38 & 10.00 & 9.07 & 28.09 & 0.7673 & 5 & 99 & 142 \\
\hline 431 & 125 & 120.7 & 120 & 145 & 0.36 & 0.18 & 31.93 & 20.38 & 10.00 & 9.07 & 28.09 & 0.7929 & 5 & 120 & 128 \\
\hline 432 & 125 & 128.7 & 120 & 154 & 0.36 & 0.18 & 31.93 & 20.38 & 10.00 & 9.07 & 28.09 & 1.0000 & 5 & 119 & 103 \\
\hline 433 & 125 & 121.7 & 120 & 146 & 0.36 & 0.18 & 31.93 & 20.38 & 10.00 & 9.07 & 28.09 & 0.1718 & 5 & 108 & 200 \\
\hline 434 & 125 & 115.7 & 120 & 139 & 0.36 & 0.18 & 31.93 & 20.38 & 10.00 & 9.07 & 28.09 & 0.6977 & 4 & 142 & 2 \\
\hline 435 & 125 & 119.7 & 120 & 144 & 0.36 & 0.18 & 31.93 & 20.38 & 10.00 & 9.07 & 28.09 & 0.7108 & 4 & 118 & 64 \\
\hline 436 & 125 & 117.7 & 120 & 141 & 0.36 & 0.18 & 31.93 & 20.38 & 10.00 & 9.07 & 28.09 & 1.0000 & 4 & 121 & 2 \\
\hline 437 & 125 & 118.7 & 120 & 142 & 0.36 & 0.18 & 31.93 & 20.38 & 10.00 & 9.07 & 28.09 & 0.8961 & 4 & 126 & 140 \\
\hline 438 & 125 & 120.7 & 120 & 145 & 0.36 & 0.18 & 31.93 & 20.38 & 10.00 & 9.07 & 28.09 & 0.2990 & 4 & 18 & 182 \\
\hline 439 & 125 & 120.7 & 120 & 145 & 0.36 & 0.18 & 31.93 & 20.38 & 10.00 & 9.07 & 28.09 & 0.2383 & 5 & 37 & 147 \\
\hline 440 & 125 & 119.7 & 120 & 144 & 0.36 & 0.18 & 31.93 & 20.38 & 10.00 & 9.07 & 28.09 & 0.5517 & 4 & 20 & 90 \\
\hline 441 & 125 & 119.7 & 120 & 144 & 0.36 & 0.18 & 31.93 & 20.38 & 10.00 & 9.07 & 28.09 & 0.7503 & 4 & 14 & 100 \\
\hline 442 & 125 & 119.7 & 120 & 144 & 0.36 & 0.18 & 31.93 & 20.38 & 10.00 & 9.07 & 28.09 & 0.8165 & 4 & 48 & 103 \\
\hline 443 & 125 & 121.7 & 120 & 146 & 0.36 & 0.18 & 31.93 & 20.38 & 10.00 & 9.07 & 28.09 & 0.8213 & 4 & 30 & 114 \\
\hline 444 & 125 & 120.7 & 120 & 145 & 0.36 & 0.18 & 31.93 & 20.38 & 10.00 & 9.07 & 28.09 & 0.8004 & 4 & 21 & 39 \\
\hline 445 & 125 & 120.7 & 120 & 145 & 0.36 & 0.18 & 31.93 & 20.38 & 10.00 & 9.07 & 28.09 & 0.7956 & 4 & 26 & 66 \\
\hline 446 & 125 & 123.7 & 120 & 148 & 0.36 & 0.18 & 31.93 & 20.38 & 10.00 & 9.07 & 28.09 & 0.2445 & 5 & 58 & 138 \\
\hline 447 & 125 & 119.7 & 120 & 144 & 0.36 & 0.18 & 31.93 & 20.38 & 10.00 & 9.07 & 28.09 & 0.3075 & 5 & 31 & 137 \\
\hline 448 & 125 & 118.7 & 120 & 142 & 0.36 & 0.18 & 31.93 & 20.38 & 10.00 & 9.07 & 28.09 & 0.8316 & 5 & 41 & 51 \\
\hline 449 & 125 & 118.7 & 120 & 142 & 0.36 & 0.18 & 31.93 & 20.38 & 10.00 & 9.07 & 28.09 & 0.8884 & 4 & 32 & 67 \\
\hline 450 & 125 & 116.7 & 120 & 140 & 0.36 & 0.18 & 31.93 & 20.38 & 10.00 & 9.07 & 28.09 & 0.8906 & 4 & 29 & 62 \\
\hline 451 & 125 & 121.7 & 120 & 146 & 0.36 & 0.18 & 31.93 & 20.38 & 10.00 & 9.07 & 28.09 & 0.8764 & 5 & 72 & 79 \\
\hline 452 & 125 & 119.7 & 120 & 144 & 0.36 & 0.18 & 31.93 & 20.38 & 10.00 & 9.07 & 28.09 & 0.8779 & 4 & 57 & 84 \\
\hline 453 & 125 & 119.7 & 120 & 144 & 0.36 & 0.18 & 31.93 & 20.38 & 10.00 & 9.07 & 28.09 & 0.8677 & 3 & 70 & 88 \\
\hline 454 & 125 & 119.7 & 120 & 144 & 0.36 & 0.18 & 31.93 & 20.38 & 10.00 & 9.07 & 28.09 & 0.8517 & 4 & 75 & 131 \\
\hline 455 & 125 & 119.7 & 120 & 144 & 0.36 & 0.18 & 31.93 & 20.38 & 10.00 & 9.07 & 28.09 & 0.6470 & 4 & 79 & 104 \\
\hline 456 & 125 & 119.7 & 120 & 144 & 0.36 & 0.18 & 31.93 & 20.38 & 10.00 & 9.07 & 28.09 & 0.6484 & 4 & 166 & 128 \\
\hline 457 & 125 & 116.7 & 120 & 140 & 0.36 & 0.18 & 31.93 & 20.38 & 10.00 & 9.07 & 28.09 & 0.8283 & 5 & 93 & 92 \\
\hline 458 & 125 & 118.7 & 120 & 142 & 0.36 & 0.18 & 31.93 & 20.38 & 10.00 & 9.07 & 28.09 & 0.8370 & 5 & 63 & 96 \\
\hline 459 & 125 & 121.7 & 120 & 146 & 0.36 & 0.18 & 31.93 & 20.38 & 10.00 & 9.07 & 28.09 & 0.8139 & 5 & 77 & 96 \\
\hline 460 & 125 & 118.7 & 120 & 142 & 0.36 & 0.18 & 31.93 & 20.38 & 10.00 & 9.07 & 28.09 & 0.8213 & 5 & 83 & 92 \\
\hline
\end{tabular}


Table 3. Continued -4

\begin{tabular}{|c|c|c|c|c|c|c|c|c|c|c|c|c|c|c|c|}
\hline \multirow[t]{2}{*}{ Run \# } & \multirow{2}{*}{$\begin{array}{l}\text { Temp. } \\
{ }^{\circ} \mathrm{C} \\
\end{array}$} & \multirow{2}{*}{$\begin{array}{l}\text { Press. } \\
\text { psia } \\
\end{array}$} & \multirow{2}{*}{$\begin{array}{l}\text { Total } \\
\text { Flow } \\
\\
\text { Rate, } \\
\text { SCCM } \\
\end{array}$} & \multirow{2}{*}{$\begin{array}{l}\text { Space } \\
\text { Time, s } \\
\end{array}$} & \multicolumn{7}{|c|}{ Feed Composition, v\% } & \multirow{2}{*}{$\begin{array}{c}\text { conversion } \\
\mathrm{H}_{2} \mathrm{~S}\end{array}$} & \multicolumn{3}{|c|}{$\mathrm{COS}, \mathrm{ppm}$} \\
\hline & & & & & $\mathrm{H}_{2} \mathrm{~S}$ & $\mathrm{SO}_{2}$ & $\mathrm{CO}$ & $\mathrm{H}_{2}$ & $\mathrm{H}_{2} \mathrm{O}$ & $\mathrm{CO}_{2}$ & $\mathrm{~N}_{2}$ & & $\begin{array}{c}\text { Cylinder } \\
\text { Feed }\end{array}$ & $\begin{array}{c}\text { Blank } \\
\text { Product } \\
\text { Mixture } \\
\end{array}$ & $\begin{array}{l}\text { Reaction } \\
\text { Product } \\
\text { Mixture }\end{array}$ \\
\hline 462 & 125 & 122.7 & 120 & 147 & 0.36 & 0.18 & 31.93 & 20.38 & 10.00 & 9.07 & 28.09 & 0.7943 & 5 & 90 & 121 \\
\hline 463 & 125 & 121.7 & 120 & 146 & 0.36 & 0.18 & 31.93 & 20.38 & 10.00 & 9.07 & 28.09 & 0.8040 & 6 & 69 & 97 \\
\hline 464 & 125 & 119.7 & 120 & 144 & 0.36 & 0.18 & 31.93 & 20.38 & 10.00 & 9.07 & 28.09 & 0.7853 & 5 & 84 & 107 \\
\hline 466 & 125 & 121.7 & 120 & 146 & 0.36 & 0.18 & 31.93 & 20.38 & 10.00 & 9.07 & 28.09 & 0.7700 & 5 & 91 & 151 \\
\hline 467 & 125 & 119.7 & 120 & 144 & 0.36 & 0.18 & 31.93 & 20.38 & 10.00 & 9.07 & 28.09 & 0.7879 & 12 & 75 & 118 \\
\hline 468 & 125 & 118.7 & 120 & 142 & 0.36 & 0.18 & 31.93 & 20.38 & 10.00 & 9.07 & 28.09 & 0.8565 & 5 & 68 & 107 \\
\hline 469 & 125 & 119.7 & 120 & 144 & 0.36 & 0.18 & 31.93 & 20.38 & 10.00 & 9.07 & 28.09 & 0.9181 & 5 & 112 & 129 \\
\hline 470 & 125 & 118.7 & 120 & 142 & 0.36 & 0.18 & 31.93 & 20.38 & 10.00 & 9.07 & 28.09 & 0.8565 & 5 & 80 & 207 \\
\hline 474 & 125 & 119.7 & 120 & 144 & 0.36 & 0.18 & 31.93 & 20.38 & 10.00 & 9.07 & 28.09 & 0.8941 & 4 & 53 & 164 \\
\hline 475 & 125 & 120.7 & 120 & 145 & 0.36 & 0.18 & 31.93 & 20.38 & 10.00 & 9.07 & 28.09 & 0.9626 & 6 & 73 & 159 \\
\hline
\end{tabular}

*SCCM: standard cubic centimeters per minute, volumetric flow rates of gases measured at $1 \mathrm{~atm}$ and $25^{\circ} \mathrm{C}$ 
Table 4. Effects of temperature on conversion of $\mathrm{H}_{2} \mathrm{~S}$ to elemental sulfur and formation of COS with a 120-SCCM feed stream containing 3,600-ppmv $\mathrm{H}_{2} \mathrm{~S}, 1,800-\mathrm{ppmv} \mathrm{SO}_{2}, 32-\mathrm{v} \% \mathrm{CO}, 20-\mathrm{v} \% \mathrm{H}_{2}, 9-\mathrm{v} \% \mathrm{CO}_{2}$ and $10-\mathrm{v} \%$ moisture at $120-140^{\circ} \mathrm{C}, 117-124$ psia and 135 - 149 s space time, removing elemental sulfur from a $\gamma$-alumina wash-coated monolithic catalyst support with $\mathrm{N}_{2}$ overnight.

\begin{tabular}{|c|c|c|c|c|c|c|c|c|c|c|c|c|c|c|c|c|c|c|}
\hline \multirow[t]{2}{*}{ Run\# } & \multirow{2}{*}{$\begin{array}{c}\text { Temp. } \\
{ }^{\circ} \mathrm{C} \\
\end{array}$} & \multirow{2}{*}{$\begin{array}{l}\text { Press. } \\
\text { psia }\end{array}$} & \multirow{2}{*}{$\begin{array}{l}\text { Total } \\
\text { Flow } \\
\text { Rate, } \\
\text { SCCM } \\
\end{array}$} & \multirow{2}{*}{$\begin{array}{c}\text { Space } \\
\text { Time, } \\
\text { s }\end{array}$} & \multicolumn{7}{|c|}{ Feed Composition, v\% } & \multirow{2}{*}{$\begin{array}{c}\begin{array}{c}\text { Cataly } \\
\text { st } \\
\text { Aging } \\
\text {, min }\end{array} \\
\end{array}$} & \multirow{2}{*}{$\begin{array}{c}\begin{array}{c}\text { conversio } \\
\mathrm{n}\end{array} \\
\mathrm{H}_{2} \mathrm{~S} \\
\end{array}$} & \multicolumn{4}{|c|}{$\mathrm{COS}, \mathrm{ppm}$} & \multirow[b]{2}{*}{ Remarks } \\
\hline & & & & & $\mathrm{H}_{2} \mathrm{~S}$ & $\mathrm{SO}_{2}$ & $\mathrm{CO}$ & $\mathrm{H}_{2}$ & $\mathrm{H}_{2} \mathrm{O}$ & $\mathrm{CO}_{2}$ & $\mathrm{~N}_{2}$ & & & $\begin{array}{c}\text { Forma } \\
\text { tion }\end{array}$ & $\begin{array}{c}\text { Cylinder } \\
\text { Feed }\end{array}$ & $\begin{array}{l}\text { Blank } \\
\text { Product } \\
\text { Mixture } \\
\end{array}$ & $\begin{array}{l}\text { Reaction } \\
\text { Product } \\
\text { Mixture } \\
\end{array}$ & \\
\hline 285 & 130 & 120.7 & 120 & 143 & 0.36 & 0.18 & 32.02 & 20.26 & 10.00 & 9.07 & 28.11 & 197 & 0.8095 & -29 & 13 & 76 & 47 & $\begin{array}{l}\text { removing elemental sulfur from the catalyst with } \\
\mathrm{N}_{2} \text { at } 140^{\circ} \mathrm{C} \text { overnight }\end{array}$ \\
\hline 286 & 130 & 120.7 & 120 & 143 & 0.36 & 0.18 & 32.02 & 20.26 & 10.00 & 9.07 & 28.11 & 323 & 0.8066 & 38 & 8 & 69 & 108 & \\
\hline 287 & 130 & 117.7 & 120 & 140 & 0.36 & 0.18 & 32.02 & 20.26 & 10.00 & 9.07 & 28.11 & 484 & 0.8103 & 17 & 11 & 89 & 105 & \\
\hline 288 & 130 & 120.7 & 120 & 143 & 0.36 & 0.18 & 32.02 & 20.26 & 10.00 & 9.07 & 28.11 & 682 & 0.8599 & 11 & 9 & 94 & 105 & \\
\hline 289 & 130 & 122.7 & 120 & 145 & 0.36 & 0.18 & 32.02 & 20.26 & 10.00 & 9.07 & 28.11 & 810 & 0.7929 & 4 & 9 & 112 & 116 & \\
\hline 290 & 130 & 121.7 & 120 & 144 & 0.36 & 0.18 & 32.02 & 20.26 & 10.00 & 9.07 & 28.11 & 986 & 0.8034 & -3 & 10 & 110 & 108 & \\
\hline 291 & 130 & 120.7 & 120 & 143 & 0.36 & 0.18 & 32.02 & 20.26 & 10.00 & 9.07 & 28.11 & 1118 & 0.8168 & 26 & 10 & 104 & 130 & \\
\hline 292 & 125 & 119.7 & 120 & 144 & 0.36 & 0.18 & 32.02 & 20.26 & 10.00 & 9.07 & 28.11 & 1299 & 0.7797 & -4 & 11 & 98 & 94 & \\
\hline 293 & 125 & 120.7 & 120 & 145 & 0.36 & 0.18 & 32.02 & 20.26 & 10.00 & 9.07 & 28.11 & 1547 & 0.7635 & -2 & 10 & 106 & 104 & \\
\hline 294 & 125 & 121.7 & 120 & 146 & 0.36 & 0.18 & 32.02 & 20.26 & 10.00 & 9.07 & 28.11 & 1687 & 0.7152 & 4 & 10 & 108 & 112 & \\
\hline 295 & 125 & 118.7 & 120 & 142 & 0.36 & 0.18 & 32.02 & 20.26 & 10.00 & 9.07 & 28.11 & 1838 & 0.7455 & -1 & 10 & 108 & 107 & \\
\hline 296 & 125 & 120.7 & 120 & 145 & 0.36 & 0.18 & 32.02 & 20.26 & 10.00 & 9.07 & 28.11 & 1976 & 0.7171 & 4 & 10 & 107 & 111 & \\
\hline 297 & 125 & 120.7 & 120 & 145 & 0.36 & 0.18 & 32.02 & 20.26 & 10.00 & 9.07 & 28.11 & 2166 & 0.7171 & -3 & 11 & 120 & 117 & \\
\hline 298 & 120 & 120.7 & 120 & 147 & 0.36 & 0.18 & 32.02 & 20.26 & 10.00 & 9.07 & 28.11 & 2387 & 0.6390 & 10 & 10 & 115 & 125 & \\
\hline 299 & 120 & 118.7 & 120 & 144 & 0.36 & 0.18 & 32.02 & 20.26 & 10.00 & 9.07 & 28.11 & 2587 & 0.5667 & 5 & 11 & 101 & 107 & \\
\hline 300 & 120 & 120.7 & 120 & 147 & 0.36 & 0.18 & 32.02 & 20.26 & 10.00 & 9.07 & 28.11 & 2718 & 0.4911 & 37 & 11 & 26 & 63 & \\
\hline 301 & 120 & 119.7 & 120 & 146 & 0.36 & 0.18 & 32.02 & 20.26 & 10.00 & 9.07 & 28.11 & 2980 & 0.4098 & 39 & 11 & 29 & 68 & \\
\hline 302 & 120 & 118.7 & 120 & 144 & 0.36 & 0.18 & 32.02 & 20.26 & 10.00 & 9.07 & 28.11 & 3142 & 0.5135 & 47 & 11 & 43 & 89 & \\
\hline 303 & 120 & 120.7 & 120 & 147 & 0.36 & 0.18 & 32.02 & 20.26 & 10.00 & 9.07 & 28.11 & 3299 & 0.3223 & 7 & 12 & 86 & 93 & \\
\hline 304 & 120 & 120.7 & 120 & 147 & 0.36 & 0.18 & 32.02 & 20.26 & 10.00 & 9.07 & 28.11 & 3549 & 0.1760 & 12 & 12 & 93 & 106 & removing elemental sulfur from the catalyst with \\
\hline 305 & 120 & 122.7 & 120 & 149 & 0.36 & 0.18 & 32.02 & 20.26 & 10.00 & 9.07 & 28.11 & 3673 & 0.2094 & 28 & 11 & 86 & 114 & $\mathrm{~N}_{2}$ at $270^{\circ} \mathrm{C}$ overnight \\
\hline 306 & 125 & 122.7 & 120 & 147 & 0.36 & 0.18 & 32.02 & 20.26 & 10.00 & 9.07 & 28.11 & 3823 & 0.1639 & -12 & 12 & 133 & 121 & \\
\hline 307 & 130 & 121.7 & 120 & 144 & 0.36 & 0.18 & 32.02 & 20.26 & 10.00 & 9.07 & 28.11 & 3948 & 0.1398 & 5 & 12 & 124 & 129 & \\
\hline 308 & 140 & 120.7 & 120 & 140 & 0.36 & 0.18 & 32.02 & 20.26 & 10.00 & 9.07 & 28.11 & 4073 & 0.1607 & 11 & 13 & 119 & 130 & \\
\hline 309 & 140 & 118.7 & 120 & 137 & 0.36 & 0.18 & 32.02 & 20.26 & 10.00 & 9.07 & 28.11 & 165 & 0.8925 & -6 & 12 & 125 & 119 & \\
\hline 310 & 140 & 119.7 & 120 & 138 & 0.36 & 0.18 & 32.02 & 20.26 & 10.00 & 9.07 & 28.11 & 371 & 0.8552 & -12 & 12 & 122 & 109 & \\
\hline 311 & 140 & 118.7 & 120 & 137 & 0.36 & 0.18 & 32.02 & 20.26 & 10.00 & 9.07 & 28.11 & 526 & 0.8332 & -6 & 12 & 118 & 112 & \\
\hline 312 & 140 & 120.7 & 120 & 140 & 0.36 & 0.18 & 32.02 & 20.26 & 10.00 & 9.07 & 28.11 & 648 & 0.8075 & -4 & 13 & 115 & 111 & \\
\hline
\end{tabular}


Table 4. Continued - 1

\begin{tabular}{|c|c|c|c|c|c|c|c|c|c|c|c|c|c|c|c|c|c|c|}
\hline \multirow[t]{2}{*}{ Run\# } & \multirow{2}{*}{$\begin{array}{c}\text { Temp. } \\
{ }^{\circ} \mathrm{C}\end{array}$} & \multirow{2}{*}{$\begin{array}{l}\text { Press. } \\
\text { psia }\end{array}$} & \multirow{2}{*}{$\begin{array}{l}\text { Total } \\
\text { Flow } \\
\text { Rate, } \\
\text { SCCM } \\
\end{array}$} & \multirow{2}{*}{$\begin{array}{l}\text { Space } \\
\text { Time, } \\
\text { s }\end{array}$} & \multicolumn{7}{|c|}{ Feed Composition, v\% } & \multirow{2}{*}{$\begin{array}{c}\text { Cataly } \\
\text { st } \\
\text { Aging } \\
\text {, min } \\
\end{array}$} & \multirow{2}{*}{$\begin{array}{c}\text { conversio } \\
\mathrm{n} \\
\\
\mathrm{H}_{2} \mathrm{~S} \\
\end{array}$} & \multicolumn{4}{|c|}{$\mathrm{COS}, \mathrm{ppm}$} & \multirow[b]{2}{*}{ Remarks } \\
\hline & & & & & $\mathrm{H}_{2} \mathrm{~S}$ & $\mathrm{SO}_{2}$ & $\mathrm{CO}$ & $\mathrm{H}_{2}$ & $\mathrm{H}_{2} \mathrm{O}$ & $\mathrm{CO}_{2}$ & $\mathrm{~N}_{2}$ & & & $\begin{array}{c}\text { Forma } \\
\text { tion }\end{array}$ & $\begin{array}{c}\text { Cylinder } \\
\text { Feed }\end{array}$ & $\begin{array}{c}\text { Blank } \\
\text { Product } \\
\text { Mixture }\end{array}$ & $\begin{array}{l}\text { Reaction } \\
\text { Product } \\
\text { Mixture } \\
\end{array}$ & \\
\hline 313 & 140 & 117.7 & 120 & 136 & 0.36 & 0.18 & 32.02 & 20.26 & 10.00 & 9.07 & 28.11 & 773 & 0.4480 & -7 & 12 & 115 & 108 & \\
\hline 314 & 120 & 117.7 & 120 & 143 & 0.36 & 0.18 & 32.02 & 20.26 & 10.00 & 9.07 & 28.11 & 932 & 0.7617 & 14 & 12 & 74 & 88 & \\
\hline 315 & 120 & 120.7 & 120 & 147 & 0.36 & 0.18 & 32.02 & 20.26 & 10.00 & 9.07 & 28.11 & 1125 & 0.6981 & 37 & 13 & 61 & 99 & \\
\hline 316 & 120 & 119.7 & 120 & 146 & 0.36 & 0.18 & 32.02 & 20.26 & 10.00 & 9.07 & 28.11 & 1253 & 0.5888 & 25 & 13 & 77 & 101 & \\
\hline 317 & 120 & 118.7 & 120 & 144 & 0.36 & 0.18 & 32.02 & 20.26 & 10.00 & 9.07 & 28.11 & 1444 & 0.5506 & 9 & 13 & 96 & 5 & \\
\hline 318 & 120 & 119.7 & 120 & 146 & 0.36 & 0.18 & 32.02 & 20.26 & 10.00 & 9.07 & 28.11 & 1543 & 0.4650 & 38 & 13 & 75 & 113 & \\
\hline 319 & 120 & 117.7 & 120 & 143 & 0.36 & 0.18 & 32.02 & 20.26 & 10.00 & 9.07 & 28.11 & 1672 & 0.6981 & 40 & 13 & 65 & 104 & \\
\hline 320 & 140 & 116.7 & 120 & 135 & 0.36 & 0.18 & 32.02 & 20.26 & 10.00 & 9.07 & 28.11 & 1895 & 0.4799 & -11 & 14 & 128 & 118 & \\
\hline 321 & 140 & 118.7 & 120 & 137 & 0.36 & 0.18 & 32.02 & 20.26 & 10.00 & 9.07 & 28.11 & 2085 & 0.4297 & -8 & 14 & 138 & 130 & \\
\hline 322 & 140 & 118.7 & 120 & 137 & 0.36 & 0.18 & 32.02 & 20.26 & 10.00 & 9.07 & 28.11 & 2250 & 0.3554 & -16 & 13 & 120 & 103 & \\
\hline 323 & 140 & 118.7 & 120 & 137 & 0.36 & 0.18 & 32.02 & 20.26 & 10.00 & 9.07 & 28.11 & 2348 & 0.3777 & -16 & 13 & 121 & 106 & \\
\hline 324 & 140 & 119.7 & 120 & 138 & 0.36 & 0.18 & 32.02 & 20.26 & 10.00 & 9.07 & 28.11 & 2476 & 0.2955 & 0 & 13 & 110 & 110 & \\
\hline 325 & 140 & 119.7 & 120 & 138 & 0.36 & 0.18 & 32.02 & 20.26 & 10.00 & 9.07 & 28.11 & 2603 & 0.3816 & -19 & 15 & 109 & 90 & \\
\hline 326 & 140 & 121.7 & 120 & 141 & 0.36 & 0.18 & 32.02 & 20.26 & 10.00 & 9.07 & 28.11 & 2824 & 0.3009 & -5 & 14 & 96 & 91 & \\
\hline 327 & 140 & 120.7 & 120 & 140 & 0.36 & 0.18 & 32.02 & 20.26 & 10.00 & 9.07 & 28.11 & 2923 & 0.3179 & 2 & 14 & 101 & 103 & \\
\hline 328 & 140 & 123.7 & 120 & 143 & 0.36 & 0.18 & 32.02 & 20.26 & 10.00 & 9.07 & 28.11 & 3055 & 0.2225 & -3 & 15 & 97 & 94 & \\
\hline 329 & 140 & 118.7 & 120 & 137 & 0.36 & 0.18 & 32.02 & 20.26 & 10.00 & 9.07 & 28.11 & 3168 & 0.2230 & 1 & 15 & 118 & 119 & New GC Column \\
\hline 330 & 140 & 117.7 & 120 & 136 & 0.36 & 0.18 & 32.02 & 20.26 & 10.00 & 9.07 & 28.11 & 3359 & 0.3355 & -11 & 15 & 114 & 103 & \\
\hline 331 & 140 & 119.7 & 120 & 138 & 0.36 & 0.18 & 32.02 & 20.26 . & 10.00 & 9.07 & 28.11 & 3607 & 0.2711 & -11 & 15 & 99 & 88 & \\
\hline
\end{tabular}

Table 5. Effects of catalyst aging on conversion of $\mathrm{H}_{2} \mathrm{~S}$ and formation of $\mathrm{COS}$ with a $\gamma$-alumina wash-coated monolithic catalyst support soaked in $1-\mathrm{w} \% \mathrm{Zn}$ aqueous solution and heated for 4 hours at $450^{\circ} \mathrm{C}$, removing elemental sulfur from the catalyst with $\mathrm{N}_{2}$ overnight at $140^{\circ} \mathrm{C}$.

\begin{tabular}{|c|c|c|c|c|c|c|c|c|c|c|c|c|c|c|c|c|c|c|}
\hline \multirow[t]{2}{*}{ Run \# } & \multirow{2}{*}{$\begin{array}{l}\text { Temp. } \\
{ }^{\circ} \mathrm{C} \\
\end{array}$} & \multirow{2}{*}{$\begin{array}{l}\text { Press. } \\
\text { psia }\end{array}$} & \multirow{2}{*}{$\begin{array}{l}\text { Total } \\
\text { Flow } \\
\text { Rate, } \\
\text { SCCM } \\
\end{array}$} & \multirow{2}{*}{$\begin{array}{c}\text { Space } \\
\text { Time, } \\
\text { s }\end{array}$} & \multicolumn{7}{|c|}{ Feed Composition, v\% } & \multirow{2}{*}{$\begin{array}{c}\begin{array}{c}\text { Cataly } \\
\text { st } \\
\text { Aging } \\
\text { min }\end{array} \\
\end{array}$} & \multirow{2}{*}{$\begin{array}{c}\begin{array}{c}\text { conversio } \\
\mathrm{n}\end{array} \\
\mathrm{H}_{2} \mathrm{~S} \\
\end{array}$} & \multicolumn{4}{|c|}{$\mathrm{COS}, \mathrm{ppm}$} & \multirow[b]{2}{*}{ Remarks } \\
\hline & & & & & $\mathrm{H}_{2} \mathrm{~S}$ & $\mathrm{SO}_{2}$ & $\mathrm{CO}$ & $\mathrm{H}_{2}$ & $\mathrm{H}_{2} \mathrm{O}$ & $\mathrm{CO}_{2}$ & $\mathrm{~N}_{2}$ & & & $\begin{array}{c}\text { Forma } \\
\text { tion }\end{array}$ & $\begin{array}{c}\text { Cylinder } \\
\text { Feed } \\
\end{array}$ & $\begin{array}{c}\text { Blank } \\
\text { Product } \\
\text { Mixture } \\
\end{array}$ & $\begin{array}{l}\text { Reaction } \\
\text { Product } \\
\text { Mixture } \\
\end{array}$ & \\
\hline 362 & 125 & 121.7 & 120 & 146 & 0.36 & 0.18 & 32.02 & 20.26 & 10.00 & 9.07 & 28.11 & 157 & 0.8760 & -23 & 19 & 53 & 25 & $\begin{array}{l}\text { soaked in } 1-w \% \mathrm{Zn} \text { aqueous solution and heated } \\
\text { for } 4 \text { hours at } 450^{\circ} \mathrm{C} \text {, removing elemental sulfur } \\
\text { from the catalyst with } \mathrm{N}_{2} \text { at } 140^{\circ} \mathrm{C} \text { overnight }\end{array}$ \\
\hline 363 & 125 & 117.7 & 120 & 141 & 0.36 & 0.18 & 32.02 & 20.26 & 10.00 & 9.07 & 28.11 & 317 & 0.9529 & 50 & 19 & 67 & 117 & \\
\hline 364 & 125 & 120.7 & 120 & 145 & 0.36 & 0.18 & 32.02 & 20.26 & 10.00 & 9.07 & 28.11 & 494 & 0.9231 & 71 & 20 & 58 & 128 & \\
\hline
\end{tabular}


Table 5. Continued -1

\begin{tabular}{|c|c|c|c|c|c|c|c|c|c|c|c|c|c|c|c|c|c|c|}
\hline \multirow[t]{2}{*}{ Run\# } & \multirow{2}{*}{$\begin{array}{l}\text { Temp. } \\
{ }^{\circ} \mathrm{C} \\
\end{array}$} & \multirow{2}{*}{$\begin{array}{l}\text { Press. } \\
\text { psia }\end{array}$} & \multirow{2}{*}{$\begin{array}{c}\text { Total } \\
\text { Flow } \\
\text { Rate, } \\
\text { SCCM } \\
\end{array}$} & \multirow{2}{*}{$\begin{array}{c}\text { Space } \\
\text { Time, } \\
\text { s }\end{array}$} & \multicolumn{7}{|c|}{ Feed Composition, v\% } & \multirow{2}{*}{ 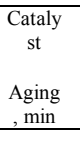 } & \multirow{2}{*}{$\begin{array}{c}\begin{array}{c}\text { conversio } \\
\mathrm{n}\end{array} \\
\mathrm{H}_{2} \mathrm{~S} \\
\end{array}$} & \multicolumn{4}{|c|}{$\mathrm{COS}, \mathrm{ppm}$} & \multirow[b]{2}{*}{ Remarks } \\
\hline & & & & & $\mathrm{H}_{2} \mathrm{~S}$ & $\mathrm{SO}_{2}$ & $\mathrm{CO}$ & $\mathrm{H}_{2}$ & $\mathrm{H}_{2} \mathrm{O}$ & $\mathrm{CO}_{2}$ & $\mathrm{~N}_{2}$ & & & $\begin{array}{c}\text { Forma } \\
\text { tion }\end{array}$ & $\begin{array}{c}\text { Cylinder } \\
\text { Feed } \\
\end{array}$ & $\begin{array}{c}\text { Blank } \\
\text { Product } \\
\text { Mixture } \\
\end{array}$ & $\begin{array}{c}\text { Reaction } \\
\text { Product } \\
\text { Mixture } \\
\end{array}$ & \\
\hline 365 & 125 & 121.7 & 120 & 146 & 0.36 & 0.18 & 32.02 & 20.26 & 10.00 & 9.07 & 28.11 & 623 & 0.9331 & 79 & 20 & 49 & 128 & \\
\hline 366 & 125 & 121.7 & 120 & 146 & 0.36 & 0.18 & 32.02 & 20.26 & 10.00 & 9.07 & 28.11 & 782 & 0.9326 & 58 & 19 & 56 & 114 & \\
\hline 367 & 125 & 115.7 & 120 & 139 & 0.36 & 0.18 & 32.02 & 20.26 & 10.00 & 9.07 & 28.11 & 967 & 0.9285 & 67 & 20 & 56 & 122 & \\
\hline 368 & 125 & 118.7 & 120 & 142 & 0.36 & 0.18 & 32.02 & 20.26 & 10.00 & 9.07 & 28.11 & 1206 & 0.8644 & 61 & 20 & 71 & 133 & \\
\hline 369 & 125 & 118.7 & 120 & 142 & 0.36 & 0.18 & 32.02 & 20.26 & 10.00 & 9.07 & 28.11 & 1337 & 0.8942 & 73 & 20 & 62 & 135 & \\
\hline 370 & 125 & 118.7 & 120 & 142 & 0.36 & 0.18 & 32.02 & 20.26 & 10.00 & 9.07 & 28.11 & 1495 & 0.7891 & 43 & 21 & 92 & 135 & \\
\hline 371 & 125 & 119.7 & 120 & 144 & 0.36 & 0.18 & 32.02 & 20.26 & 10.00 & 9.07 & 28.11 & 1654 & 0.7402 & 104 & 21 & 89 & 193 & \\
\hline 372 & 125 & 117.7 & 120 & 141 & 0.36 & 0.18 & 32.02 & 20.26 & 10.00 & 9.07 & 28.11 & 1812 & 0.7520 & 95 & 21 & 109 & 204 & \\
\hline 373 & 125 & 118.7 & 132 & 130 & 0.33 & 0.16 & 29.11 & 18.42 & 18.18 & 8.25 & 25.55 & 1915 & 0.6703 & 167 & 20 & 169 & 336 & \\
\hline 374 & 125 & 121.7 & 132 & 133 & 0.33 & 0.16 & 29.11 & 18.42 & 18.18 & 8.25 & 25.55 & 2042 & 0.6499 & 150 & 25 & 152 & 302 & \\
\hline 375 & 125 & 118.7 & 132 & 130 & 0.33 & 0.16 & 29.11 & 18.42 & 18.18 & 8.25 & 25.55 & 2149 & 0.582 & 166 & 24 & 154 & 320 & \\
\hline 376 & 125 & 118.7 & 114 & 150 & 0.38 & 0.19 & 33.71 & 21.32 & 5.26 & 9.55 & 29.59 & 2280 & 0.7115 & 85 & 24 & 152 & 237 & \\
\hline 377 & 125 & 121.7 & 114 & 154 & 0.38 & 0.19 & 33.61 & 21.45 & 5.26 & 9.54 & 29.57 & 2409 & 0.6578 & 118 & 10 & 64 & 183 & \\
\hline 378 & 125 & 121.7 & 114 & 154 & 0.38 & 0.19 & 33.61 & 21.45 & 5.26 & 9.54 & 29.57 & 2511 & 0.6821 & 154 & 7 & 61 & 216 & \\
\hline 379 & 125 & 118.7 & 114 & 150 & 0.38 & 0.19 & 33.61 & 21.45 & 5.26 & 9.54 & 29.57 & 2639 & 0.6316 & 255 & 7 & 75 & 330 & \\
\hline
\end{tabular}

*SCCM: standard cubic centimeters per minute, volumetric flow rates of gases measured at 1 atm and $25^{\circ} \mathrm{C}$

Table 6. Effects of removal temperature of elemental sulfur attached to a catalyst on conversion of $\mathrm{H}_{2} \mathrm{~S}$ and formation of $\mathrm{COS}$ with the $\gamma$-alumina wash-coated monolithic catalyst support soaked in 1-w\% Zn aqueous solution followed by heating it for 4 hours at $450^{\circ} \mathrm{C}$, removing elemental sulfur from the catalyst with $\mathrm{N}_{2}$ overnight.

\begin{tabular}{|c|c|c|c|c|c|c|c|c|c|c|c|c|c|c|c|c|c|c|}
\hline \multirow[t]{2}{*}{ Run \# } & \multirow{2}{*}{$\begin{array}{l}\text { Temp. } \\
{ }^{\circ} \mathrm{C}\end{array}$} & \multirow{2}{*}{$\begin{array}{l}\text { Press. } \\
\text { psia }\end{array}$} & \multirow{2}{*}{$\begin{array}{l}\text { Total } \\
\text { Flow } \\
\text { Rate, } \\
\text { SCCM } \\
\end{array}$} & \multirow{2}{*}{$\begin{array}{l}\text { Space } \\
\text { Time, } \\
\text { s }\end{array}$} & \multicolumn{7}{|c|}{ Feed Composition, $\mathrm{v} \%$} & \multirow{2}{*}{$\begin{array}{c}\text { Cataly } \\
\text { st } \\
\text { Aging } \\
\text { min } \\
\end{array}$} & \multirow{2}{*}{$\begin{array}{c}\begin{array}{c}\text { conversio } \\
\mathrm{n}\end{array} \\
\mathrm{H}_{2} \mathrm{~S} \\
\end{array}$} & \multicolumn{4}{|c|}{$\mathrm{COS}, \mathrm{ppm}$} & \multirow[b]{2}{*}{ Remarks } \\
\hline & & & & & $\mathrm{H}_{2} \mathrm{~S}$ & $\mathrm{SO}_{2}$ & $\mathrm{CO}$ & $\mathrm{H}_{2}$ & $\mathrm{H}_{2} \mathrm{O}$ & $\mathrm{CO}_{2}$ & $\mathrm{~N}_{2}$ & & & $\begin{array}{c}\text { Forma } \\
\text { tion }\end{array}$ & $\begin{array}{l}\text { Cylinde } \\
\text { r Feed }\end{array}$ & $\begin{array}{l}\text { Blank } \\
\text { Product } \\
\text { Mixture } \\
\end{array}$ & $\begin{array}{l}\text { Reaction } \\
\text { Product } \\
\text { Mixture } \\
\end{array}$ & \\
\hline 377 & 125 & 121.7 & 114 & 154 & 0.38 & 0.19 & 33.61 & 21.45 & 5.26 & 9.54 & 29.57 & 2409 & 0.6578 & 118 & 10 & 64 & 183 & $\begin{array}{l}\text { sulfur removed from the catalyst with } \mathrm{N}_{2} \text { at } \\
140^{\circ} \mathrm{C} \text { overnight }\end{array}$ \\
\hline 378 & 125 & 121.7 & 114 & 154 & 0.38 & 0.19 & 33.61 & 21.45 & 5.26 & 9.54 & 29.57 & 2511 & 0.6821 & 154 & 7 & 61 & 216 & \\
\hline 379 & 125 & 118.7 & 114 & 150 & 0.38 & 0.19 & 33.61 & 21.45 & 5.26 & 9.54 & 29.57 & 2639 & 0.6316 & 255 & 7 & 75 & 330 & he catalyst with $\mathrm{N}_{2}$ at \\
\hline 380 & 125 & 119.7 & 114 & 151 & 0.38 & 0.19 & 33.61 & 21.45 & 5.26 & 9.54 & 29.57 & 2767 & 0.6298 & 118 & 6 & 74 & 193 & $200^{\circ} \mathrm{C}$ overnight \\
\hline 381 & 125 & 119.7 & 114 & 151 & 0.38 & 0.19 & 33.61 & 21.45 & 5.26 & 9.54 & 29.57 & 2869 & 0.3957 & 98 & 6 & 89 & 187 & \\
\hline
\end{tabular}


Table 7. Effects of elemental sulfur removed from a monolithic catalyst on conversion of $\mathrm{H}_{2} \mathrm{~S}$ and formation of COS with the $\gamma$ alumina wash-coated catalyst support soaked in $1-\mathrm{w} \% \mathrm{Zn}$ aqueous solution followed by heating it for 4 hours at $450^{\circ} \mathrm{C}$, removing elemental sulfur from the catalyst with $\mathrm{N}_{2}$ at $200^{\circ} \mathrm{C}$ overnight.

\begin{tabular}{|c|c|c|c|c|c|c|c|c|c|c|c|c|c|c|c|c|c|c|}
\hline \multirow[t]{2}{*}{ Run \# } & \multirow[t]{2}{*}{ Temp. } & \multirow[t]{2}{*}{ Press. } & \multirow{2}{*}{$\begin{array}{l}\text { Total } \\
\text { Flow } \\
\text { Rate, }\end{array}$} & \multirow{2}{*}{$\begin{array}{l}\text { Space } \\
\text { Time, } \\
\mathrm{s}\end{array}$} & \multicolumn{7}{|c|}{ Feed Composition, $\mathrm{v} \%$} & \multirow{2}{*}{$\begin{array}{c}\begin{array}{c}\text { Cataly } \\
\text { st }\end{array} \\
\text { Aging } \\
\text {, min } \\
\end{array}$} & \multirow{2}{*}{$\begin{array}{c}\text { conversio } \\
n \\
\mathrm{H}_{2} \mathrm{~S} \\
\end{array}$} & \multicolumn{4}{|c|}{$\mathrm{COS}, \mathrm{ppm}$} & \multirow[b]{2}{*}{ Remarks } \\
\hline & & & & & $\mathrm{H}_{2} \mathrm{~S}$ & $\mathrm{SO}_{2}$ & $\mathrm{CO}$ & $\mathrm{H}_{2}$ & $\mathrm{H}_{2} \mathrm{O}$ & $\mathrm{CO}_{2}$ & $\mathrm{~N}_{2}$ & & & $\begin{array}{c}\text { Forma } \\
\text { tion }\end{array}$ & $\begin{array}{l}\text { Cylinde } \\
\text { r Feed }\end{array}$ & $\begin{array}{l}\text { Blank } \\
\text { Product } \\
\text { Mixture }\end{array}$ & $\begin{array}{c}\text { Reactio } \\
\text { n } \\
\text { Product } \\
\text { Mixture }\end{array}$ & \\
\hline
\end{tabular}

\begin{tabular}{|c|c|c|c|c|c|c|c|c|c|c|c|c|c|c|c|c|c|c|}
\hline 380 & 125 & 119.7 & 114 & 151 & 0.38 & 0.19 & 33.61 & 21.45 & 5.26 & 9.54 & 29.57 & 2767 & 0.6298 & 118 & 6 & 74 & 193 & $\begin{array}{l}\text { removing elemental sulfur from the catalyst with } \mathrm{N}_{2} \\
\text { at } 200^{\circ} \mathrm{C} \text { overnight. }\end{array}$ \\
\hline 381 & 125 & 119.7 & 114 & 151 & 0.38 & 0.19 & 33.61 & 21.45 & 5.26 & 9.54 & 29.57 & 2869 & 0.3957 & 98 & 6 & 89 & 187 & \\
\hline 382 & 125 & 120.7 & 114 & 152 & 0.38 & 0.19 & 33.61 & 21.45 & 5.26 & 9.54 & 29.57 & 3021 & 0.4566 & 54 & 6 & 94 & 147 & no sulfur removed \\
\hline 383 & 125 & 120.7 & 114 & 152 & 0.38 & 0.19 & 33.61 & 21.45 & 5.26 & 9.54 & 29.57 & 3178 & 0.3991 & 25 & 6 & 99 & 124 & \\
\hline 384 & 125 & 120.7 & 114 & 152 & 0.38 & 0.19 & 33.61 & 21.45 & 5.26 & 9.54 & 29.57 & 3415 & 0.5082 & 191 & 6 & 62 & 253 & \\
\hline 385 & 125 & 123.7 & 114 & 156 & 0.38 & 0.19 & 33.61 & 21.45 & 5.26 & 9.54 & 29.57 & 3521 & 0.3885 & 155 & 5 & 76 & 231 & \\
\hline 386 & 125 & 121.7 & 114 & 154 & 0.38 & 0.19 & 33.61 & 21.45 & 5.26 & 9.54 & 29.57 & 3649 & 0.2779 & 169 & 5 & 52 & 221 & \\
\hline
\end{tabular}

*SCCM: standard cubic centimeters per minute, volumetric flow rates of gases measured at 1 atm and $25^{\circ} \mathrm{C}$

Table 8. Effects of washing a $\gamma$-alumina wash-coated monolithic catalyst in $\mathrm{NaOH}$ aqueous solution on conversion of $\mathrm{H}_{2} \mathrm{~S}$ and formation of COS with the catalyst support soaked in 1-w\% Zn aqueous solution followed by heating it for $4 \mathrm{hrs}$ at $450^{\circ} \mathrm{C}$

\begin{tabular}{|c|c|c|c|c|c|c|c|c|c|c|c|c|c|c|c|c|c|c|}
\hline \multirow[t]{2}{*}{ Run \# } & \multirow{2}{*}{$\begin{array}{c}\text { Temp. } \\
{ }^{\circ} \mathrm{C} \\
\end{array}$} & \multirow{2}{*}{$\begin{array}{l}\text { Press. } \\
\text { psia }\end{array}$} & \multirow{2}{*}{$\begin{array}{l}\text { Total } \\
\text { Flow } \\
\\
\text { Rate, } \\
\text { SCCM } \\
\end{array}$} & \multirow{2}{*}{$\begin{array}{l}\text { Space } \\
\text { Time, } \\
\text { s }\end{array}$} & \multicolumn{7}{|c|}{ Feed Composition, v\% } & \multirow{2}{*}{$\begin{array}{c}\text { Catalyst } \\
\text { Aging, } \\
\text { min }\end{array}$} & \multirow{2}{*}{$\begin{array}{c}\text { conversi } \\
\text { on } \\
\mathrm{H}_{2} \mathrm{~S} \\
\end{array}$} & \multicolumn{4}{|c|}{$\mathrm{COS}, \mathrm{ppm}$} & \multirow[b]{2}{*}{ Remarks } \\
\hline & & & & & $\mathrm{H}_{2} \mathrm{~S}$ & $\mathrm{SO}_{2}$ & $\mathrm{CO}$ & $\mathrm{H}_{2}$ & $\mathrm{H}_{2} \mathrm{O}$ & $\mathrm{CO}_{2}$ & $\mathrm{~N}_{2}$ & & & $\begin{array}{l}\text { Format } \\
\text { ion }\end{array}$ & $\begin{array}{l}\text { Cylinde } \\
\text { r Feed }\end{array}$ & $\begin{array}{l}\text { Blank } \\
\text { Product } \\
\text { Mixture }\end{array}$ & $\begin{array}{l}\text { Reaction } \\
\text { Product } \\
\text { Mixture }\end{array}$ & \\
\hline 362 & 125 & 121.7 & 120 & 146 & 0.36 & 0.18 & 32.02 & 20.26 & 10.00 & 9.07 & 28.11 & 157 & 0.8760 & -23 & 19 & 53 & 25 & $\begin{array}{l}\text { sulfur removed from the catalyst with } \mathrm{N}_{2} \text { at } 140^{\circ} \mathrm{C} \\
\text { overnight }\end{array}$ \\
\hline 363 & 125 & 117.7 & 120 & 141 & 0.36 & 0.18 & 32.02 & 20.26 & 10.00 & 9.07 & 28.11 & 317 & 0.9529 & 50 & 19 & 67 & 117 & \\
\hline 364 & 125 & 120.7 & 120 & 145 & 0.36 & 0.18 & 32.02 & 20.26 & 10.00 & 9.07 & 28.11 & 494 & 0.9231 & 71 & 20 & 58 & 128 & \\
\hline 365 & 125 & 121.7 & 120 & 146 & 0.36 & 0.18 & 32.02 & 20.26 & 10.00 & 9.07 & 28.11 & 623 & 0.9331 & 79 & 20 & 49 & 128 & \\
\hline 366 & 125 & 121.7 & 120 & 146 & 0.36 & 0.18 & 32.02 & 20.26 & 10.00 & 9.07 & 28.11 & 782 & 0.9326 & 58 & 19 & 56 & 114 & \\
\hline 367 & 125 & 115.7 & 120 & 139 & 0.36 & 0.18 & 32.02 & 20.26 & 10.00 & 9.07 & 28.11 & 967 & 0.9285 & 67 & 20 & 56 & 122 & \\
\hline 368 & 125 & 118.7 & 120 & 142 & 0.36 & 0.18 & 32.02 & 20.26 & 10.00 & 9.07 & 28.11 & 1206 & 0.8644 & 61 & 20 & 71 & 133 & \\
\hline 369 & 125 & 118.7 & 120 & 142 & 0.36 & 0.18 & 32.02 & 20.26 & 10.00 & 9.07 & 28.11 & 1337 & 0.8942 & 73 & 20 & 62 & 135 & \\
\hline 370 & 125 & 118.7 & 120 & 142 & 0.36 & 0.18 & 32.02 & 20.26 & 10.00 & 9.07 & 28.11 & 1495 & 0.7891 & 43 & 21 & 92 & 135 & \\
\hline 371 & 125 & 119.7 & 120 & 144 & 0.36 & 0.18 & 32.02 & 20.26 & 10.00 & 9.07 & 28.11 & 1654 & 0.7402 & 104 & 21 & 89 & 193 & \\
\hline
\end{tabular}


Table 8. Continued - 1

\begin{tabular}{|c|c|c|c|c|c|c|c|c|c|c|c|c|c|c|c|c|c|c|}
\hline \multirow[t]{2}{*}{ Run \# } & \multirow{2}{*}{$\begin{array}{l}\text { Temp. } \\
{ }^{\circ} \mathrm{C} \\
\end{array}$} & \multirow{2}{*}{$\begin{array}{l}\text { Press. } \\
\text { psia }\end{array}$} & \multirow{2}{*}{$\begin{array}{c}\text { Total } \\
\text { Flow } \\
\\
\text { Rate, } \\
\text { SCCM } \\
\end{array}$} & \multirow{2}{*}{$\begin{array}{c}\text { Space } \\
\text { Time, } \\
\text { s }\end{array}$} & \multicolumn{7}{|c|}{ Feed Composition, vo } & \multirow{2}{*}{$\begin{array}{c}\text { Catalyst } \\
\text { Aging, } \\
\text { min }\end{array}$} & \multirow{2}{*}{$\begin{array}{c}\text { conversi } \\
\text { on } \\
\\
\mathrm{H}_{2} \mathrm{~S} \\
\end{array}$} & \multicolumn{4}{|c|}{$\mathrm{COS}, \mathrm{ppm}$} & \multirow[b]{2}{*}{ Remarks } \\
\hline & & & & & $\mathrm{H}_{2} \mathrm{~S}$ & $\mathrm{SO}_{2}$ & $\mathrm{CO}$ & $\mathrm{H}_{2}$ & $\mathrm{H}_{2} \mathrm{O}$ & $\mathrm{CO}_{2}$ & $\mathrm{~N}_{2}$ & & & $\begin{array}{c}\begin{array}{c}\text { Format } \\
\text { ion }\end{array} \\
\end{array}$ & $\begin{array}{c}\text { Cylinde } \\
\text { r Feed }\end{array}$ & $\begin{array}{c}\text { Blank } \\
\text { Product } \\
\text { Mixture } \\
\end{array}$ & $\begin{array}{l}\text { Reaction } \\
\text { Product } \\
\text { Mixture } \\
\end{array}$ & \\
\hline 372 & 125 & 117.7 & 120 & 141 & 0.36 & 0.18 & 32.02 & 20.26 & 10.00 & 9.07 & 28.11 & 1812 & 0.7520 & 95 & 21 & 109 & 204 & \\
\hline 373 & 125 & 118.7 & 132 & 130 & 0.33 & 0.16 & 29.11 & 18.42 & 18.18 & 8.25 & 25.55 & 1915 & 0.6703 & 167 & 20 & 169 & 336 & \\
\hline 374 & 125 & 121.7 & 132 & 133 & 0.33 & 0.16 & 29.11 & 18.42 & 18.18 & 8.25 & 25.55 & 2042 & 0.6499 & 150 & 25 & 152 & 302 & \\
\hline 375 & 125 & 118.7 & 132 & 130 & 0.33 & 0.16 & 29.11 & 18.42 & 18.18 & 8.25 & 25.55 & 2149 & 0.5820 & 166 & 24 & 154 & 320 & \\
\hline 376 & 125 & 118.7 & 114 & 150 & 0.38 & 0.19 & 33.71 & 21.32 & 5.26 & 9.55 & 29.59 & 2280 & 0.7115 & 85 & 24 & 152 & 237 & \\
\hline 377 & 125 & 121.7 & 114 & 154 & 0.38 & 0.19 & 33.61 & 21.45 & 5.26 & 9.54 & 29.57 & 2409 & 0.6578 & 118 & 10 & 64 & 183 & \\
\hline 378 & 125 & 121.7 & 114 & 154 & 0.38 & 0.19 & 33.61 & 21.45 & 5.26 & 9.54 & 29.57 & 2511 & 0.6821 & 154 & 7 & 61 & 216 & \\
\hline 379 & 125 & 118.7 & 114 & 150 & 0.38 & 0.19 & 33.61 & 21.45 & 5.26 & 9.54 & 29.57 & 2639 & 0.6316 & 255 & 7 & 75 & 330 & sulfur removed from the catalyst with $\mathrm{N}_{2}$ at $200^{\circ} \mathrm{C}$ \\
\hline 380 & 125 & 119.7 & 114 & 151 & 0.38 & 0.19 & 33.61 & 21.45 & 5.26 & 9.54 & 29.57 & 2767 & 0.6298 & 118 & 6 & 74 & 193 & overnight \\
\hline 381 & 125 & 119.7 & 114 & 151 & 0.38 & 0.19 & 33.61 & 21.45 & 5.26 & 9.54 & 29.57 & 2869 & 0.3957 & 98 & 6 & 89 & 187 & no sulfur removed from the catalyst with $\mathrm{N}_{2}$ \\
\hline 382 & 125 & 120.7 & 114 & 152 & 0.38 & 0.19 & 33.61 & 21.45 & 5.26 & 9.54 & 29.57 & 3021 & 0.4566 & 54 & 6 & 94 & 147 & overnight \\
\hline 383 & 125 & 120.7 & 114 & 152 & 0.38 & 0.19 & 33.61 & 21.45 & 5.26 & 9.54 & 29.57 & 3178 & 0.3991 & 25 & 6 & 99 & 124 & \\
\hline 384 & 125 & 120.7 & 114 & 152 & 0.38 & 0.19 & 33.61 & 21.45 & 5.26 & 9.54 & 29.57 & 3415 & 0.5082 & 191 & 6 & 62 & 253 & \\
\hline 385 & 125 & 123.7 & 114 & 156 & 0.38 & 0.19 & 33.61 & 21.45 & 5.26 & 9.54 & 29.57 & 3521 & 0.3885 & 155 & 5 & 76 & 231 & \\
\hline 386 & 125 & 121.7 & 114 & 154 & 0.38 & 0.19 & 33.61 & 21.45 & 5.26 & 9.54 & 29.57 & 3649 & 0.2779 & 169 & 5 & 52 & 221 & catalyst washed in $0.1 \mathrm{M} \mathrm{NaOH}$ aqueous solution \\
\hline 389 & 125 & 120.7 & 120 & 145 & 0.36 & 0.18 & 31.93 & 20.38 & 10.00 & 9.07 & 28.09 & 3827 & 0.8731 & 163 & 5 & 57 & 220 & overnight \\
\hline 391 & 125 & 118.7 & 120 & 142 & 0.36 & 0.18 & 31.93 & 20.38 & 10.00 & 9.07 & 28.09 & 3974 & 0.6987 & 196 & 4 & 52 & 248 & catalyst not washed in $\mathrm{NaOH}$ aqueous solution \\
\hline 392 & 125 & 122.7 & 120 & 147 & 0.36 & 0.18 & 31.93 & 20.38 & 10.00 & 9.07 & 28.09 & 4141 & 0.3410 & 133 & 5 & 51 & 184 & $\begin{array}{l}\text { overnight } \\
\text { catalyst washed in } 0.1 \mathrm{M} \mathrm{NaOH} \text { aqueous solution }\end{array}$ \\
\hline 398 & 125 & 117.7 & 120 & 141 & 0.36 & 0.18 & 31.93 & 20.38 & 10.00 & 9.07 & 28.09 & 4303 & 0.8108 & 128 & 5 & 79 & 207 & overnight, and heated for $4 \mathrm{hrs}$ at $450^{\circ} \mathrm{C}$ \\
\hline 399 & 125 & 119.7 & 120 & 144 & 0.36 & 0.18 & 31.93 & 20.38 & 10.00 & 9.07 & 28.09 & 4467 & 0.7348 & 165 & 5 & 59 & 224 & \\
\hline 400 & 125 & 120.7 & 120 & 145 & 0.36 & 0.18 & 31.93 & 20.38 & 10.00 & 9.07 & 28.09 & 4617 & 0.7744 & 91 & 5 & 72 & 163 & \\
\hline 403 & 125 & 119.7 & 120 & 144 & 0.36 & 0.18 & 31.93 & 20.38 & 10.00 & 9.07 & 28.09 & 4758 & 0.7339 & 93 & 5 & 45 & 138 & $0.3 \mathrm{M} \mathrm{NaOH}$ washed overnight, heated for $4 \mathrm{hrs}$ \\
\hline 408 & 125 & 118.7 & 120 & 142 & 0.36 & 0.18 & 31.93 & 20.38 & 10.00 & 9.07 & 28.09 & 4940 & 0.8602 & 38 & 7 & 69 & 106 & at $900^{\circ} \mathrm{C}$, no sulfur removed \\
\hline 409 & 125 & 118.7 & 120 & 142 & 0.36 & 0.18 & 31.93 & 20.38 & 10.00 & 9.07 & 28.09 & 5114 & 0.9269 & 61 & 5 & 60 & 121 & \\
\hline 410 & 125 & 120.7 & 120 & 145 & 0.36 & 0.18 & 31.93 & 20.38 & 10.00 & 9.07 & 28.09 & 5325 & 0.9309 & 86 & 4 & 59 & 145 & \\
\hline 411 & 125 & 122.7 & 120 & 147 & 0.36 & 0.18 & 31.93 & 20.38 & 10.00 & 9.07 & 28.09 & 5441 & 0.9027 & 29 & 4 & 148 & 178 & \\
\hline 412 & 125 & 122.7 & 120 & 147 & 0.36 & 0.18 & 31.93 & 20.38 & 10.00 & 9.07 & 28.09 & 5530 & 0.8547 & 36 & 5 & 125 & 161 & \\
\hline 413 & 125 & 119.7 & 120 & 144 & 0.36 & 0.18 & 31.93 & 20.38 & 10.00 & 9.07 & 28.09 & 5710 & 0.8410 & 11 & 4 & 177 & 188 & \\
\hline 414 & 125 & 120.7 & 120 & 145 & 0.36 & 0.18 & 31.93 & 20.38 & 10.00 & 9.07 & 28.09 & 5957 & 0.7072 & 74 & 4 & 116 & 190 & \\
\hline
\end{tabular}


Table 8. Continued -2

\begin{tabular}{|c|c|c|c|c|c|c|c|c|c|c|c|c|c|c|c|c|c|c|}
\hline \multirow[t]{2}{*}{ Run\# } & \multirow{2}{*}{$\begin{array}{l}\text { Temp. } \\
{ }^{\circ} \mathrm{C} \\
\end{array}$} & \multirow{2}{*}{$\begin{array}{l}\text { Press. } \\
\text { psia }\end{array}$} & \multirow{2}{*}{$\begin{array}{c}\text { Total } \\
\text { Flow } \\
\\
\text { Rate, } \\
\text { SCCM } \\
\end{array}$} & \multirow{2}{*}{$\begin{array}{c}\text { Space } \\
\text { Time, } \\
\text { s }\end{array}$} & \multicolumn{7}{|c|}{ Feed Composition, v\% } & \multirow{2}{*}{$\begin{array}{c}\text { Catalyst } \\
\begin{array}{c}\text { Aging, } \\
\text { min }\end{array} \\
\end{array}$} & \multirow{2}{*}{$\begin{array}{c}\text { conversi } \\
\text { on } \\
\\
\mathrm{H}_{2} \mathrm{~S} \\
\end{array}$} & \multicolumn{4}{|c|}{$\mathrm{COS}, \mathrm{ppm}$} & \multirow[b]{2}{*}{ Remarks } \\
\hline & & & & & $\mathrm{H}_{2} \mathrm{~S}$ & $\mathrm{SO}_{2}$ & $\mathrm{CO}$ & $\mathrm{H}_{2}$ & $\mathrm{H}_{2} \mathrm{O}$ & $\mathrm{CO}_{2}$ & $\mathrm{~N}_{2}$ & & & $\begin{array}{c}\begin{array}{c}\text { Format } \\
\text { ion }\end{array} \\
\end{array}$ & $\begin{array}{c}\text { Cylinde } \\
\text { r Feed }\end{array}$ & $\begin{array}{l}\text { Blank } \\
\text { Product } \\
\text { Mixture } \\
\end{array}$ & $\begin{array}{l}\text { Reaction } \\
\text { Product } \\
\text { Mixture } \\
\end{array}$ & \\
\hline 415 & 125 & 119.7 & 120 & 144 & 0.36 & 0.18 & 31.93 & 20.38 & 10.00 & 9.07 & 28.09 & 6109 & 0.6785 & 68 & 4 & 97 & 165 & \\
\hline 416 & 125 & 122.7 & 120 & 147 & 0.36 & 0.18 & 31.93 & 20.38 & 10.00 & 9.07 & 28.09 & 6282 & 0.8935 & 81 & 4 & 110 & 191 & \\
\hline 417 & 125 & 122.7 & 120 & 147 & 0.36 & 0.18 & 31.93 & 20.38 & 10.00 & 9.07 & 28.09 & 6531 & 0.7925 & 94 & 4 & 121 & 216 & \\
\hline 418 & 125 & 121.7 & 120 & 146 & 0.36 & 0.18 & 31.93 & 20.38 & 10.00 & 9.07 & 28.09 & 6683 & 0.7027 & 126 & 4 & 122 & 248 & \\
\hline 419 & 125 & 119.7 & 120 & 144 & 0.36 & 0.18 & 31.93 & 20.38 & 10.00 & 9.07 & 28.09 & 6814 & 0.6082 & 74 & 5 & 157 & 231 & \\
\hline 420 & 125 & 121.7 & 120 & 146 & 0.36 & 0.18 & 31.93 & 20.38 & 10.00 & 9.07 & 28.09 & 7020 & 0.5535 & 100 & 5 & 116 & 215 & \\
\hline 421 & 125 & 119.7 & 120 & 144 & 0.36 & 0.18 & 31.93 & 20.38 & 10.00 & 9.07 & 28.09 & 7242 & 0.6156 & 93 & 4 & 116 & 209 & \\
\hline 422 & 125 & 119.7 & 120 & 144 & 0.36 & 0.18 & 31.93 & 20.38 & 10.00 & 9.07 & 28.09 & 7379 & 0.7023 & 86 & 4 & 101 & 187 & \\
\hline 423 & 125 & 116.7 & 120 & 140 & 0.36 & 0.18 & 31.93 & 20.38 & 10.00 & 9.07 & 28.09 & 7536 & 0.7857 & 91 & 4 & 110 & 202 & \\
\hline 424 & 125 & 119.7 & 120 & 144 & 0.36 & 0.18 & 31.93 & 20.38 & 10.00 & 9.07 & 28.09 & 7640 & 0.7343 & 112 & 4 & 111 & 223 & \\
\hline 425 & 125 & 121.7 & 120 & 146 & 0.36 & 0.18 & 31.93 & 20.38 & 10.00 & 9.07 & 28.09 & 7765 & 0.6678 & 101 & 4 & 142 & 243 & \\
\hline 426 & 125 & 120.7 & 120 & 145 & 0.36 & 0.18 & 31.93 & 20.38 & 10.00 & 9.07 & 28.09 & 7902 & 0.6056 & 89 & 5 & 129 & 218 & \\
\hline 427 & 125 & 115.7 & 120 & 139 & 0.36 & 0.18 & 31.93 & 20.38 & 10.00 & 9.07 & 28.09 & 8003 & 0.7794 & 273 & 4 & 129 & 402 & \\
\hline 433 & 125 & 121.7 & 120 & 146 & 0.36 & 0.18 & 31.93 & 20.38 & 10.00 & 9.07 & 28.09 & 8100 & 0.1718 & 92 & 5 & 108 & 200 & $\begin{array}{l}\text { sulfur removed at } 200^{\circ} \mathrm{C} \text { for several days } \\
\text { washed in } 0.3 \mathrm{M} \mathrm{NaOH} \text { aqueous solution }\end{array}$ \\
\hline 438 & 125 & 120.7 & 120 & 145 & 0.36 & 0.18 & 31.93 & 20.38 & 10.00 & 9.07 & 28.09 & 8228 & 0.2990 & 164 & 4 & 18 & 182 & overnight, and heated for $4 \mathrm{hrs}$ at $900^{\circ} \mathrm{C}$ \\
\hline 439 & 125 & 120.7 & 120 & 145 & 0.36 & 0.18 & 31.93 & 20.38 & 10.00 & 9.07 & 28.09 & 8350 & 0.2383 & 110 & 5 & 37 & 147 & no sulfur removed \\
\hline 446 & 125 & 123.7 & 120 & 148 & 0.36 & 0.18 & 31.93 & 20.38 & 10.00 & 9.07 & 28.09 & 8516 & 0.2445 & 80 & 5 & 58 & 138 & \\
\hline 447 & 125 & 119.7 & 120 & 144 & 0.36 & 0.18 & 31.93 & 20.38 & 10.00 & 9.07 & 28.09 & 8685 & 0.3075 & 106 & 5 & 31 & 137 & \\
\hline
\end{tabular}

*SCCM: standard cubic centimeters per minute, volumetric flow rates of gases measured at 1 atm and $25^{\circ} \mathrm{C}$ 
Table 9. Effects of elemental sulfur removed from a $\gamma$-alumina wash-coated catalyst on conversion of $\mathrm{H}_{2} \mathrm{~S}$ and formation of COS with the catalyst support soaked in $1-\mathrm{w} \% \mathrm{Zn}$ aqueous solution followed by heating it for 4 hours at $450^{\circ} \mathrm{C}$, and then washed in $0.3 \mathrm{M} \mathrm{NaOH}$ aqueous solution followed by heating it for $4 \mathrm{hrs}$ at $900^{\circ} \mathrm{C}$, removing elemental sulfur from the catalyst with $\mathrm{N}_{2}$ at $200^{\circ} \mathrm{C}$

\begin{tabular}{|c|c|c|c|c|c|c|c|c|c|c|c|c|c|c|c|c|c|c|}
\hline \multirow[t]{2}{*}{ Run \# } & \multirow{2}{*}{$\begin{array}{l}\text { Temp. } \\
{ }^{\circ} \mathrm{C}\end{array}$} & \multirow{2}{*}{$\begin{array}{l}\text { Press. } \\
\text { psia }\end{array}$} & \multirow{2}{*}{$\begin{array}{l}\text { Total } \\
\text { Flow } \\
\text { Rate, } \\
\text { SCCM }\end{array}$} & \multirow{2}{*}{$\begin{array}{l}\text { Space } \\
\text { Time, } \\
\text { s }\end{array}$} & \multicolumn{7}{|c|}{ Feed Composition, v\% } & \multirow{2}{*}{$\begin{array}{c}\text { Catalyst } \\
\text { Aging, } \\
\text { min }\end{array}$} & \multirow{2}{*}{ 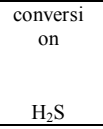 } & \multicolumn{4}{|c|}{$\mathrm{COS}, \mathrm{ppm}$} & \multirow[b]{2}{*}{ Remarks } \\
\hline & & & & & $\mathrm{H}_{2} \mathrm{~S}$ & $\mathrm{SO}_{2}$ & $\mathrm{CO}$ & $\mathrm{H}_{2}$ & $\mathrm{H}_{2} \mathrm{O}$ & $\mathrm{CO}_{2}$ & $\mathrm{~N}_{2}$ & & & $\begin{array}{l}\text { Form } \\
\text { ation }\end{array}$ & $\begin{array}{l}\text { Cylinder } \\
\text { Feed }\end{array}$ & $\begin{array}{c}\text { Blank } \\
\text { Product } \\
\text { Mixture }\end{array}$ & $\begin{array}{l}\text { Reaction } \\
\text { Product } \\
\text { Mixture }\end{array}$ & \\
\hline
\end{tabular}

washed in $0.3 \mathrm{M} \mathrm{NaOH}$ aqueous solution and heated for $4 \mathrm{hrs}$ at $900^{\circ} \mathrm{C}$, no sulfur

\begin{tabular}{|c|c|c|c|c|c|c|c|c|c|c|c|c|c|c|c|}
\hline 408 & 125 & 118.7 & 120 & 142 & 0.36 & 0.18 & 31.93 & 20.38 & 10.00 & 9.07 & 28.09 & 4940 & 0.8602 & 38 & 7 \\
\hline 409 & 125 & 118.7 & 120 & 142 & 0.36 & 0.18 & 31.93 & 20.38 & 10.00 & 9.07 & 28.09 & 5114 & 0.9269 & 61 & 5 \\
\hline 410 & 125 & 120.7 & 120 & 145 & 0.36 & 0.18 & 31.93 & 20.38 & 10.00 & 9.07 & 28.09 & 5325 & 0.9309 & 86 & 4 \\
\hline 411 & 125 & 122.7 & 120 & 147 & 0.36 & 0.18 & 31.93 & 20.38 & 10.00 & 9.07 & 28.09 & 5441 & 0.9027 & 29 & 4 \\
\hline 412 & 125 & 122.7 & 120 & 147 & 0.36 & 0.18 & 31.93 & 20.38 & 10.00 & 9.07 & 28.09 & 5530 & 0.8547 & 36 & 5 \\
\hline 413 & 125 & 119.7 & 120 & 144 & 0.36 & 0.18 & 31.93 & 20.38 & 10.00 & 9.07 & 28.09 & 5710 & 0.841 & 11 & 4 \\
\hline 414 & 125 & 120.7 & 120 & 145 & 0.36 & 0.18 & 31.93 & 20.38 & 10.00 & 9.07 & 28.09 & 5957 & 0.7072 & 74 & 4 \\
\hline 415 & 125 & 119.7 & 120 & 144 & 0.36 & 0.18 & 31.93 & 20.38 & 10.00 & 9.07 & 28.09 & 6109 & 0.6785 & 68 & 4 \\
\hline 416 & 125 & 122.7 & 120 & 147 & 0.36 & 0.18 & 31.93 & 20.38 & 10.00 & 9.07 & 28.09 & 6282 & 0.8935 & 81 & 4 \\
\hline 417 & 125 & 122.7 & 120 & 147 & 0.36 & 0.18 & 31.93 & 20.38 & 10.00 & 9.07 & 28.09 & 6531 & 0.7925 & 94 & 4 \\
\hline 418 & 125 & 121.7 & 120 & 146 & 0.36 & 0.18 & 31.93 & 20.38 & 10.00 & 9.07 & 28.09 & 6683 & 0.7027 & 126 & 4 \\
\hline 419 & 125 & 119.7 & 120 & 144 & 0.36 & 0.18 & 31.93 & 20.38 & 10.00 & 9.07 & 28.09 & 6814 & 0.6082 & 74 & 5 \\
\hline 420 & 125 & 121.7 & 120 & 146 & 0.36 & 0.18 & 31.93 & 20.38 & 10.00 & 9.07 & 28.09 & 7020 & 0.5535 & 100 & 5 \\
\hline 421 & 125 & 119.7 & 120 & 144 & 0.36 & 0.18 & 31.93 & 20.38 & 10.00 & 9.07 & 28.09 & 7242 & 0.6156 & 93 & 4 \\
\hline 422 & 125 & 119.7 & 120 & 144 & 0.36 & 0.18 & 31.93 & 20.38 & 10.00 & 9.07 & 28.09 & 7379 & 0.7023 & 86 & 4 \\
\hline 423 & 125 & 116.7 & 120 & 140 & 0.36 & 0.18 & 31.93 & 20.38 & 10.00 & 9.07 & 28.09 & 7536 & 0.7857 & 91 & 4 \\
\hline 424 & 125 & 119.7 & 120 & 144 & 0.36 & 0.18 & 31.93 & 20.38 & 10.00 & 9.07 & 28.09 & 7640 & 0.7343 & 112 & 4 \\
\hline 425 & 125 & 121.7 & 120 & 146 & 0.36 & 0.18 & 31.93 & 20.38 & 10.00 & 9.07 & 28.09 & 7765 & 0.6678 & 101 & 4 \\
\hline 426 & 125 & 120.7 & 120 & 145 & 0.36 & 0.18 & 31.93 & 20.38 & 10.00 & 9.07 & 28.09 & 7902 & 0.6056 & 89 & 5 \\
\hline 427 & 125 & 115.7 & 120 & 139 & 0.36 & 0.18 & 31.93 & 20.38 & 10.00 & 9.07 & 28.09 & 8003 & 0.7794 & 273 & 4 \\
\hline 433 & 125 & 121.7 & 120 & 146 & 0.36 & 0.18 & 31.93 & 20.38 & 10.00 & 9.07 & 28.09 & 8100 & 0.1718 & 92 & 5 \\
\hline 438 & 125 & 120.7 & 120 & 145 & 0.36 & 0.18 & 31.93 & 20.38 & 10.00 & 9.07 & 28.09 & 8228 & 0.299 & 164 & 4 \\
\hline 439 & 125 & 120.7 & 120 & 145 & 0.36 & 0.18 & 31.93 & 20.38 & 10.00 & 9.07 & 28.09 & 8350 & 0.2383 & 110 & 5 \\
\hline 446 & 125 & 123.7 & 120 & 148 & 0.36 & 0.18 & 31.93 & 20.38 & 10.00 & 9.07 & 28.09 & 8516 & 0.2445 & 80 & 5 \\
\hline 447 & 125 & 119.7 & 120 & 144 & 0.36 & 0.18 & 31.93 & 20.38 & 10.00 & 9.07 & 28.09 & 8685 & 0.3075 & 106 & 5 \\
\hline
\end{tabular}

*SCCM: standard cubic centimeters per minute, volumetric flow rates of gases measured at 1 atm and $25^{\circ} \mathrm{C}$ 
Table 10. Effects of washing a $\gamma$-alumina wash-coated monolithic catalyst support in $\mathrm{NaOH}$ aqueous solution on conversion of $\mathrm{H}_{2} \mathrm{~S}$ and formation of COS.

\begin{tabular}{|c|c|c|c|c|c|c|c|c|c|c|c|c|c|c|c|c|c|c|}
\hline \multirow[t]{2}{*}{ Run\# } & \multirow{2}{*}{$\begin{array}{l}\text { Temp. } \\
{ }^{\circ} \mathrm{C} \\
\end{array}$} & \multirow{2}{*}{$\begin{array}{l}\text { Press. } \\
\text { psia }\end{array}$} & \multirow{2}{*}{$\begin{array}{l}\text { Total } \\
\text { Flow } \\
\text { Rate, } \\
\text { SCCM } \\
\end{array}$} & \multirow{2}{*}{$\begin{array}{l}\text { Space } \\
\text { Time, } \\
\text { s }\end{array}$} & \multicolumn{7}{|c|}{ Feed Composition, v\% } & \multirow{2}{*}{$\begin{array}{l}\text { Catalyst } \\
\text { Aging, } \\
\text { min }\end{array}$} & \multirow{2}{*}{$\begin{array}{c}\text { conversi } \\
\text { on } \\
\mathrm{H}_{2} \mathrm{~S} \\
\end{array}$} & \multicolumn{4}{|c|}{ COS, ppm } & \multirow[b]{2}{*}{ Remarks } \\
\hline & & & & & $\mathrm{H}_{2} \mathrm{~S}$ & $\mathrm{SO}_{2}$ & $\mathrm{CO}$ & $\mathrm{H}_{2}$ & $\mathrm{H}_{2} \mathrm{O}$ & $\mathrm{CO}_{2}$ & $\mathrm{~N}_{2}$ & & & $\begin{array}{c}\text { Forma } \\
\text { tion } \\
\end{array}$ & $\begin{array}{l}\text { Cylinder } \\
\text { Feed }\end{array}$ & $\begin{array}{l}\text { Blank } \\
\text { Product } \\
\text { Mixture } \\
\end{array}$ & $\begin{array}{l}\text { Reaction } \\
\text { Product } \\
\text { Mixture } \\
\end{array}$ & \\
\hline 352 & 125 & 121.7 & 120 & 146 & 0.36 & 0.18 & 32.02 & 20.26 & 10.00 & 9.07 & 28.11 & 147 & 0.9057 & 25 & 18 & 49 & 74 & $\begin{array}{l}\text { removing sulfur from the catalyst with } \mathrm{N}_{2} \text { at } \\
140^{\circ} \mathrm{C} \text { overnight }\end{array}$ \\
\hline 353 & 125 & 119.7 & 120 & 144 & 0.36 & 0.18 & 32.02 & 20.26 & 10.00 & 9.07 & 28.11 & 254 & 0.9479 & 82 & 19 & 52 & 134 & \\
\hline 354 & 125 & 117.7 & 120 & 141 & 0.36 & 0.18 & 32.02 & 20.26 & 10.00 & 9.07 & 28.11 & 358 & 0.8795 & 109 & 19 & 48 & 157 & \\
\hline 355 & 125 & 117.7 & 120 & 141 & 0.36 & 0.18 & 32.02 & 20.26 & 10.00 & 9.07 & 28.11 & 516 & 0.8676 & 79 & 19 & 43 & 121 & \\
\hline 356 & 125 & 123.7 & 120 & 148 & 0.36 & 0.18 & 32.02 & 20.26 & 10.00 & 9.07 & 28.11 & 679 & 0.8974 & 68 & 18 & 38 & 107 & \\
\hline 357 & 125 & 116.7 & 120 & 140 & 0.36 & 0.18 & 32.02 & 20.26 & 10.00 & 9.07 & 28.11 & 810 & 0.9005 & 72 & 19 & 58 & 130 & \\
\hline 358 & 125 & 118.7 & 120 & 142 & 0.36 & 0.18 & 32.02 & 20.26 & 10.00 & 9.07 & 28.11 & 939 & 0.9034 & 67 & 19 & 58 & 125 & \\
\hline 359 & 125 & 119.7 & 120 & 144 & 0.36 & 0.18 & 32.02 & 20.26 & 10.00 & 9.07 & 28.11 & 1076 & 0.8823 & 65 & 19 & 58 & 123 & \\
\hline 360 & 125 & 120.7 & 120 & 145 & 0.36 & 0.18 & 32.02 & 20.26 & 10.00 & 9.07 & 28.11 & 1248 & 0.8568 & 72 & 19 & 47 & 119 & \\
\hline 361 & 125 & 118.7 & 120 & 142 & 0.36 & 0.18 & 32.02 & 20.26 & 10.00 & 9.07 & 28.11 & 1434 & 0.8965 & 58 & 19 & 65 & 123 & removing sulfur from the catalyst with $\mathrm{N}_{2}$ at \\
\hline 387 & 125 & 121.7 & 120 & 146 & 0.36 & 0.18 & 31.93 & 20.38 & 10.00 & 9.07 & 28.09 & 1641 & 0.9044 & 78 & 4 & 62 & 141 & $200^{\circ} \mathrm{C}$ overnight \\
\hline 388 & 125 & 122.7 & 114 & 155 & 0.38 & 0.19 & 33.61 & 21.45 & 5.26 & 9.54 & 29.57 & 1763 & 0.8395 & 43 & 3 & 85 & 128 & \\
\hline 390 & 125 & 118.7 & 120 & 142 & 0.36 & 0.18 & 31.93 & 20.38 & 10.00 & 9.07 & 28.09 & 1946 & 0.9287 & 70 & 5 & 71 & 141 & washed in $0.1 \mathrm{M} \mathrm{NaOH}$ overnight \\
\hline 393 & 125 & 120.7 & 120 & 145 & 0.36 & 0.18 & 31.93 & 20.38 & 10.00 & 9.07 & 28.09 & 2159 & 0.7553 & 77 & 6 & 63 & 139 & \\
\hline 394 & 125 & 121.7 & 120 & 146 & 0.36 & 0.18 & 31.93 & 20.38 & 10.00 & 9.07 & 28.09 & 2330 & 0.5210 & 10 & 5 & 123 & 133 & \\
\hline 395 & 125 & 119.7 & 120 & 144 & 0.36 & 0.18 & 31.93 & 20.38 & 10.00 & 9.07 & 28.09 & 2429 & 0.5254 & 37 & 5 & 142 & 179 & $\begin{array}{l}\text { washed in } 0.1 \mathrm{M} \mathrm{NaOH} \text { aqueous solution } \\
\text { overnight, and heated for } 4 \text { hrs at } 450^{\circ} \mathrm{C} \text {, } \\
\text { removed sulfur from the catalyst with } \mathrm{N}_{2} \text { at } \\
200^{\circ} \mathrm{C}\end{array}$ \\
\hline 396 & 125 & 120.7 & 120 & 145 & 0.36 & 0.18 & 31.93 & 20.38 & 10.00 & 9.07 & 28.09 & 2559 & 0.3428 & 46 & 6 & 53 & 99 & \\
\hline 397 & 125 & 120.7 & 120 & 145 & 0.36 & 0.18 & 31.93 & 20.38 & 10.00 & 9.07 & 28.09 & 2680 & 0.2062 & 31 & 6 & 89 & 121 & \\
\hline 401 & 125 & 119.7 & 120 & 144 & 0.36 & 0.18 & 31.93 & 20.38 & 10.00 & 9.07 & 28.09 & 2893 & 0.8154 & 108 & 5 & 53 & 161 & $\begin{array}{l}\text { washed in } 0.2 \mathrm{M} \mathrm{NaOH} \text { aqueous solution } \\
\text { overnight, and heated for } 4 \text { hrs at } 450^{\circ} \mathrm{C} \text {, } \\
\text { removed sulfur from the catalyst with } \mathrm{N}_{2} \text { at } \\
200^{\circ} \mathrm{C}\end{array}$ \\
\hline 402 & 125 & 121.7 & 120 & 146 & 0.36 & 0.18 & 31.93 & 20.38 & 10.00 & 9.07 & 28.09 & 3094 & 0.1779 & 131 & 5 & 62 & 193 & $\begin{array}{l}\text { washed in } 0.3 \mathrm{M} \mathrm{NaOH} \text { aqueous solution } \\
\text { overnight, and heated for } 1.5 \mathrm{hrs} \text { at } 900^{\circ} \mathrm{C} \text {, } \\
\text { removed sulfur from the catalyst with } \mathrm{N}_{2} \text { at }\end{array}$ \\
\hline 404 & 125 & 121.7 & 120 & 146 & 0.36 & 0.18 & 31.93 & 20.38 & 10.00 & 9.07 & 28.09 & 3249 & 0.8201 & 70 & 5 & 48 & 119 & $200^{\circ} \mathrm{C}$ \\
\hline 405 & 125 & 123.7 & 120 & 148 & 0.36 & 0.18 & 31.93 & 20.38 & 10.00 & 9.07 & 28.09 & 3484 & 0.6095 & 85 & 4 & 68 & 153 & \\
\hline 406 & 125 & 119.7 & 120 & 144 & 0.36 & 0.18 & 31.93 & 20.38 & 10.00 & 9.07 & 28.09 & 3613 & 0.3270 & 67 & 5 & 70 & 137 & \\
\hline
\end{tabular}


Table 10. Continued - 1

\begin{tabular}{|c|c|c|c|c|c|c|c|c|c|c|c|c|c|c|c|c|c|c|}
\hline \multirow[t]{2}{*}{ Run\# } & \multirow{2}{*}{$\begin{array}{l}\text { Temp. } \\
{ }^{\circ} \mathrm{C} \\
\end{array}$} & \multirow{2}{*}{$\begin{array}{c}\text { Press. } \\
\text { psia } \\
\end{array}$} & \multirow{2}{*}{$\begin{array}{l}\text { Total } \\
\text { Flow } \\
\\
\text { Rate, } \\
\text { SCCM } \\
\end{array}$} & \multirow{2}{*}{$\begin{array}{c}\text { Space } \\
\text { Time, } \\
\mathrm{s}\end{array}$} & \multicolumn{7}{|c|}{ Feed Composition, $\mathrm{v} \%$} & \multirow{2}{*}{$\begin{array}{c}\text { Catalyst } \\
\text { Aging, } \\
\text { min }\end{array}$} & \multirow{2}{*}{$\begin{array}{c}\text { conversi } \\
\text { on } \\
\mathrm{H}_{2} \mathrm{~S} \\
\end{array}$} & \multicolumn{4}{|c|}{$\mathrm{COS}, \mathrm{ppm}$} & \multirow[b]{2}{*}{ Remarks } \\
\hline & & & & & $\mathrm{H}_{2} \mathrm{~S}$ & $\mathrm{SO}_{2}$ & $\mathrm{CO}$ & $\mathrm{H}_{2}$ & $\mathrm{H}_{2} \mathrm{O}$ & $\mathrm{CO}_{2}$ & $\mathrm{~N}_{2}$ & & & $\begin{array}{c}\text { Forma } \\
\text { tion } \\
\end{array}$ & $\begin{array}{c}\text { Cylinder } \\
\text { Feed } \\
\end{array}$ & $\begin{array}{c}\text { Blank } \\
\text { Product } \\
\text { Mixture } \\
\end{array}$ & $\begin{array}{l}\text { Reaction } \\
\text { Product } \\
\text { Mixture } \\
\end{array}$ & \\
\hline 407 & 125 & 120.7 & 120 & 145 & 0.36 & 0.18 & 31.93 & 20.38 & 10.00 & 9.07 & 28.09 & 3745 & 0.2864 & 42 & 6 & 80 & 121 & $\begin{array}{l}\text { washed in } 0.4 \mathrm{M} \mathrm{NaOH} \text { aqueous solution } \\
\text { overnight, and heated for } 4 \mathrm{hrs} \text { at } 900^{\circ} \mathrm{C} \text {, } \\
\text { removed sulfur from the catalyst with } \mathrm{N}_{2} \text { at } \\
200^{\circ} \mathrm{C}\end{array}$ \\
\hline 429 & 125 & 121.7 & 120 & 146 & 0.36 & 0.18 & 31.93 & 20.38 & 10.00 & 9.07 & 28.09 & 4061 & 0.9073 & 18 & 5 & 98 & 115 & no sulfur removed \\
\hline 430 & 125 & 117.7 & 120 & 141 & 0.36 & 0.18 & 31.93 & 20.38 & 10.00 & 9.07 & 28.09 & 4186 & 0.7673 & 42 & 5 & 99 & 142 & \\
\hline 431 & 125 & 120.7 & 120 & 145 & 0.36 & 0.18 & 31.93 & 20.38 & 10.00 & 9.07 & 28.09 & 4385 & 0.7929 & 8 & 5 & 120 & 128 & \\
\hline 444 & 125 & 120.7 & 120 & 145 & 0.36 & 0.18 & 31.93 & 20.38 & 10.00 & 9.07 & 28.09 & 4590 & 0.8004 & 18 & 4 & 21 & 39 & \\
\hline 445 & 125 & 120.7 & 120 & 145 & 0.36 & 0.18 & 31.93 & 20.38 & 10.00 & 9.07 & 28.09 & & 0.7956 & 40 & 4 & 26 & 66 & \\
\hline
\end{tabular}

*SCCM: standard cubic centimeters per minute, volumetric flow rates of gases measured at 1 atm and $25^{\circ} \mathrm{C}$

Table 11. Conversion of $\mathrm{H}_{2} \mathrm{~S}$ and formation of COS with a $\gamma$-alumina wash-coated monolithic catalyst support, soaked in 4-w\% $\mathrm{Zn}$ aqueous solution followed by heating it for $4 \mathrm{hrs}$ at $600^{\circ} \mathrm{C}$, and soaked in $4-\mathrm{w} \% \mathrm{KOH}$ aqueous solution followed by heating it for $4 \mathrm{hrs}$ at $550^{\circ} \mathrm{C}$.

\begin{tabular}{|c|c|c|c|c|c|c|c|c|c|c|c|c|c|c|c|c|c|c|}
\hline \multirow[t]{2}{*}{ Run \# } & \multirow{2}{*}{$\begin{array}{l}\text { Temp. } \\
{ }^{\circ} \mathrm{C}\end{array}$} & \multirow{2}{*}{$\begin{array}{l}\text { Press. } \\
\text { psia }\end{array}$} & \multirow{2}{*}{$\begin{array}{c}\text { Total } \\
\text { Flow } \\
\\
\text { Rate, } \\
\text { SCCM }\end{array}$} & \multirow{2}{*}{$\begin{array}{l}\text { Space } \\
\text { Time, } \\
\text { s }\end{array}$} & \multicolumn{7}{|c|}{ Feed Composition, v\% } & \multirow{2}{*}{$\begin{array}{l}\text { Catalyst } \\
\text { Aging, } \\
\text { min }\end{array}$} & \multirow{2}{*}{$\begin{array}{c}\begin{array}{c}\text { conversi } \\
\text { on }\end{array} \\
\mathrm{H}_{2} \mathrm{~S}\end{array}$} & \multicolumn{4}{|c|}{$\mathrm{COS}, \mathrm{ppm}$} & \multirow[b]{2}{*}{ Remarks } \\
\hline & & & & & $\mathrm{H}_{2} \mathrm{~S}$ & $\mathrm{SO}_{2}$ & $\mathrm{CO}$ & $\mathrm{H}_{2}$ & $\mathrm{H}_{2} \mathrm{O}$ & $\mathrm{CO}_{2}$ & $\mathrm{~N}_{2}$ & & & $\begin{array}{c}\text { Forma } \\
\text { tion }\end{array}$ & $\begin{array}{l}\text { Cylinder } \\
\text { Feed }\end{array}$ & $\begin{array}{l}\text { Blank } \\
\text { Product } \\
\text { Mixture }\end{array}$ & $\begin{array}{l}\text { Reaction } \\
\text { Product } \\
\text { Mixture }\end{array}$ & \\
\hline 432 & 125 & 128.7 & 120 & 154 & 0.36 & 0.18 & 31.93 & 20.38 & 10.00 & 9.07 & 28.09 & 136 & 1.0000 & -16 & Thu & 119 & 103 & $\begin{array}{l}\text { soaked with } 4-w \% \mathrm{Zn} \text { aqueous solution and } \\
\text { heated for } 4 \mathrm{hrs} \text { at } 600^{\circ} \mathrm{C}\end{array}$ \\
\hline 436 & 125 & 117.7 & 120 & 141 & 0.36 & 0.18 & 31.93 & 20.38 & 10.00 & 9.07 & 28.09 & 232 & 1.0000 & -118 & 4 & 121 & 2 & $\begin{array}{l}\text { heated for } 4 \text { hrs at } 550^{\circ} \mathrm{C} \text {. } \\
\text { no sulfur removed }\end{array}$ \\
\hline 437 & 125 & 118.7 & 120 & 142 & 0.36 & 0.18 & 31.93 & 20.38 & 10.00 & 9.07 & 28.09 & 469 & 0.8961 & 14 & 4 & 126 & 140 & \\
\hline 468 & 125 & 118.7 & 120 & 142 & 0.36 & 0.18 & 31.93 & 20.38 & 10.00 & 9.07 & 28.09 & 719 & 0.8565 & 39 & 5 & 68 & 107 & \\
\hline 469 & 125 & 119.7 & 120 & 144 & 0.36 & 0.18 & 31.93 & 20.38 & 10.00 & 9.07 & 28.09 & 893 & 0.9181 & 16 & 5 & 112 & 129 & \\
\hline 470 & 125 & 118.7 & 120 & 142 & 0.36 & 0.18 & 31.93 & 20.38 & 10.00 & 9.07 & 28.09 & 1112 & 0.8565 & 127 & 5 & 80 & 207 & \\
\hline 471 & 125 & 119.7 & 120 & 144 & 0.36 & 0.18 & 31.93 & 20.38 & 10.00 & 9.07 & 28.09 & 1432 & 0.9087 & 376 & 5 & 84 & 460 & \\
\hline 472 & 125 & 118.7 & 120 & 142 & 0.36 & 0.18 & 31.93 & 20.38 & 10.00 & 9.07 & 28.09 & 1579 & 0.9584 & 145 & 5 & 54 & 199 & \\
\hline 473 & 125 & 117.7 & 120 & 141 & 0.36 & 0.18 & 31.93 & 20.38 & 10.00 & 9.07 & 28.09 & 1748 & 0.7669 & 138 & 5 & 58 & 196 & \\
\hline 474 & 125 & 119.7 & 120 & 144 & 0.36 & 0.18 & 31.93 & 20.38 & 10.00 & 9.07 & 28.09 & 1920 & 0.8941 & 111 & 4 & 53 & 164 & \\
\hline 475 & 125 & 120.7 & 120 & 145 & 0.36 & 0.18 & 31.93 & 20.38 & 10.00 & 9.07 & 28.09 & 2061 & 0.9626 & 86 & 6 & 73 & 159 & \\
\hline
\end{tabular}


Table 12. Conversion of $\mathrm{H}_{2} \mathrm{~S}$ and formation of $\mathrm{COS}$ with a $\gamma$-alumina wash-coated monolithic catalyst support soaked in 4-w\% $\mathrm{KOH}$ aqueous solution followed by heating it for $4 \mathrm{hrs}$ at $550^{\circ} \mathrm{C}$.

\begin{tabular}{|c|c|c|c|c|c|c|c|c|c|c|c|c|c|c|c|c|c|c|}
\hline \multirow[t]{2}{*}{ Run \# } & \multirow{2}{*}{$\begin{array}{l}\text { Temp. } \\
{ }^{\circ} \mathrm{C}\end{array}$} & \multirow{2}{*}{$\begin{array}{c}\text { Press. } \\
\text { psia }\end{array}$} & \multirow{2}{*}{$\begin{array}{c}\text { Total } \\
\text { Flow } \\
\\
\text { Rate, } \\
\text { SCCM }\end{array}$} & \multirow{2}{*}{$\begin{array}{l}\text { Space } \\
\text { Time, } \\
\text { s }\end{array}$} & \multicolumn{7}{|c|}{ Feed Composition, v\% } & \multirow{2}{*}{$\begin{array}{c}\text { Catalyst } \\
\text { Aging, } \\
\text { min }\end{array}$} & \multirow{2}{*}{$\begin{array}{c}\begin{array}{c}\text { conversi } \\
\text { on }\end{array} \\
\mathrm{H}_{2} \mathrm{~S} \\
\end{array}$} & \multicolumn{4}{|c|}{$\mathrm{COS}, \mathrm{ppm}$} & \multirow[b]{2}{*}{ Remarks } \\
\hline & & & & & $\mathrm{H}_{2} \mathrm{~S}$ & $\mathrm{SO}_{2}$ & $\mathrm{CO}$ & $\mathrm{H}_{2}$ & $\mathrm{H}_{2} \mathrm{O}$ & $\mathrm{CO}_{2}$ & $\mathrm{~N}_{2}$ & & & $\begin{array}{c}\text { Forma } \\
\text { tion }\end{array}$ & $\begin{array}{l}\text { Cylinder } \\
\text { Feed }\end{array}$ & $\begin{array}{l}\text { Blank } \\
\text { Product } \\
\text { Mixture }\end{array}$ & $\begin{array}{l}\text { Reaction } \\
\text { Product } \\
\text { Mixture }\end{array}$ & \\
\hline
\end{tabular}

\begin{tabular}{|c|c|c|c|c|c|c|c|c|c|c|c|c|c|c|c|c|c|c|}
\hline 434 & 125 & 115.7 & 120 & 139 & 0.36 & 0.18 & 31.93 & 20.38 & 10.00 & 9.07 & 28.09 & 209 & 0.6977 & -140 & 4 & 142 & 2 & $\begin{array}{l}\text { soaked with } 4-w \% \mathrm{KOH} \text { aqueous solution and } \\
\text { heated for } 4 \text { hrs at } 550^{\circ} \mathrm{C}\end{array}$ \\
\hline 435 & 125 & 119.7 & 120 & 144 & 0.36 & 0.18 & 31.93 & 20.38 & 10.00 & 9.07 & 28.09 & 365 & 0.7108 & -54 & 4 & 118 & 64 & no sulfur removed \\
\hline 440 & 125 & 119.7 & 120 & 144 & 0.36 & 0.18 & 31.93 & 20.38 & 10.00 & 9.07 & 28.09 & 574 & 0.5517 & 70 & 4 & 20 & 90 & \\
\hline 441 & 125 & 119.7 & 120 & 144 & 0.36 & 0.18 & 31.93 & 20.38 & 10.00 & 9.07 & 28.09 & 718 & 0.7503 & 86 & 4 & 14 & 100 & \\
\hline 442 & 125 & 119.7 & 120 & 144 & 0.36 & 0.18 & 31.93 & 20.38 & 10.00 & 9.07 & 28.09 & 912 & 0.8165 & 54 & 4 & 48 & 103 & \\
\hline 443 & 125 & 121.7 & 120 & 146 & 0.36 & 0.18 & 31.93 & 20.38 & 10.00 & 9.07 & 28.09 & 1049 & 0.8213 & 85 & 4 & 30 & 114 & \\
\hline
\end{tabular}

*SCCM: standard cubic centimeters per minute, volumetric flow rates of gases measured at 1 atm and $25^{\circ} \mathrm{C}$

Table 13. Conversion of $\mathrm{H}_{2} \mathrm{~S}$ and formation of $\mathrm{COS}$ with a $\gamma$-alumina wash-coated monolithic catalyst support soaked in 2-w\% $\mathrm{Fe}^{3+}$ aqueous solution followed by heating it for $4 \mathrm{hrs}$ at $450^{\circ} \mathrm{C}$, removing sulfur from the catalyst with $\mathrm{N}_{2}$ overnight.

\begin{tabular}{|c|c|c|c|c|c|c|c|c|c|c|c|c|c|c|c|c|c|c|}
\hline \multirow[t]{2}{*}{ Run \# } & \multirow{2}{*}{$\begin{array}{c}\text { Temp. } \\
{ }^{\circ} \mathrm{C} \\
\end{array}$} & \multirow{2}{*}{$\begin{array}{r}\text { Press. } \\
\text { psia }\end{array}$} & \multirow{2}{*}{$\begin{array}{c}\text { Total } \\
\text { Flow } \\
\text { Rate, } \\
\text { SCCM } \\
\end{array}$} & \multirow{2}{*}{$\begin{array}{c}\text { Space } \\
\text { Time, } \\
\mathrm{s}\end{array}$} & \multicolumn{7}{|c|}{ Feed Composition, v\% } & \multirow{2}{*}{$\begin{array}{c}\text { Catalyst } \\
\text { Aging, } \\
\text { min }\end{array}$} & \multirow{2}{*}{$\begin{array}{c}\text { conversi } \\
\text { on } \\
\\
\mathrm{H}_{2} \mathrm{~S} \\
\end{array}$} & \multicolumn{4}{|c|}{ COS, ppm } & \multirow[b]{2}{*}{ Remarks } \\
\hline & & & & & $\mathrm{H}_{2} \mathrm{~S}$ & $\mathrm{SO}_{2}$ & $\mathrm{CO}$ & $\mathrm{H}_{2}$ & $\mathrm{H}_{2} \mathrm{O}$ & $\mathrm{CO}_{2}$ & $\mathrm{~N}_{2}$ & & & $\begin{array}{c}\text { Forma } \\
\text { tion }\end{array}$ & $\begin{array}{l}\text { Cylinder } \\
\text { Feed }\end{array}$ & $\begin{array}{c}\text { Blank } \\
\text { Product } \\
\text { Mixture }\end{array}$ & $\begin{array}{l}\text { Reaction } \\
\text { Product } \\
\text { Mixture }\end{array}$ & \\
\hline 332 & 140 & 118.7 & 120 & 137 & 0.36 & 0.18 & 32.02 & 20.26 & 10.00 & 9.07 & 28.11 & 194 & 0.9760 & 54 & 15 & 94 & 149 & $\begin{array}{l}\text { soaked with } 2-\mathrm{w}^{0} \% \mathrm{Fe}^{3+} \text { aqueous solution and heated } \\
\text { for } 4 \text { hrs at } 450^{\circ} \mathrm{C} \text {. removing sulfur from the catalyst } \\
\text { with } \mathrm{N} \text { at } 270^{\circ} \mathrm{C}\end{array}$ \\
\hline 333 & 140 & 118.7 & 120 & 137 & 0.36 & 0.18 & 32.02 & 20.26 & 10.00 & 9.07 & 28.11 & 385 & 0.9331 & 184 & 16 & 102 & 286 & \\
\hline 334 & 140 & 119.7 & 120 & 138 & 0.36 & 0.18 & 32.02 & 20.26 & 10.00 & 9.07 & 28.11 & 530 & 0.4850 & 133 & 16 & 102 & 235 & \\
\hline 335 & 140 & 118.7 & 120 & 137 & 0.36 & 0.18 & 32.02 & 20.26 & 10.00 & 9.07 & 28.11 & 640 & 0.3630 & 117 & 18 & 101 & 218 & \\
\hline 336 & 125 & 117.7 & 120 & 141 & 0.36 & 0.18 & 32.02 & 20.26 & 10.00 & 9.07 & 28.11 & 726 & 0.4461 & 136 & 16 & 64 & 200 & removing sulfur from the catalyst with $\mathrm{N}_{2}$ at $200^{\circ} \mathrm{C}$ \\
\hline 345 & 125 & 121.7 & 120 & 146 & 0.36 & 0.18 & 32.02 & 20.26 & 10.00 & 9.07 & 28.11 & 214 & na & 34 & 18 & 100 & 135 & overnight \\
\hline 346 & 125 & 120.7 & 120 & 145 & 0.36 & 0.18 & 32.02 & 20.26 & 10.00 & 9.07 & 28.11 & 450 & 0.9649 & 71 & 18 & 100 & 171 & \\
\hline 347 & 125 & 120.7 & 120 & 145 & 0.36 & 0.18 & 32.02 & 20.26 & 10.00 & 9.07 & 28.11 & 648 & 0.7282 & 71 & 18 & 124 & 196 & \\
\hline 348 & 125 & 116.7 & 120 & 140 & 0.36 & 0.18 & 32.02 & 20.26 & 10.00 & 9.07 & 28.11 & 807 & -0.0440 & 95 & 18 & 126 & 221 & \\
\hline 349 & 125 & 121.7 & 120 & 146 & 0.36 & 0.18 & 32.02 & 20.26 & 10.00 & 9.07 & 28.11 & 943 & -0.8358 & 155 & 19 & 29 & 184 & \\
\hline 350 & 125 & 122.7 & 120 & 147 & 0.36 & 0.18 & 32.02 & 20.26 & 10.00 & 9.07 & 28.11 & 1081 & -0.3571 & 135 & 18 & 26 & 161 & \\
\hline
\end{tabular}


Table 14. Conversion of $\mathrm{H}_{2} \mathrm{~S}$ and formation of COS with a $\gamma$-alumina wash-coated monolithic catalyst support, soaked in $0.6-\mathrm{M}$ $\mathrm{NaOH}$ aqueous solution followed by heating it for $4 \mathrm{hrs}$ at $950^{\circ} \mathrm{C}$, soaked in $4-\mathrm{w} \% \mathrm{KOH}$ aqueous solution followed by heating it for 2 $\mathrm{h}$ at $550^{\circ} \mathrm{C}$, and soaked in $0.5-\mathrm{w} \% \mathrm{MgCl}_{2}$ aqueous solution followed by heating it for $2 \mathrm{hrs}$ at $550^{\circ} \mathrm{C}$, removing no sulfur.

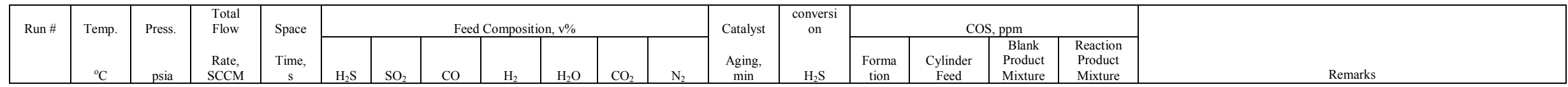

$\begin{array}{llllllllllll}448 & 125 & 118.7 & 120 & 142 & 0.36 & 0.18 & 31.93 & 20.38 & 10.00 & 9.07 & 28.09 \\ 449 & 125 & 118.7 & 120 & 142 & 0.36 & 0.18 & 31.93 & 20.38 & 10.00 & 9.07 & 28.09 \\ 450 & 125 & 116.7 & 120 & 140 & 0.36 & 0.18 & 31.93 & 20.38 & 10.00 & 9.07 & 28.09 \\ 451 & 125 & 121.7 & 120 & 146 & 0.36 & 0.18 & 31.93 & 20.38 & 10.00 & 9.07 & 28.09 \\ 452 & 125 & 119.7 & 120 & 144 & 0.36 & 0.18 & 31.93 & 20.38 & 10.00 & 9.07 & 28.09 \\ 453 & 125 & 119.7 & 120 & 144 & 0.36 & 0.18 & 31.93 & 20.38 & 10.00 & 9.07 & 28.09 \\ 454 & 125 & 119.7 & 120 & 144 & 0.36 & 0.18 & 31.93 & 20.38 & 10.00 & 9.07 & 28.09 \\ 457 & 125 & 116.7 & 120 & 140 & 0.36 & 0.18 & 31.93 & 20.38 & 10.00 & 9.07 & 28.09 \\ 458 & 125 & 118.7 & 120 & 142 & 0.36 & 0.18 & 31.93 & 20.38 & 10.00 & 9.07 & 28.09 \\ 459 & 125 & 121.7 & 120 & 146 & 0.36 & 0.18 & 31.93 & 20.38 & 10.00 & 9.07 & 28.09 \\ 460 & 125 & 118.7 & 120 & 142 & 0.36 & 0.18 & 31.93 & 20.38 & 10.00 & 9.07 & 28.09 \\ 461 & 125 & 120.7 & 120 & 145 & 0.36 & 0.18 & 31.93 & 20.38 & 10.00 & 9.07 & 28.09 \\ 462 & 125 & 122.7 & 120 & 147 & 0.36 & 0.18 & 31.93 & 20.38 & 10.00 & 9.07 & 28.09 \\ 463 & 125 & 121.7 & 120 & 146 & 0.36 & 0.18 & 31.93 & 20.38 & 10.00 & 9.07 & 28.09 \\ 464 & 125 & 119.7 & 120 & 144 & 0.36 & 0.18 & 31.93 & 20.38 & 10.00 & 9.07 & 28.09 \\ 465 & 125 & 121.7 & 120 & 146 & 0.36 & 0.18 & 31.93 & 20.38 & 10.00 & 9.07 & 28.09 \\ 466 & 125 & 121.7 & 120 & 146 & 0.36 & 0.18 & 31.93 & 20.38 & 10.00 & 9.07 & 28.09 \\ 467 & 125 & 119.7 & 120 & 144 & 0.36 & 0.18 & 31.93 & 20.38 & 10.00 & 9.07 & 28.09\end{array}$

$\begin{array}{llllll}204 & 0.8316 & 10 & 5 & 41 & 51 \\ 401 & 0.8884 & 35 & 4 & 32 & 67 \\ 600 & 0.8906 & 33 & 4 & 29 & 62 \\ 772 & 0.8764 & 7 & 5 & 72 & 79 \\ 962 & 0.8779 & 27 & 4 & 57 & 84 \\ 1132 & 0.8677 & 19 & 3 & 70 & 88 \\ 1330 & 0.8517 & 56 & 4 & 75 & 131 \\ 1585 & 0.8283 & -1 & 5 & 93 & 92 \\ 1750 & 0.8370 & 33 & 5 & 63 & 96 \\ 1939 & 0.8139 & 19 & 5 & 77 & 96 \\ 2103 & 0.8213 & 8 & 5 & 83 & 92 \\ 2284 & 0.7894 & 28 & 5 & 74 & 102 \\ 2460 & 0.7943 & 31 & 5 & 90 & 121 \\ 2598 & 0.8040 & 28 & 6 & 69 & 97 \\ 2770 & 0.7853 & 23 & 5 & 84 & 107 \\ 2932 & 0.7803 & 50 & 18 & 77 & 127 \\ 3097 & 0.7700 & 60 & 5 & 91 & 151 \\ 3264 & 0.7879 & 43 & 12 & 75 & 118\end{array}$

soaked in $0.6-\mathrm{M} \mathrm{NaOH}$ aqueous solution followed by heating it for $4 \mathrm{hrs}$ at $950^{\circ} \mathrm{C}$, soaked in $4-w \%$ $\mathrm{KOH}$ followed by heating it for $2 \mathrm{~h}$ at $550^{\circ} \mathrm{C}$, and soaked in $0.5-\mathrm{w} \% \mathrm{MgCl}_{2}$ aqueous solution followed by heating it for $2 \mathrm{hrs}$ at $550^{\circ} \mathrm{C}$

removing no sulfur 


\section{CALCULATIONS}

Concentrations of $\mathrm{H}_{2} \mathrm{~S}$ and $\mathrm{COS}$ in the outlet stream from a monolithic catalyst reactor are analyzed by using a gas chromatograph equipped with a flame photometric detector (FPD) and a thermal conductivity detector (TCD), and a calibration curve. A calibration curve for $\mathrm{H}_{2} \mathrm{~S}$ is developed with three $\mathrm{H}_{2} \mathrm{~S}$ samples in different concentrations such as 4,980 ppmv, $996 \mathrm{ppmv}$, and 249 ppmv, whereas a calibration curve for COS is developed with three COS samples in different concentrations such as 45 ppmv, 30 ppmv, and 15 ppmv.

Each experimental reaction run proceeds after a blank run, which is carried out in the absence of moisture and monolithic catalyst in a reactor. Conversions of $\mathrm{H}_{2} \mathrm{~S}$ are obtained with concentrations of $\mathrm{H}_{2} \mathrm{~S}$ from a reaction run and those from its blank run, as shown in the following equation.

$$
x=\frac{\left(C_{B}-C_{R}\right)}{C_{B}}
$$

where $x$ : conversion of $\mathrm{H}_{2} \mathrm{~S}$.

$C_{\mathrm{B}}$ : concentration of $\mathrm{H}_{2} \mathrm{~S}$ in the outlet stream for a blank run.

$C_{\mathrm{R}}$ : concentration of $\mathrm{H}_{2} \mathrm{~S}$ in the outlet stream for a reaction run

Elemental sulfur is formed with the following reversible stoichiometric reaction formula, as shown in Equation (2). COS is formed in the presence of moisture and catalyst according to the reversible stoichiometric reaction formula, as shown in Equation (3) and Equation (4), which is obtained by adding Equation (2) to Equation (3) multiplied by 3, whereas COS is formed in the absence of moisture and catalyst according to the reversible stoichiometric reaction formula, as shown in Equation (5).

$$
\begin{aligned}
& 2 \mathrm{H}_{2} \mathrm{~S}+\mathrm{SO}_{2} \leftrightarrow 3 \mathrm{~S}+2 \mathrm{H}_{2} \mathrm{O} \\
& \mathrm{CO}+\mathrm{S} \leftrightarrow \mathrm{COS} \\
& 2 \mathrm{H}_{2} \mathrm{~S}+\mathrm{SO} 2+3 \mathrm{CO} \leftrightarrow 3 \mathrm{COS}+2 \mathrm{H}_{2} \mathrm{O} \\
& \mathrm{CO}+\mathrm{H}_{2} \mathrm{~S} \leftrightarrow \mathrm{COS}+\mathrm{H}_{2}
\end{aligned}
$$

\section{RESULTS AND DISCUSSION}

Experiments on conversion of hydrogen sulfide into element sulfur were carried out over the space time range of $130-156$ seconds at $120-140^{\circ} \mathrm{C}$ (see Table 3 ) to formulate catalysts suitable for the removal of $\mathrm{H}_{2} \mathrm{~S}$ and $\mathrm{COS}$ from coal gases, evaluate removal capabilities of hydrogen sulfide and COS from coal gases with formulated catalysts, and develop an economic regeneration method of deactivated catalysts. Catalysts were formulated by soaking $\gamma$-alumina wash-coated monolithic catalyst supports in catalytically active additive aqueous solutions followed by heating them under air environment at elevated temperatures. Simulated coal gas mixtures consist of 3,300 - 3,800 ppmv hydrogen sulfide, 1,600 - 1,900 ppmv sulfur dioxide, 29 $-34 \mathrm{v} \% \mathrm{CO}, 18-21 \mathrm{v} \%$ hydrogen, $5-18 \mathrm{vol} \%$ moisture, $8-10 \mathrm{v} \% \mathrm{CO}_{2}$, and nitrogen as remainder. Volumetric feed rates of a simulated coal gas mixture to a monolithic catalyst reactor are $130-156 \mathrm{~cm}^{3} / \mathrm{min}$ at room temperature and atmospheric pressure (SCCM). The temperature 
of the reactor is controlled in an oven at $120-140^{\circ} \mathrm{C}$. The pressure of the reactor is maintained at $116-129$ psia. Elemental sulfur deposited on a monolithic catalyst is removed with nitrogen at $140-270^{\circ} \mathrm{C}$ overnight.

\section{Effects of Temperature on Conversion of $\mathrm{H}_{2} \mathrm{~S}$ into Elemental Sulfur and formation of COS}

Experiments on conversion of hydrogen sulfide to elemental sulfur and formation of COS with a 2 -cm-diameter 15 -cm-long $\gamma$-alumina wash-coated 400 -cells/inch ${ }^{2}$ monolithic catalyst were carried out over the space time range of 135 - $149 \mathrm{~s}$ to evaluate effects of reaction temperature on conversion of hydrogen sulfide to elemental sulfur and formation of COS at 120 $140^{\circ} \mathrm{C}$ and $117-124$ psia, using quadruple experimental data. Gas mixtures are fed to a monolithic catalyst reactor containing 3,600-ppmv $\mathrm{H}_{2} \mathrm{~S}, 1,800$ ppmv $\mathrm{SO}_{2}, 32-\mathrm{v} \% \mathrm{CO}, 20$-v\% hydrogen, $10-\mathrm{v} \%$ moisture, $9-\mathrm{v} \% \mathrm{CO}_{2}$, and nitrogen as remainder. Volumetric feed rates of gas mixtures to the monolithic catalyst reactor are $120 \mathrm{SCCM}$. Conversion of $\mathrm{H}_{2} \mathrm{~S}$ to elemental sulfur is $0.50-0.82$.

Conversion of $\mathrm{H}_{2} \mathrm{~S}$ to elemental sulfur does not follow the Arrhenius' equation, although conversion of $\mathrm{H}_{2} \mathrm{~S}$ to elemental sulfur increases with increased reaction temperature over the temperature range of $120-140^{\circ} \mathrm{C}$ (see Figure 2).

Figure 2. Effects of temperature on conversion of $\mathrm{H}_{2} \mathrm{~S}$ to elemental sulfur and formation of COS with a 120-SCCM feed stream containing 3,600-ppmv $\mathrm{H}_{2} \mathrm{~S}, 1,800-\mathrm{ppmv} \mathrm{SO}_{2}, 32-\mathrm{v} \% \mathrm{CO}, 20-\mathrm{v} \%$ $\mathrm{H}_{2}, 9-\mathrm{v} \% \mathrm{CO}_{2}$ and $10-\mathrm{v} \%$ moisture at $120-140^{\circ} \mathrm{C}, 117-124$ psia and $135-149$ s space time, removing elemental sulfur from a $\gamma$-alumina wash-coated monolithic catalyst with $\mathrm{N}_{2}$ overnight.

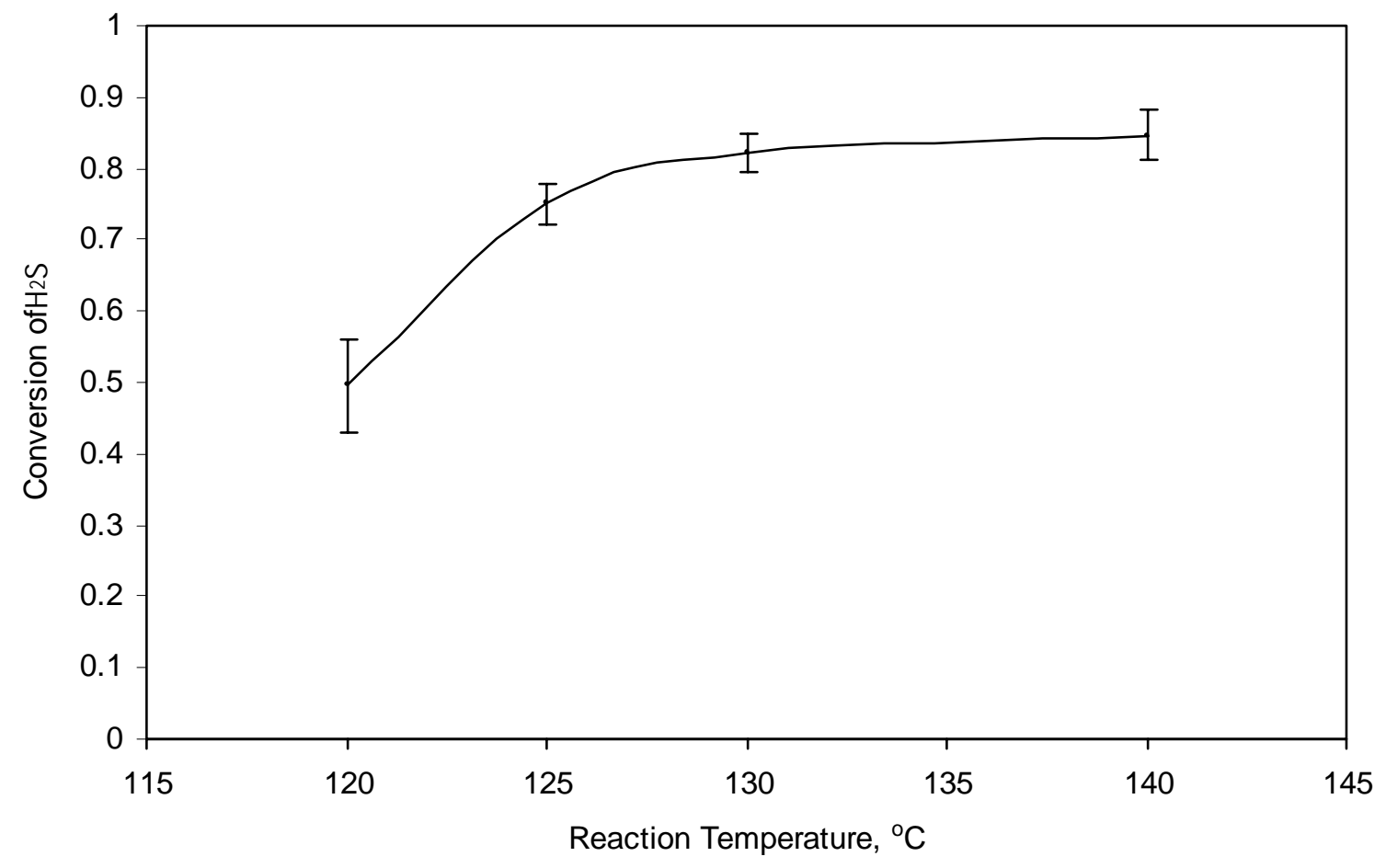




\section{Effects of Catlayst Aging on Conversion of $\mathrm{H}_{2} \mathrm{~S}$ into Elemental Sulfur and formation of COS}

Experiments on conversion of hydrogen sulfide to elemental sulfur and formation of COS with a 2 -cm-diameter 15 -cm-long $\gamma$-alumina wash-coated 400 -cells/inch ${ }^{2}$ monolithic catalyst were carried out over the space time range of 130 - $154 \mathrm{~s}$ to evaluate effects of catalyst aging on conversion of hydrogen sulfide to elemental sulfur and formation of COS at $125^{\circ} \mathrm{C}$ and $116-$ 122 psia. Gas mixtures are fed to a monolithic catalyst reactor containing 3,300-3,800-ppmv $\mathrm{H}_{2} \mathrm{~S}, 1,600$ - 1,900 ppmv $\mathrm{SO}_{2}, 29$ - 34-v\% CO, 18 - 21-v\% hydrogen, 5 -18-v\% moisture, 8 - 10 $\mathrm{v} \% \mathrm{CO}_{2}$, and nitrogen as remainder. Volumetric feed rates of gas mixtures to the monolithic catalyst reactor are 114 - 132 SCCM. A $\gamma$-alumina wash-coated 400-cells/inch ${ }^{2}$ monolithic catalyst support is soaked in $1-\mathrm{w} \% \mathrm{Zn}$ aqueous solution and heated for 4 hours at $450^{\circ} \mathrm{C}$. Elemental sulfur was removed from the catalyst with $\mathrm{N}_{2}$ at $140^{\circ} \mathrm{C}$ overnight. Conversion of $\mathrm{H}_{2} \mathrm{~S}$ to elemental sulfur is $0.58-0.95$.

Figure 3. Effects of catalyst aging on conversion of $\mathrm{H}_{2} \mathrm{~S}$ and formation of $\mathrm{COS}$ with a $\gamma$-alumina wash-coated catalyst support soaked in 1-w\% $\mathrm{Zn}$ aqueous solution followed by heating it for 4 hours at $450^{\circ} \mathrm{C}$, removing elemental sulfur from the catalyst with $\mathrm{N}_{2}$ overnight at $140^{\circ} \mathrm{C}$.

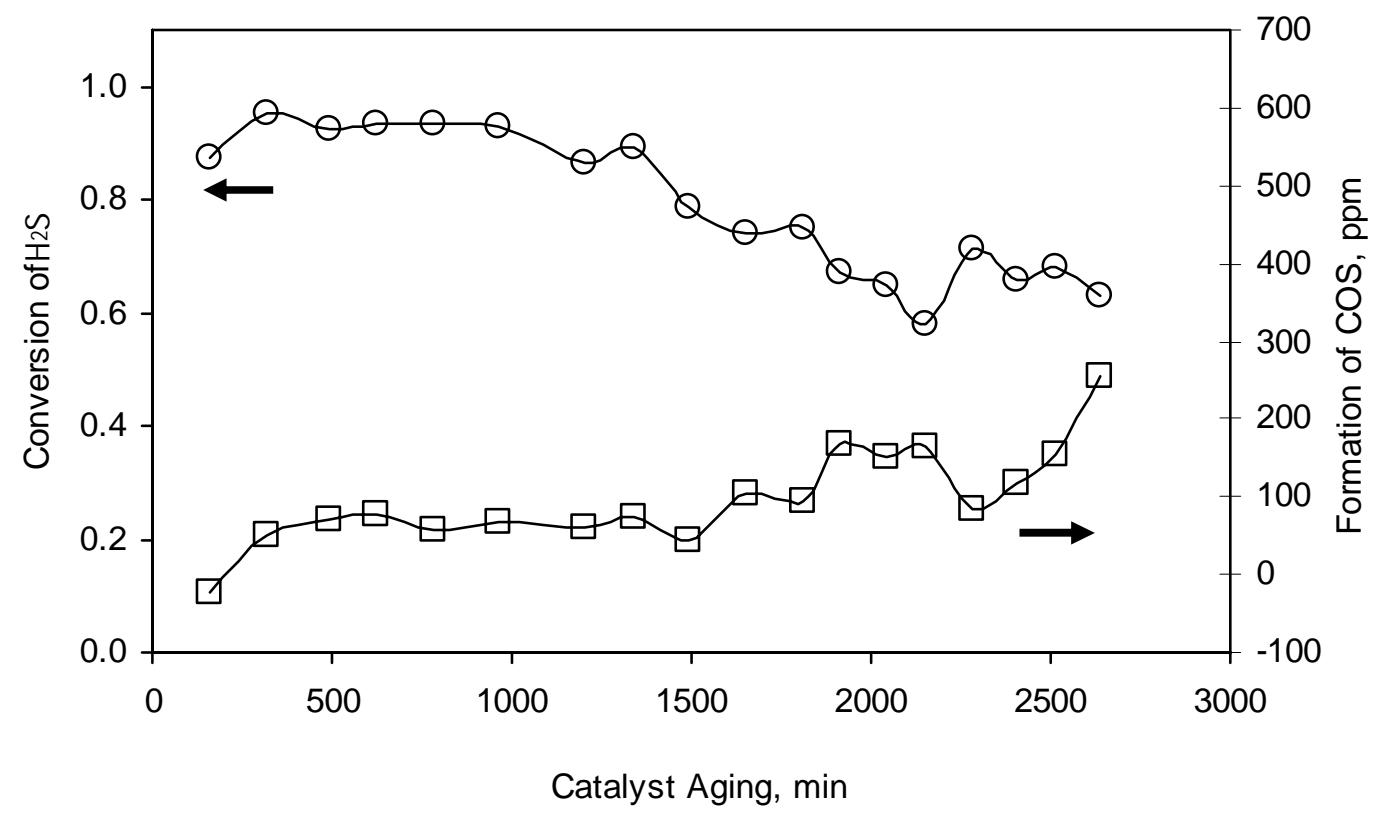

Conversion of $\mathrm{H}_{2} \mathrm{~S}$ into elemental sulfur and formation of COS are constant up to 1,400min catalyst aging. Thereafter, conversion of $\mathrm{H}_{2} \mathrm{~S}$ into elemental sulfur decreases with increased catalyst aging, while formation of COS increases with increased catalyst aging, as shown in Figure 3.

\section{Temperature Effects of Removing Elemental Sulfur from a Catalyst on Conversion of $\mathrm{H}_{2} \mathrm{~S}$ and formation of COS.}

Conversion of $\mathrm{H}_{2} \mathrm{~S}$ into elemental sulfur and formation of COS decrease with increased temperature at which elemental sulfur is removed from the catalyst soaked with $1-\mathrm{w} \% \mathrm{Zn}$ aqueous solution followed by heating it for 4 hours at $450^{\circ} \mathrm{C}$ (see Figure 4). 
Figure 4. Effects of removal temperature of elemental sulfur attached to a $\gamma$-alumina wash-coated catalyst on conversion of $\mathrm{H}_{2} \mathrm{~S}$ and formation of COS with the monolithic catalyst support soaked in $1-\mathrm{w} \% \mathrm{Zn}$ aqueous solution followed by heating it for 4 hours at $450^{\circ} \mathrm{C}$, removing elemental sulfur from the catalyst with $\mathrm{N}_{2}$ overnight.

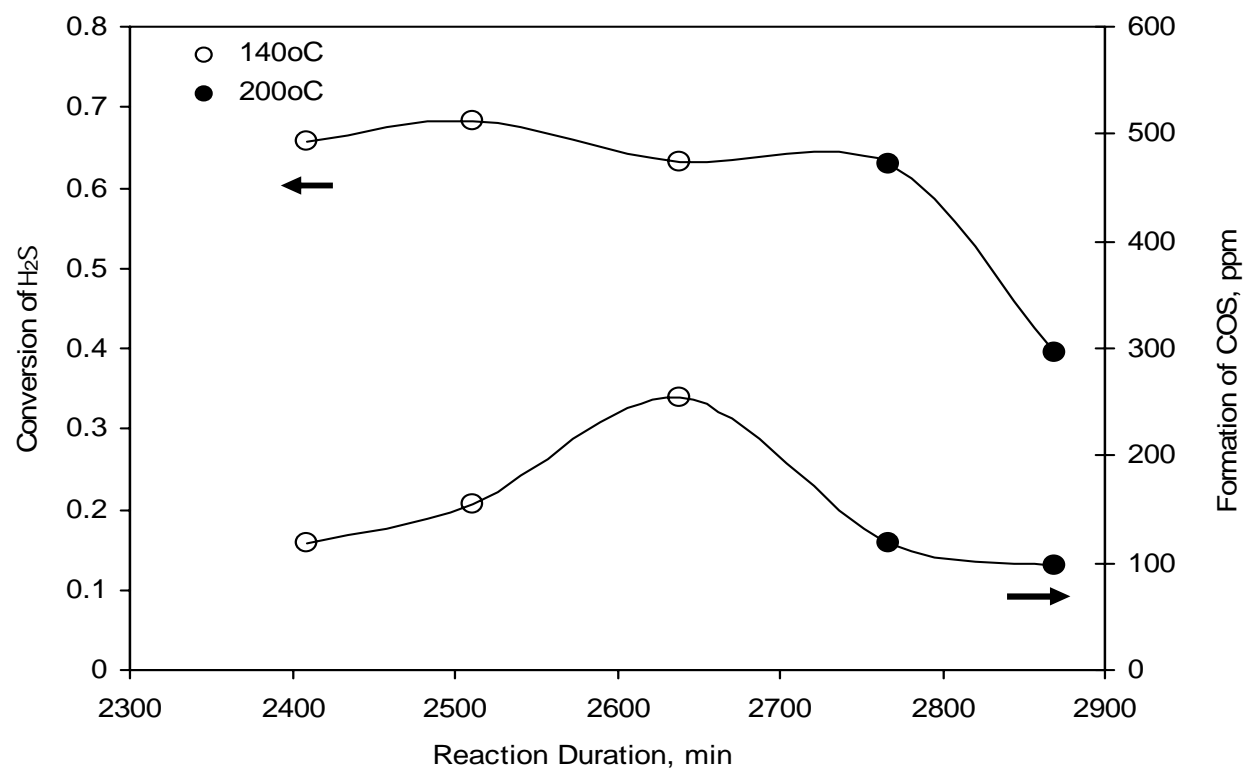

\section{Effects of Sulfur Removal from a Zn-treated Monolithic Catalyst on Conversion of $\mathrm{H}_{2} \mathrm{~S}$ and Formation of COS}

Figure 5. Effects of sulfur removal from a $\gamma$-alumina wash-coated monolithic catalyst on conversion of $\mathrm{H}_{2} \mathrm{~S}$ and formation of COS with the catalyst support soaked with $1-\mathrm{w} \% \mathrm{Zn}$ aqueous solution followed by heating it for 4 hours at $450^{\circ} \mathrm{C}$, removing elemental sulfur from the catalyst with $\mathrm{N}_{2}$ at $200^{\circ} \mathrm{C}$ overnight.

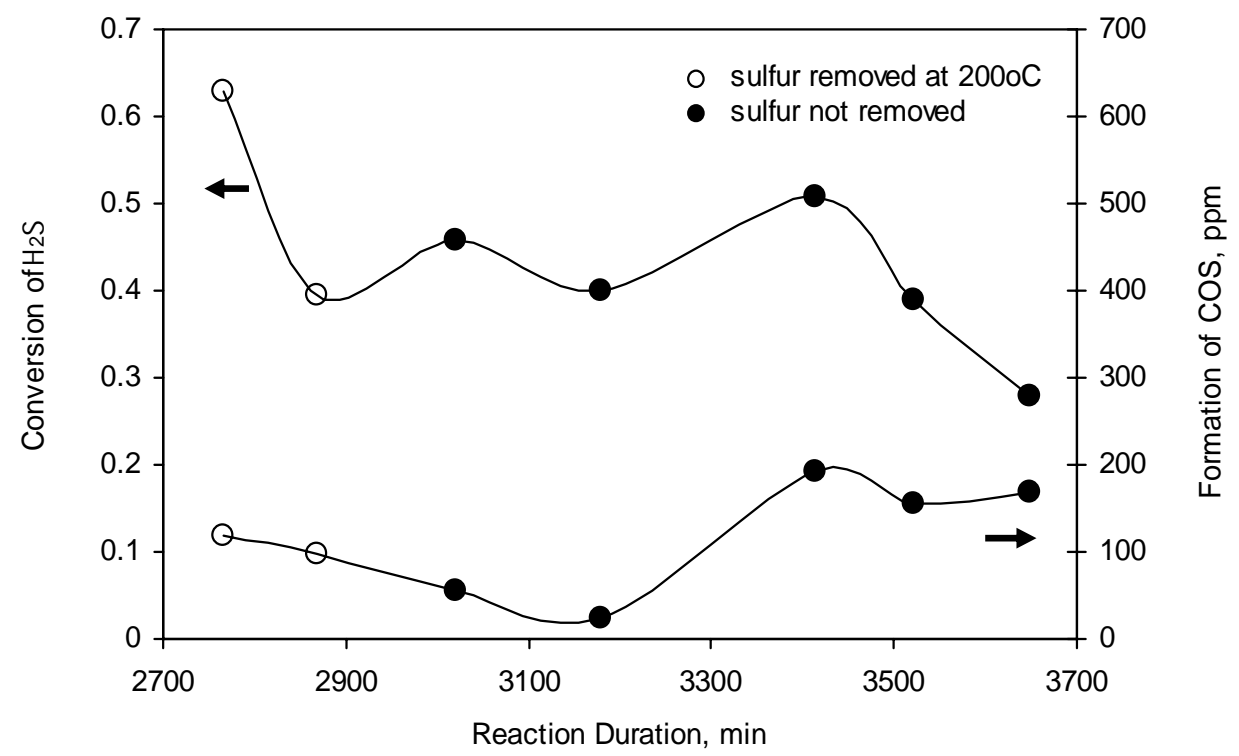


A $\gamma$-alumina wash-coated catalyst support was soaked in 1-w\% Zn aqueous solution followed by heating it for 4 hours at $450^{\circ} \mathrm{C}$ to increase conversion of $\mathrm{H}_{2} \mathrm{~S}$ into elemental sulfur and decrease formation of COS. Elemental sulfur was removed from the catalyst by heating the catalyst with $\mathrm{N}_{2}$ at $200^{\circ} \mathrm{C}$ overnight. Conversion of $\mathrm{H}_{2} \mathrm{~S}$ into elemental sulfur seems to be higher on removing elemental sulfur from the catalyst than leaving elemental sulfur on the catalyst. Formation of COS seems to lower on removing elemental sulfur from the catalyst than leaving elemental sulfur on the catalyst.

\section{Effects of Soaking a Zn-Treated Catalyst in $\mathrm{NaOH}$ Aqueous Solution on Conversion of $\mathrm{H}_{2} \mathrm{~S}$ and Formation of COS}

Figure 6. Effects of soaking a catalyst in $\mathrm{NaOH}$ aqueous solution on conversion of $\mathrm{H}_{2} \mathrm{~S}$ and formation of COS with the $\gamma$-alumina wash-coated monolithic catalyst support soaked in 1-w\% $\mathrm{Zn}$ aqueous solution followed by heating it for $4 \mathrm{hrs}$ at $450^{\circ} \mathrm{C}$

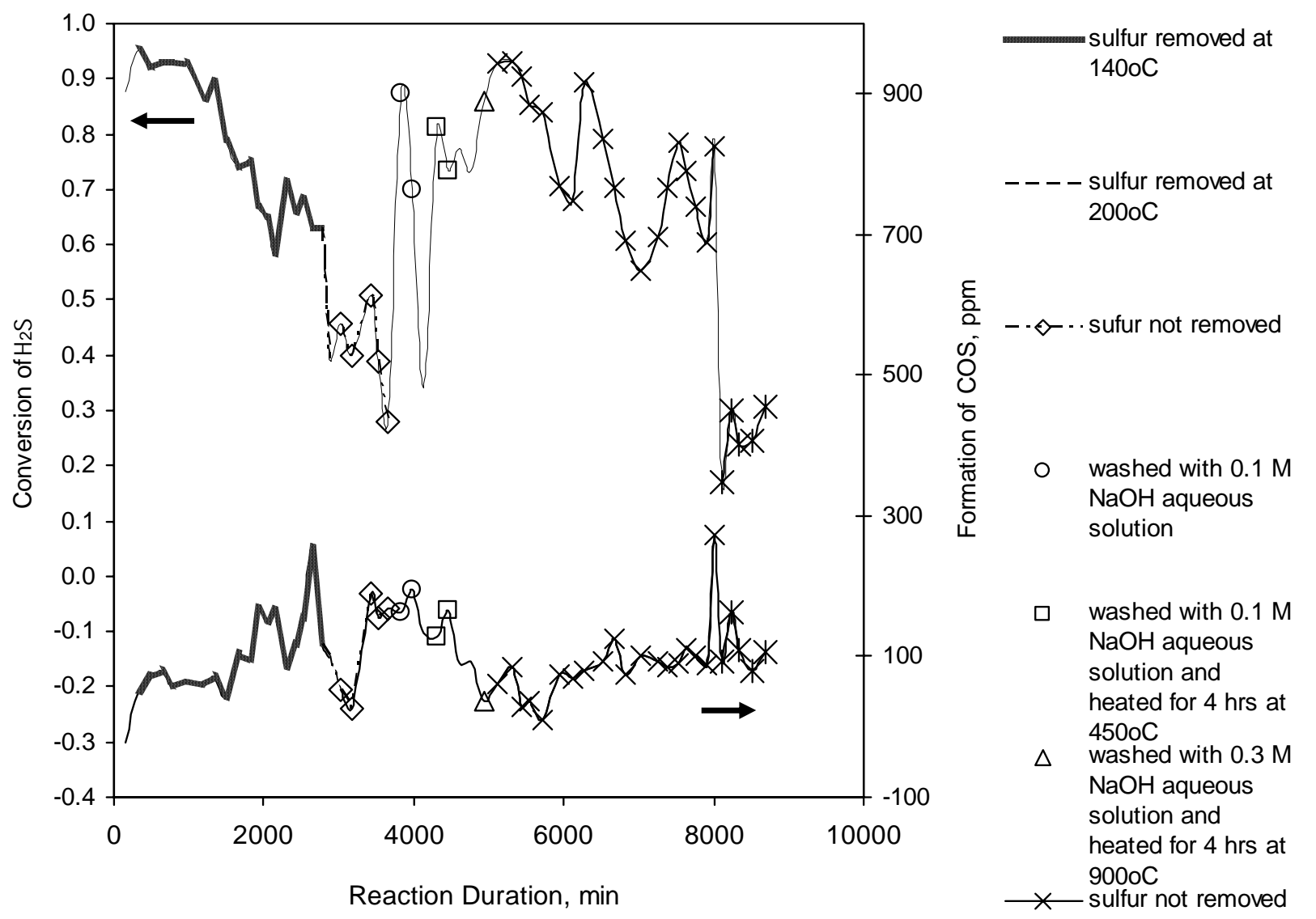

A $\gamma$-alumina wash-coated catalyst support was soaked with 1-w\% Zn aqueous solution followed by heating it for 4 hours at $450^{\circ} \mathrm{C}$ to increase conversion of $\mathrm{H}_{2} \mathrm{~S}$ into elemental sulfur and decrease formation of COS. Conversion of $\mathrm{H}_{2} \mathrm{~S}$ into elemental sulfur decreases and formation of COS increases with increased catalyst aging, although elemental sulfur was removed from the catalyst by heating the catalyst with $\mathrm{N}_{2}$ at either 140 or $200^{\circ} \mathrm{C}$ overnight.

The catalyst was washed in $0.1-\mathrm{M} \mathrm{NaOH}$ aqueous solution overnight followed by heating it for $4 \mathrm{hrs}$ at $450^{\circ} \mathrm{C}$ and then washed in $0.3-\mathrm{M} \mathrm{NaOH}$ aqueous solution overnight followed by heating it for $4 \mathrm{hrs}$ at $900^{\circ} \mathrm{C}$ for the regeneration of the deactivated catalyst. Effects of washing 
the catalyst in $\mathrm{NaOH}$ aqueous solution overnight followed by heating it for $4 \mathrm{hrs}$ at $450^{\circ} \mathrm{C}$ and then for $4 \mathrm{hrs}$ at $900^{\circ} \mathrm{C}$ on conversion of $\mathrm{H}_{2} \mathrm{~S}$ into elemental sulfur are pronounced and longlived, although elemental sulfur was not removed from the catalyst by heating it overnight, as shown in Figure 6.

\section{Effects of Removing Elemental Sulfur from a Zn-Treated and NaOH-Regenerated Catalyst on Conversion of $\mathrm{H}_{2} \mathrm{~S}$ and Formation of COS.}

A catalyst washed in $0.1-\mathrm{M} \mathrm{NaOH}$ aqueous solution overnight followed by heating it for $4 \mathrm{hrs}$ at $450^{\circ} \mathrm{C}$ and then washed in $0.3-\mathrm{M} \mathrm{NaOH}$ aqueous solution overnight followed by heating it for $4 \mathrm{hrs}$ at $900^{\circ} \mathrm{C}$ for the regeneration of the catalyst was used for the removal of $\mathrm{H}_{2} \mathrm{~S}$ without removing elemental sulfur from the catalyst overnight by heating it for the 3,000 min reaction duration. Thereafter, elemental sulfur was removed from the catalyst by heating it overnight at $200^{\circ} \mathrm{C}$. Conversion of $\mathrm{H}_{2} \mathrm{~S}$ into elemental sulfur decreases drastically upon removing elemental sulfur from the catalyst, as shown in Figure 7. This observation may suggest that the elemental sulfur deposited on the catalyst play a catalytic role in removing $\mathrm{H}_{2} \mathrm{~S}$ from the catalyst.

Figure 7. Effects of removing elemental sulfur from a catalyst on conversion of $\mathrm{H}_{2} \mathrm{~S}$ and formation of COS with the $\gamma$-alumina wash-coated catalyst support soaked in $1-\mathrm{w} \% \mathrm{Zn}$ aqueous solution followed by heating it for 4 hours at $450^{\circ} \mathrm{C}$, and washed in $0.3 \mathrm{M} \mathrm{NaOH}$ aqueous solution followed by heating it for $4 \mathrm{hrs}$ at $900^{\circ} \mathrm{C}$, removing sulfur from the catalyst with $\mathrm{N}_{2}$ at $200^{\circ} \mathrm{C}$ overnight.

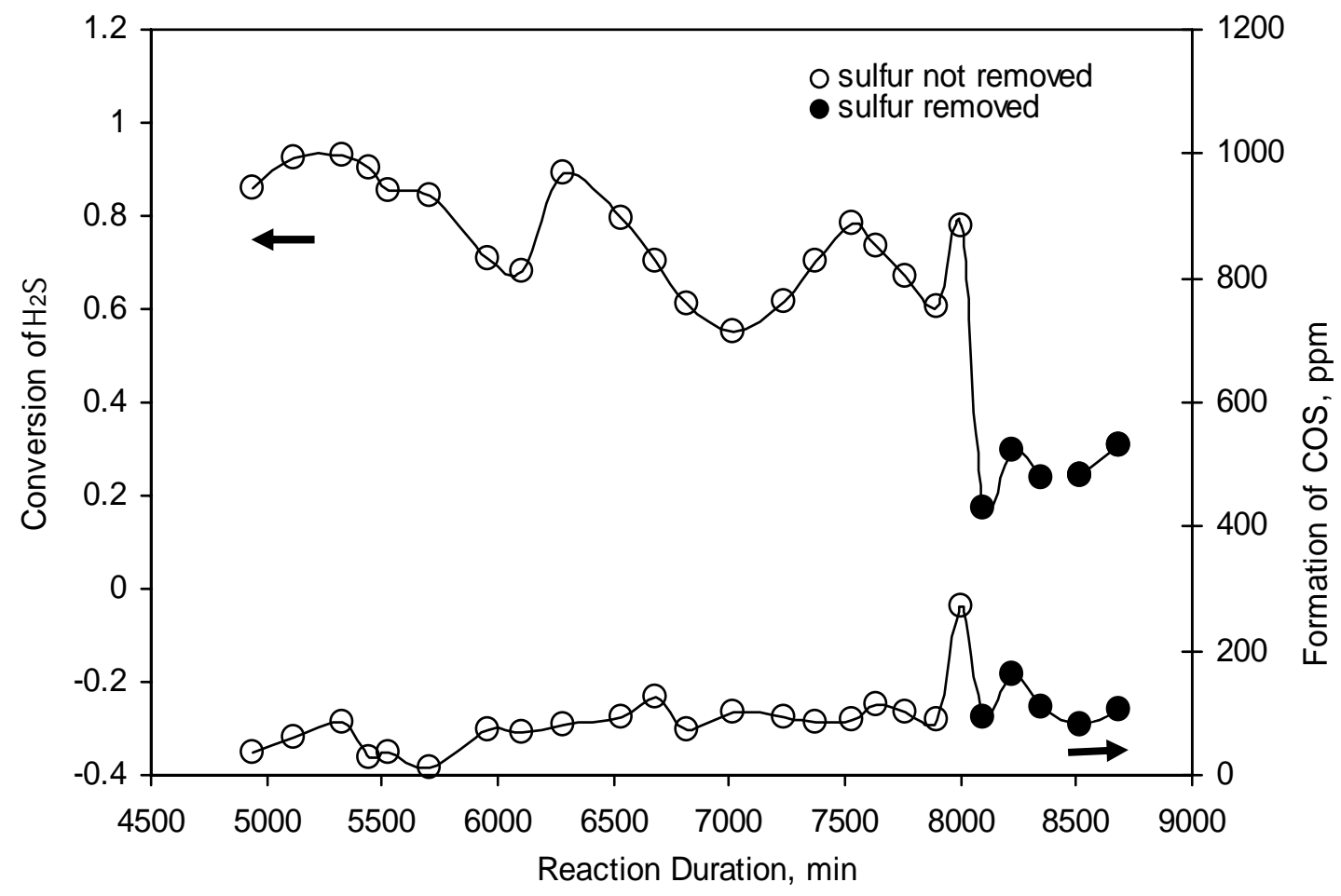




\section{Effects of Washing a Catalyst in $\mathrm{NaOH}$ Aqueous Solution on Conversion of $\mathrm{H}_{2} \mathrm{~S}$ and Formation of COS}

Catalysts are mainly deactivated by liquid elemental sulfur deposition below the dew temperature of elemental sulfur, carbon deposition, aluminum sulfate formation, and catalyst aging. Catalysts are washed in $\mathrm{NaOH}$ aqueous solutions to dissolve alumina sulfate or other water-soluble substances on catalyst surfaces. Catalysts are heated at elevated temperatures to remove elemental sulfur from catalysts by vaporizing it.

Effects of washing a $\gamma$-alumina wash-coated catalyst support in $0.1-\mathrm{M} \mathrm{NaOH}$ aqueous solution, washing the catalyst support in $0.2-\mathrm{M} \mathrm{NaOH}$ aqueous solution followed by heating it for $4 \mathrm{hrs}$ at $450^{\circ} \mathrm{C}$, and washing the catalyst in $0.3-\mathrm{M} \mathrm{NaOH}$ aqueous solution followed by heating it for 1.5 hrs at $900^{\circ} \mathrm{C}$ on conversion of $\mathrm{H}_{2} \mathrm{~S}$ into elemental sulfur are short-lived. However, effects of washing the catalyst in $0.4-\mathrm{M} \mathrm{NaOH}$ aqueous solution followed by heating it for $4 \mathrm{hrs}$ at $900^{\circ} \mathrm{C}$ on conversion of $\mathrm{H}_{2} \mathrm{~S}$ into elemental sulfur is long-lived, as shown in Figure 8.

Figure 8. Effects of washing a $\gamma$-alumina wash-coated monolithic catalyst support in $\mathrm{NaOH}$ aqueous solution on conversion of $\mathrm{H}_{2} \mathrm{~S}$ and formation of $\mathrm{COS}$.

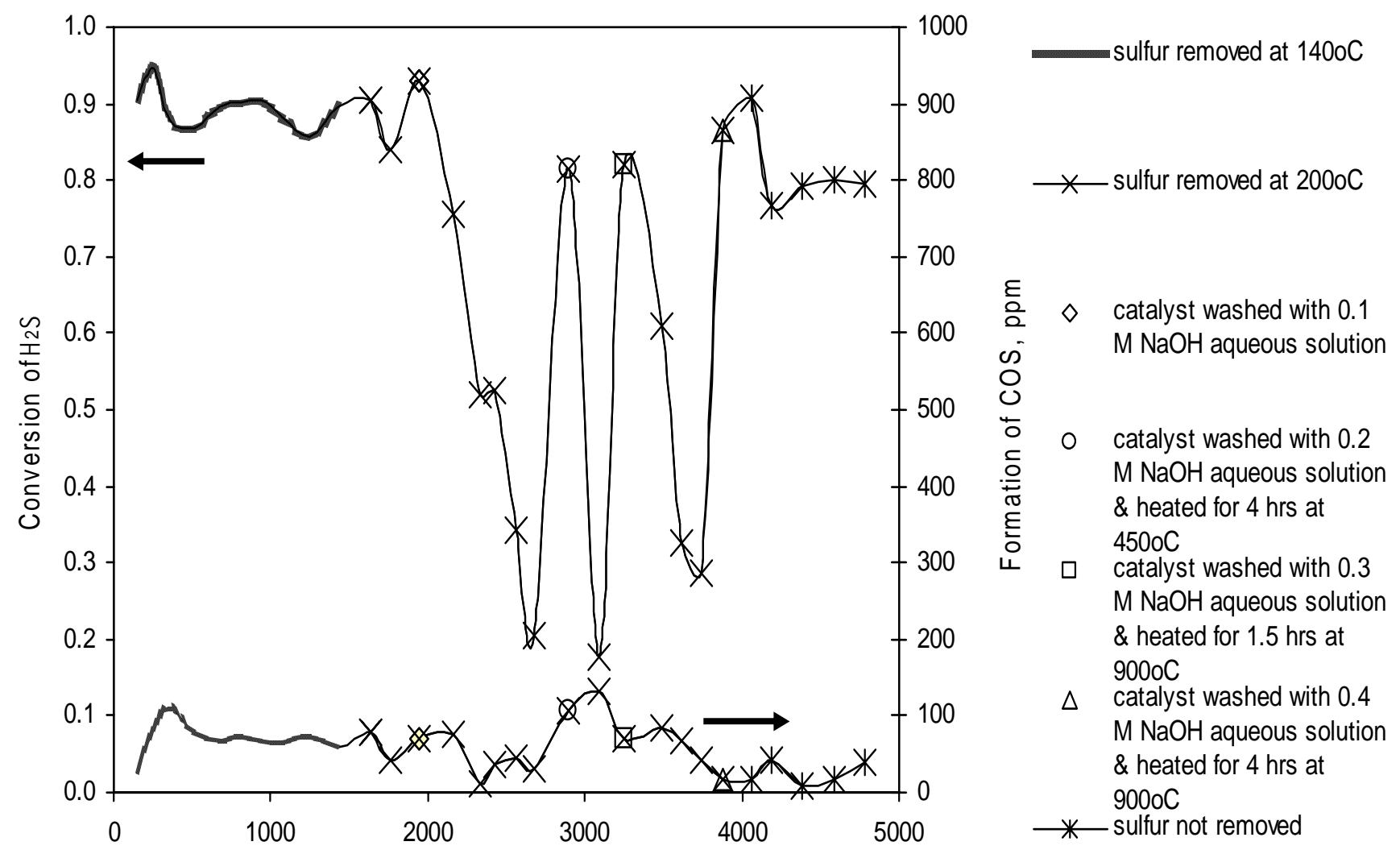

Reaction Duration, min 


\section{Effects of Soaking a Catalyst in Zn Aqueous Solution and then KOH Aqueous Solution on Conversion of $\mathrm{H}_{2} \mathrm{~S}$ and Formation of $\mathrm{COS}$}

A $\gamma$-alumina catalyst support was soaked in $4-w \% \mathrm{Zn}$ aqueous solution followed by heating it for $4 \mathrm{hrs}$ at $600^{\circ} \mathrm{C}$, and then soaked in $4-\mathrm{w} \% \mathrm{KOH}$ aqueous solution followed by heating it for $4 \mathrm{hrs}$ at $550^{\circ} \mathrm{C}$ to increase conversion of $\mathrm{H}_{2} \mathrm{~S}$ and reduce formation of COS. Elemental sulfur deposited on the catalyst is not removed. Effects of soaking the catalyst with $\mathrm{Zn}$ and $\mathrm{KOH}$ aqueous solutions on conversion of $\mathrm{H}_{2} \mathrm{~S}$ seem to be good initially. However, effects of soaking the catalyst in $\mathrm{Zn}$ and $\mathrm{KOH}$ aqueous solutions on formation of COS seem to be shortlived by changing formation of COS from negative to positive, as shown in Figure 9.

Figure 9. Conversion of $\mathrm{H}_{2} \mathrm{~S}$ and formation of $\mathrm{COS}$ with a $\gamma$-alumina wash-coated monolithic catalyst support, soaked in $4-\mathrm{w} \% \mathrm{Zn}$ aqueous solution followed by heating it for $4 \mathrm{hrs}$ at $600^{\circ} \mathrm{C}$, and then soaked in $4-\mathrm{w} \% \mathrm{KOH}$ aqueous solution followed by heating it for $4 \mathrm{hrs}$ at $550^{\circ} \mathrm{C}$.

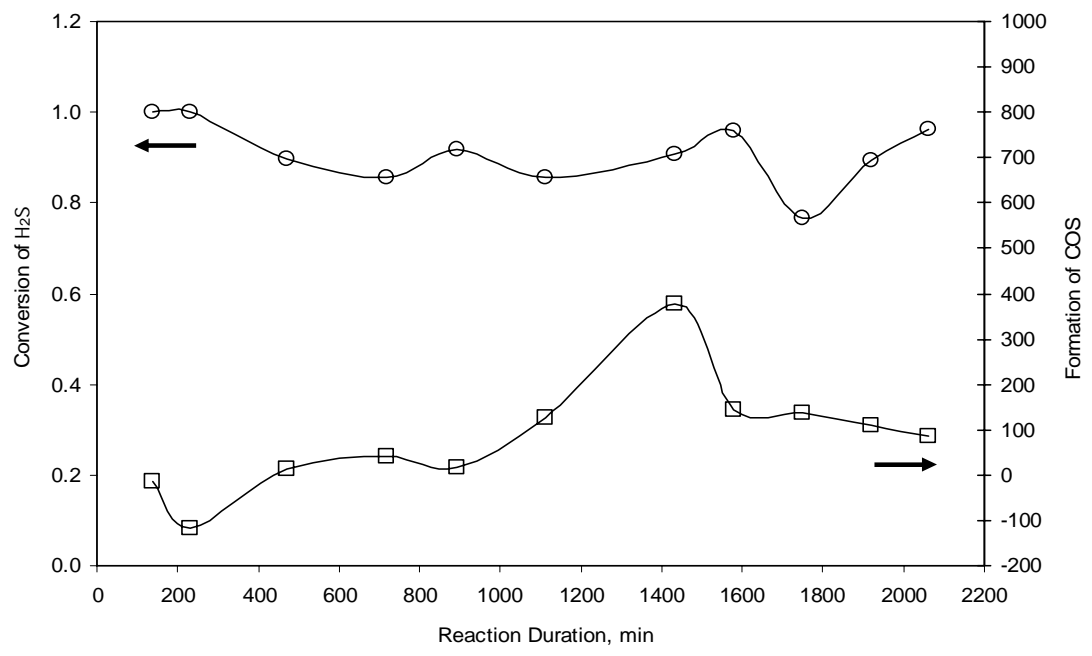

Figure 10. Conversion of $\mathrm{H}_{2} \mathrm{~S}$ and formation of $\mathrm{COS}$ with a $\gamma$-alumina wash-coated monolithic catalyst support soaked with $4-\mathrm{w} \% \mathrm{KOH}$ aqueous solution followed by heating it for $4 \mathrm{hrs}$ at $550^{\circ} \mathrm{C}$

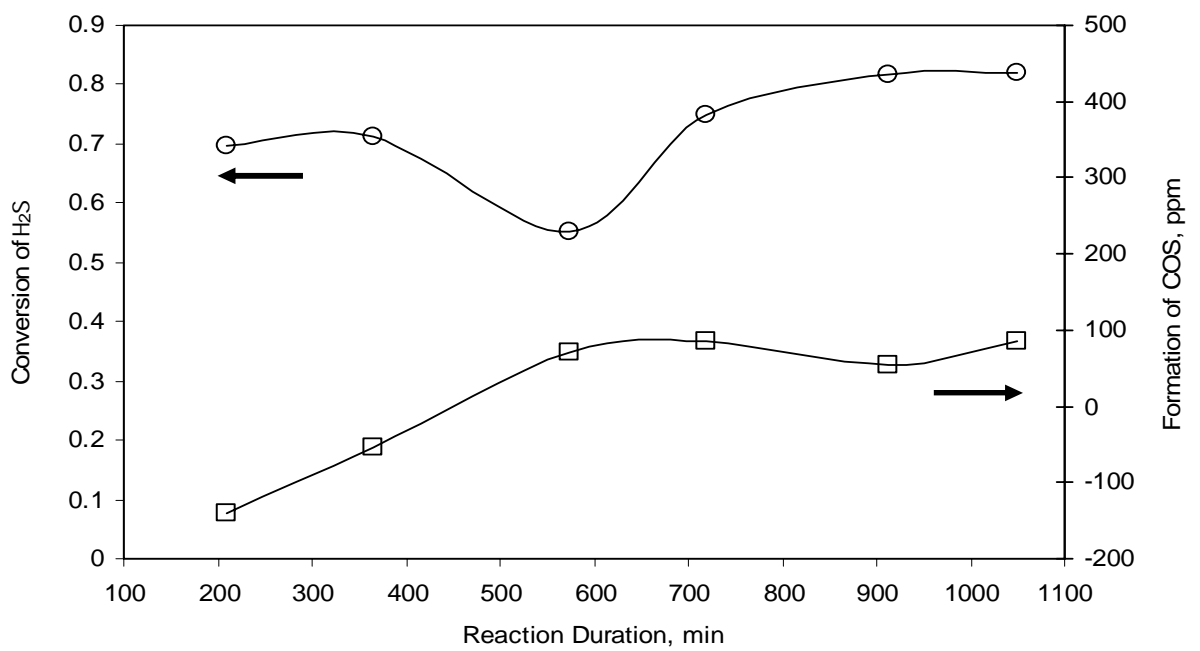


A catalyst support was soaked in 4-w\% $\mathrm{KOH}$ aqueous solution followed by heating it for $4 \mathrm{hrs}$ at $550^{\circ} \mathrm{C}$. Effects of soaking the catalyst in $\mathrm{KOH}$ aqueous solutions on conversion of $\mathrm{H}_{2} \mathrm{~S}$ are good initially. However, favorable effects of soaking the catalyst in $\mathrm{KOH}$ aqueous solution on formation of COS seem to be short-lived, as shown in Figure 10. Conversion of $\mathrm{H}_{2} \mathrm{~S}$ into elemental sulfur is much higher with the catalyst soaked in $\mathrm{Zn}$ and $\mathrm{KOH}$ aqueous solutions than that in $\mathrm{KOH}$ aqueous solution only (see Figures 9 and 10).

\section{Effects of Soaking a Catalyst in $\mathrm{Fe}^{3+}$ Aqueous Solution on Conversion of $\mathrm{H}_{2} \mathrm{~S}$ and Formation of COS}

A $\gamma$-alumina wash-coated catalyst support was soaked in $2-\mathrm{w} \% \mathrm{Fe}^{3+}$ aqueous solution followed by heating it for $4 \mathrm{hrs}$ at $550^{\circ} \mathrm{C}$. Conversion of $\mathrm{H}_{2} \mathrm{~S}$ drastically decreases with increased reaction duration with removing sulfur from the catalyst with $\mathrm{N}_{2}$ at $270^{\circ} \mathrm{C}$, as shown in Figure 11.

Figure 11. Conversion of $\mathrm{H}_{2} \mathrm{~S}$ and formation of COS with a $\gamma$-alumina wash-coated monolithic catalyst support soaked in $2-\mathrm{w} \% \mathrm{Fe}^{3+}$ aqueous solution followed by heating it for $4 \mathrm{hrs}$ at $450^{\circ} \mathrm{C}$, removing elemental sulfur from the catalyst with $\mathrm{N}_{2}$ at $270^{\circ} \mathrm{C}$.

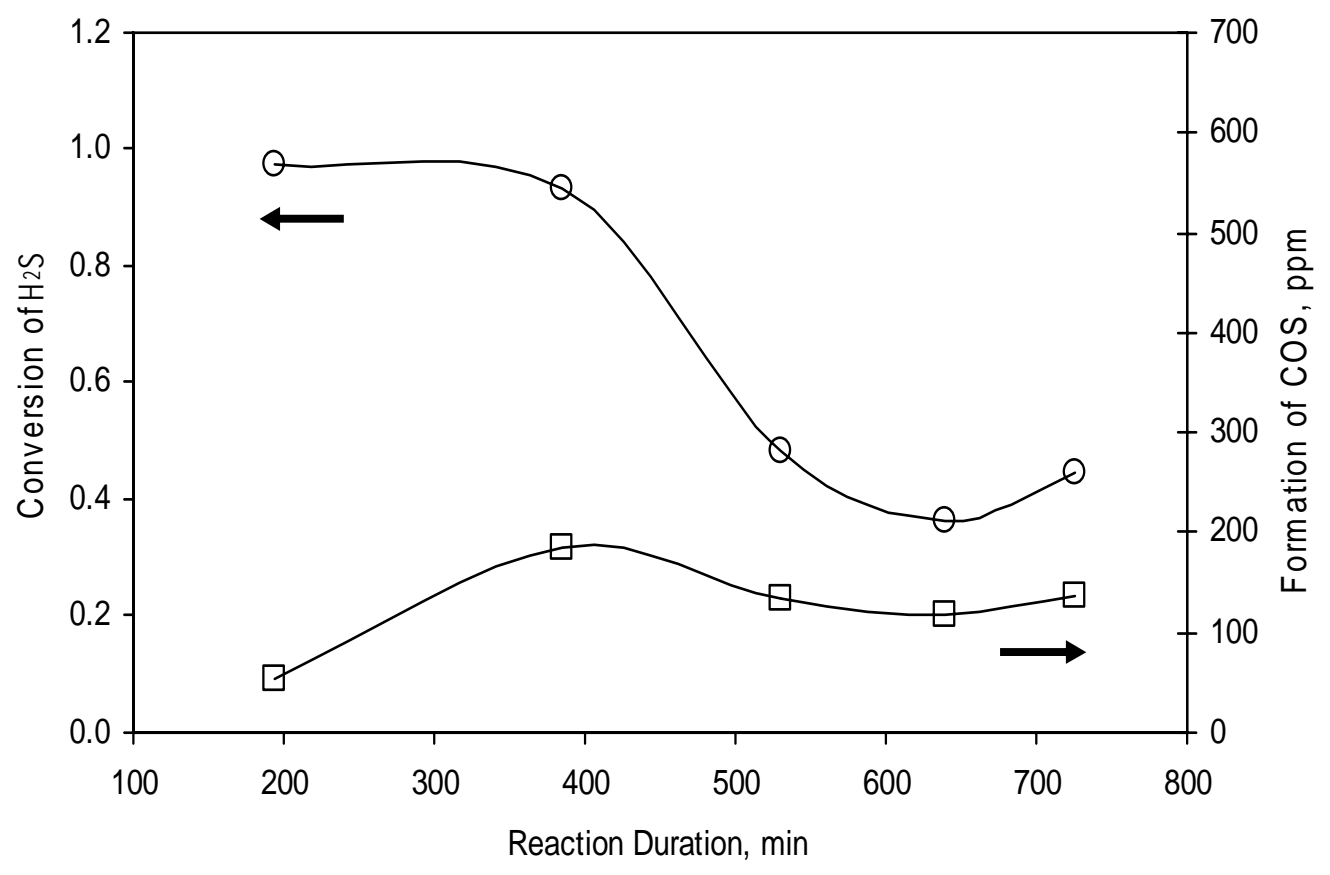

Conversion of $\mathrm{H}_{2} \mathrm{~S}$ drastically decreases and becomes negative with increased reaction duration with removing sulfur from the $2-\mathrm{w} \% \mathrm{Fe}^{3+}$ treated catalyst with $\mathrm{N}_{2}$ at $200^{\circ} \mathrm{C}$, as shown in Figure 12. This fact may suggest that $\mathrm{H}_{2} \mathrm{~S}$ be produced rather than removed from the simulated coal gas. Formation of COS is very high with the catalyst soaked in $2-\mathrm{w} \% \mathrm{Fe}^{3+}$ aqueous solution followed by heating it for $4 \mathrm{hrs}$ at $550^{\circ} \mathrm{C}$. 
Figure 12. Conversion of $\mathrm{H}_{2} \mathrm{~S}$ and formation of COS with a $\gamma$-alumina wash-coated monolithic catalyst support soaked in $2-\mathrm{w} \% \mathrm{Fe}^{3+}$ aqueous solution followed by heating it for $4 \mathrm{hrs}$ at $450^{\circ} \mathrm{C}$, removing sulfur from the catalyst with $\mathrm{N}_{2}$ at $200^{\circ} \mathrm{C}$ overnight.

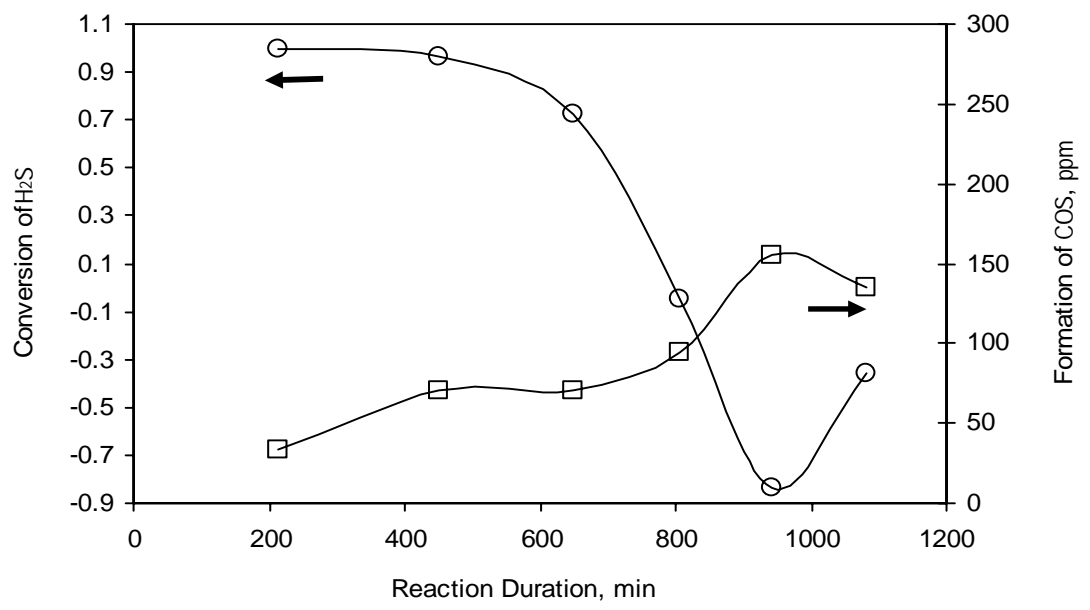

\section{Effects of Soaking a Catalyst in $\mathrm{NaOH}, \mathrm{KOH}$, and $\mathrm{MgCl}_{2} \mathrm{Aqueous}$ Solutions on Conversion of $\mathrm{H}_{2} \mathrm{~S}$ and Formation of $\mathrm{COS}$}

A $\gamma$-alumina wash-coated monolithic catalyst support was soaked in $0.6-\mathrm{M} \mathrm{NaOH}$ aqueous solution followed by heating it for $4 \mathrm{hrs}$ at $950^{\circ} \mathrm{C}$, soaked in $4-\mathrm{w} \% \mathrm{KOH}$ followed by heating it for $2 \mathrm{hrs}$ at $550^{\circ} \mathrm{C}$, and soaked in $0.5-\mathrm{w} \% \mathrm{MgCl}_{2}$ aqueous solution followed by heating it for $2 \mathrm{hrs}$ at $550^{\circ} \mathrm{C}$. Conversion of $\mathrm{H}_{2} \mathrm{~S}$ decreases and formation of COS increases with increased reaction duration, although elemental sulfur is removed from the catalyst throughout experiments.

Figure 13. Conversion of $\mathrm{H}_{2} \mathrm{~S}$ and formation of $\mathrm{COS}$ with a $\gamma$-alumina wash-coated monolithic catalyst support, soaked in $0.6-\mathrm{M} \mathrm{NaOH}$ aqueous solution followed by heating it for $4 \mathrm{hrs}$ at $950^{\circ} \mathrm{C}$, soaked in $4-\mathrm{w} \% \mathrm{KOH}$ followed by heating it for $2 \mathrm{~h}$ at $550^{\circ} \mathrm{C}$, and soaked in $0.5-\mathrm{w} \%$ $\mathrm{MgCl}_{2}$ aqueous solution by heating it for $2 \mathrm{hrs}$ at $550^{\circ} \mathrm{C}$, removing no sulfur.

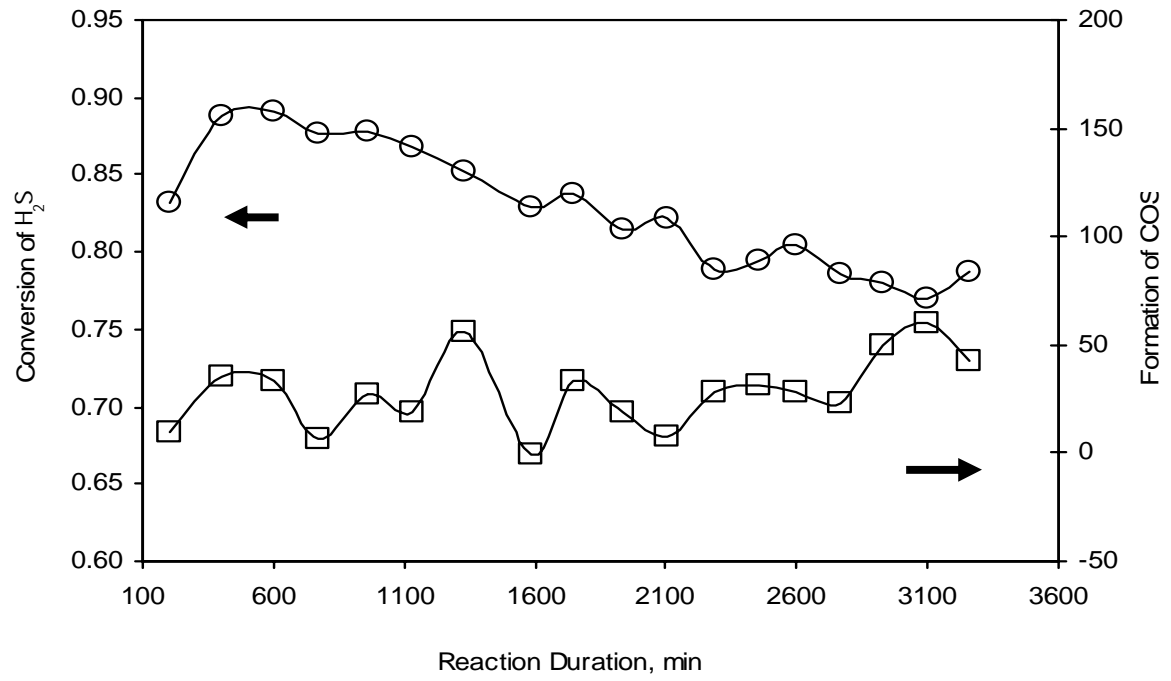




\section{CONCLUSIONS}

The following conclusions were drawn based on experimental data generated from the monolithic catalyst reactor system, and their interpretations. Each reaction experimental run proceeds after a blank experimental run, which is carried out in the absence of moisture and a monolithic catalyst.

Conversion of $\mathrm{H}_{2} \mathrm{~S}$ to elemental sulfur does not follow the Arrhenius' equation, although conversion of $\mathrm{H}_{2} \mathrm{~S}$ to elemental sulfur increases with increased reaction temperature over the temperature range of $120-140^{\circ} \mathrm{C}$. Conversion of $\mathrm{H}_{2} \mathrm{~S}$ into elemental sulfur and formation of COS decrease with increased temperature at which elemental sulfur is removed from the catalyst soaked with $1-\mathrm{w} \% \mathrm{Zn}$ aqueous solution followed by heating it for 4 hours at $450^{\circ} \mathrm{C}$.

Conversion of $\mathrm{H}_{2} \mathrm{~S}$ into elemental sulfur and formation of COS are constant up to 1,400min aging of the $1-\mathrm{w} \% \mathrm{Zn}$-treated $\gamma$-alumina wash-coated catalyst. Thereafter, conversion of $\mathrm{H}_{2} \mathrm{~S}$ into elemental sulfur decreases with increased catalyst aging, while formation of COS increases with increased catalyst aging. However, conversion of $\mathrm{H}_{2} \mathrm{~S}$ into elemental sulfur decreases and formation of COS increases with increased aging of the other 1-w\% Zn-treated catalyst, although elemental sulfur was removed from the catalyst by heating the catalyst with $\mathrm{N}_{2}$ at either 140 or $200^{\circ} \mathrm{C}$ overnight.

Effects of washing the deactivated $\mathrm{Zn}$-treated catalyst in $\mathrm{NaOH}$ aqueous solution overnight followed by heating it for $4 \mathrm{hrs}$ at $900^{\circ} \mathrm{C}$ on conversion of $\mathrm{H}_{2} \mathrm{~S}$ into elemental sulfur are pronounced and long-lived, although elemental sulfur was not removed from the catalyst by heating it overnight. Effects of washing the deactivated $\gamma$-alumina wash-coated support itself in $0.4-\mathrm{M} \mathrm{NaOH}$ aqueous solution followed by heating it for $4 \mathrm{hrs}$ at $900^{\circ} \mathrm{C}$ on conversion of $\mathrm{H}_{2} \mathrm{~S}$ into elemental sulfur also is long-lived.

Conversion of $\mathrm{H}_{2} \mathrm{~S}$ into elemental sulfur decreases drastically upon removing elemental sulfur from the catalyst treated with $\mathrm{NaOH}$ and $\mathrm{Zn}$ aqueous solutions. This observation may suggest that the elemental sulfur deposited on the catalyst play a catalytic role in removing $\mathrm{H}_{2} \mathrm{~S}$ from the catalyst.

Effects of soaking the catalyst with $\mathrm{Zn}$ and $\mathrm{KOH}$ aqueous solutions on conversion of $\mathrm{H}_{2} \mathrm{~S}$ seem to be good initially. However, effects of soaking the catalyst with $\mathrm{Zn}$ and $\mathrm{KOH}$ aqueous solutions on formation of COS seem to be short-lived by changing formation of COS from negative to positive. Effects of soaking the catalyst in $\mathrm{KOH}$ aqueous solution only on conversion of $\mathrm{H}_{2} \mathrm{~S}$ are good initially. However, favorable effects of soaking the catalyst in $\mathrm{KOH}$ aqueous solution on formation of COS seem to be short-lived. Conversion of $\mathrm{H}_{2} \mathrm{~S}$ into elemental sulfur is much higher with the catalyst soaked in $\mathrm{Zn}$ and $\mathrm{KOH}$ aqueous solutions than that in $\mathrm{KOH}$ aqueous solution only. Conversion of $\mathrm{H}_{2} \mathrm{~S}$ decreases and formation of $\mathrm{COS}$ increases with increased reaction duration with the catalyst treated with $\mathrm{NaOH}, \mathrm{KOH}$, and $\mathrm{MgCl}_{2}$, although Elemental sulfur deposited on the catalyst is not removed throughout experiments.

Conversion of $\mathrm{H}_{2} \mathrm{~S}$ drastically decreases with increased reaction duration with removing a sulfur from the $2-\mathrm{w} \% \mathrm{Fe}^{3+}$ treated catalyst with $\mathrm{N}_{2}$ at $270^{\circ} \mathrm{C}$. Conversion of $\mathrm{H}_{2} \mathrm{~S}$ drastically 
decreases and becomes negative with increased reaction duration with removing elemental sulfur from the $2-\mathrm{w} \% \mathrm{Fe}^{3+}$ treated catalyst with $\mathrm{N}_{2}$ at $200^{\circ} \mathrm{C}$. This fact may suggest that $\mathrm{H}_{2} \mathrm{~S}$ be produced rather than removed from the simulated coal gas. Formation of COS is very high with the catalyst soaked in $2-\mathrm{w} \% \mathrm{Fe}^{3+}$ aqueous solution followed by heating it for $4 \mathrm{hrs}$ at $550^{\circ} \mathrm{C}$

\section{REFERENCES}

1. Octave Levenspiel, Chemical Reaction Engineering, 3rd Edition, John Wiley \& Sons, 1999

2. Gilbert F. Froment, Chemical Reactor Analysis and Design, 2nd Edition, John Wiley \& Sons, 1990

3. James J. Carberry, Chemical and Catalytic Reaction Engineering, McGraw-Hill, 1976

\section{PUBLICATIONS AND PRESENTATIONS}

1. Conversion of Hydrogen Sulfide in Coal Gases to Liquid Elemental Sulfur with Monolithic Catalysts, 2006 DOE/NETL HBCU/OMI Contractors Review Conference, June 5 - 6, 2007

2. Removal of Hydrogen Sulfide from Coal Gases, Using a Monolithic Catalyst Reactor, AIChE National Meeting, Salt Lake City, 559e, 10:10 am, November 8, 2007

3. Effects of Regenerated Monolithic Catalysts on Removal of Hydrogen Sulfide in Coal Gases, AIChE National Meeting, Salt Lake City, 281g, 530 pm, November 4 - 9, 2007

\section{STUDENTS ASSIGNED FOR THIS PROJECT}

Claudell Burnell, Tikia Allen, and Brittany Williams 